\title{
EFEITO DE SELÊNIO E VITAMINA E SOBRE O DESENVOLVIMENTO IMUNOLÓGICO DE BEZERROS
}

\author{
ROSANA BESSI
}

Engenheira Agrônoma

Orientador: Prof. Dr. RAUL MACHADO NETO

\begin{abstract}
Dissertação apresentada à Escola Superior de Agricultura "Luiz de Queiroz", da Universidade de São Paulo, para obtenção do título de Mestre em Agronomia, Área de Concentração: Ciência Animal e Pastagens.
\end{abstract}

PIRACICABA

Estado de São Paulo - Brasil

Outubro - 1996 
Dados Internacionais de Catalogação na Publicação (CIP) DIVISÃO DE BIBLIOTECA E DOCUMENTAÇÃO - Campus "Luiz de Queiroz"/USP

\author{
Bessi, Rosana \\ Efeito de selènio e vitamina E sobre o desenvolvimento imunológico de bezerros / \\ Rosana Bessi. - Piracicaba, 1996. \\ $102 \mathrm{p}$. \\ Dissertação (mestrado) - - Escola Superior de Agricultura Luiz de Queiroz, 1996. \\ Bibliografia. \\ 1. Bezerro 2. Imunologia 3. Nutrição animal 4. Selènio 5. Vitamina E I. Título
}

CDD 636.085 


\section{EFEITO DE SELÊNIO E VITAMINA E SOBRE O DESENVOLVIMENTO IMUNOLÓGICO DE BEZERROS}

ROSANA BESS!

Aprovada em: 18 de dezembro de 1996.

Comissão Julgadora:

Prof. Dr. Raul Dantas d'Arce

ESALQ/USP

Prof. Dr. Ciniro Costa

UNESP/Botucatu

Prof. Dr. Raul Machado Neto

ESALQ/USP

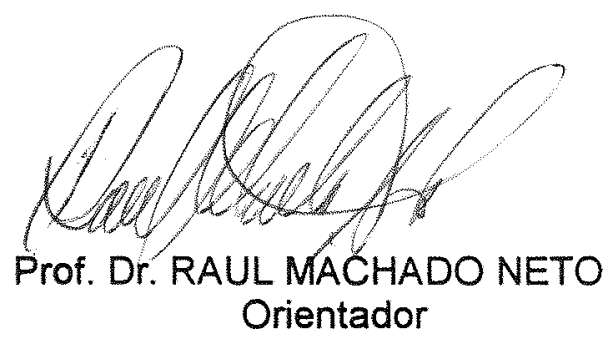


À minha familia, com reconhecimento e gratidão Ao querido e paciente Marcelo 


\section{AGRADECIMENTOS}

Ao Prof. Dr. Raul Machado Neto, pela paciência e confiança constantes e pelo exemplo de dedicação e profissionalismo;

Ao Prof. Dr. Raul Dantas d'Arce, pela valiosa colaboração e apoio recebidos;

Ao Prof. Dr. Irineu Umberto Packer, pela dedicada ajuda na realização das análises estatísticas;

Aos professores Prof. Dr. Ailton Rocha Monteiro e Prof. Dr. Mário Massayuki Inomoto, pelas sugestões feitas e pela leitura e correção do original;

Ao Prof. Dr. Helio Vanuchi, pela realização das análise de vitamina E;

À CAPES, pela concessão da bolsa de estudo;

Às amigas Fernanda, Gladys e Patricia que me ajudaram com muita dedicação em todas as fases experimentais;

Aos funcionários do Departamento de Zootecnia, Sr. Evilásio e Sr. João, pela colaboração constante e grande amizade que facilitaram a realização deste trabalho;

Aos funcionários do Departamento de Zoologia, especialmente Sonia R. A. C. de Moraes, pelo carinho e amizade;

Às queridas Helenice e Verônica e outros companheiros do curso de Mestrado. 


\section{INDICE}

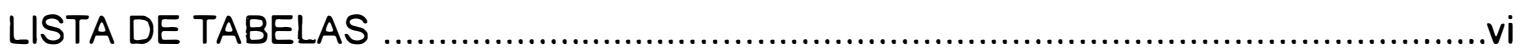

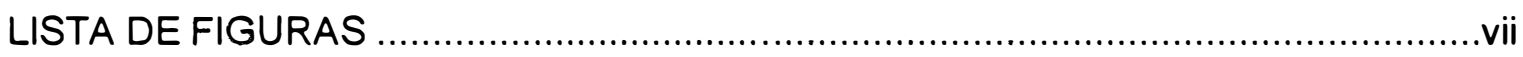

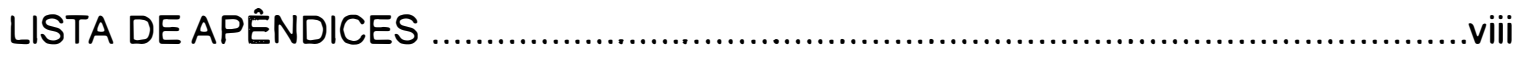

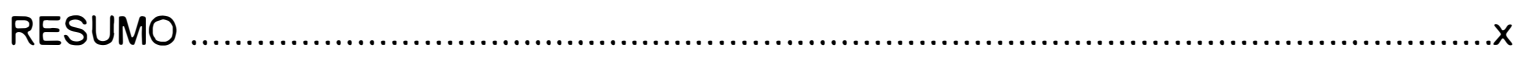

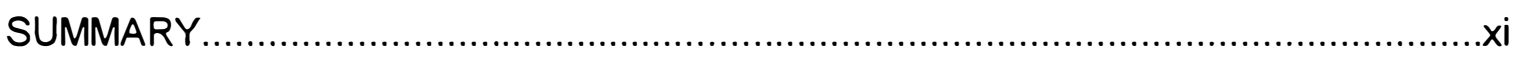

1. INTRODUÇÃO

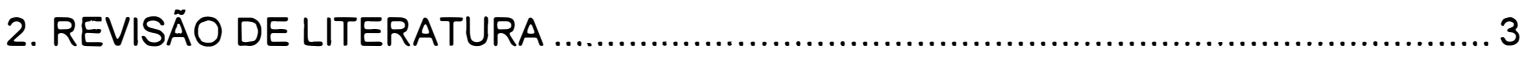

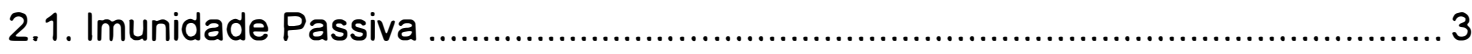

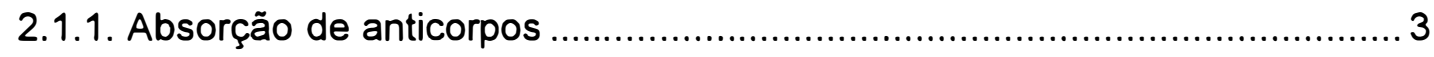

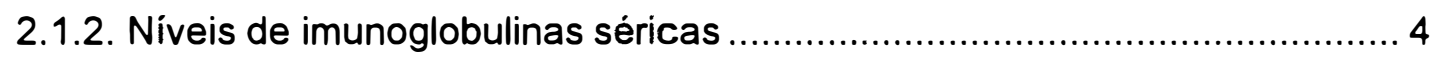

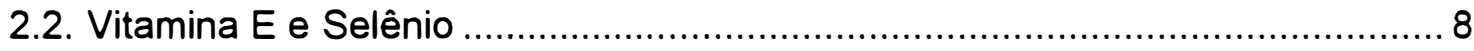

2.3. Atividade Antioxidante de Vitamina E e Selênio ........................................... 12

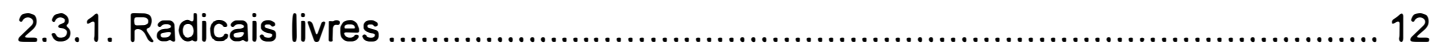

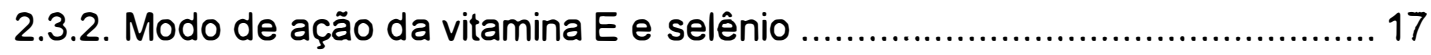

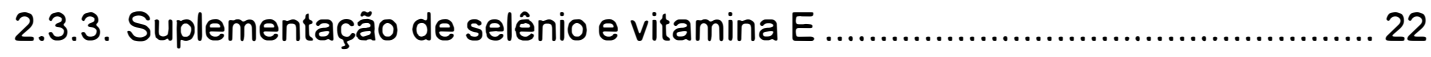

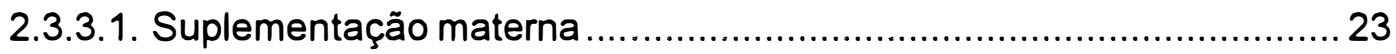

2.3.3.2. Vitamina E e selênio no colostro e leite........................................... 25

2.3.3.3. Suplementação do bezerro recém-nascido....................................... 26

2.4. Selênio e Vitamina $E$ e Resposta Imunológica em Bovinos ........................... 29

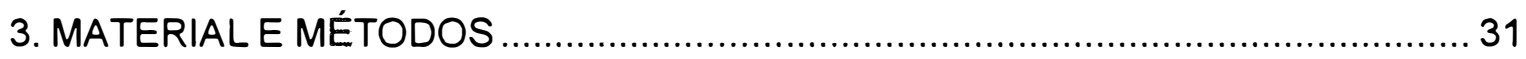

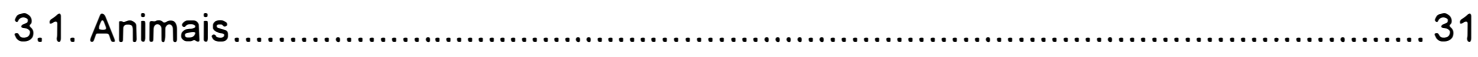

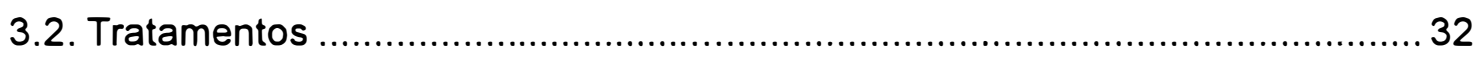

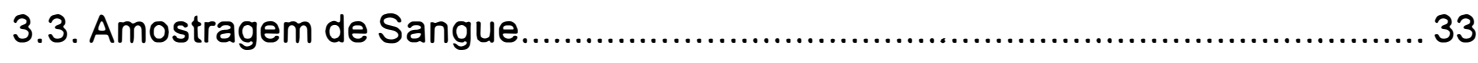

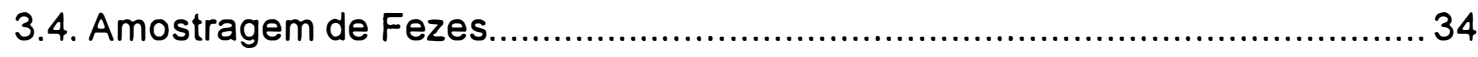

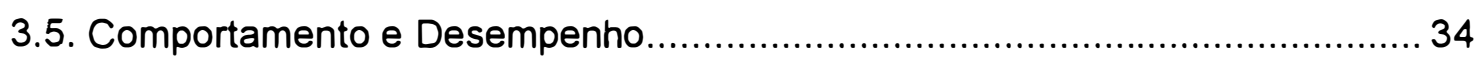

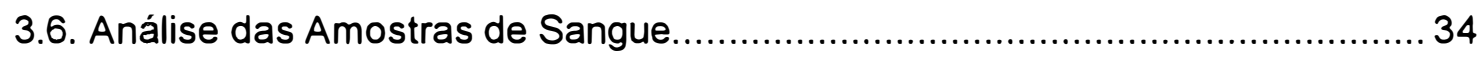

3.7. Delineamento Experimental e Análise Estatística........................................... 36

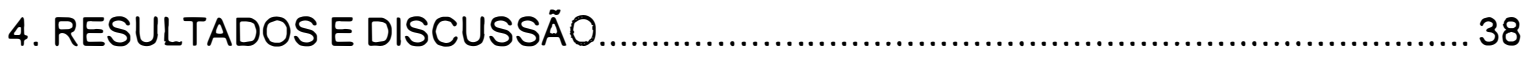

4.1. Condição Inicial de Vitamina E e Selênio ....................................................... 38 


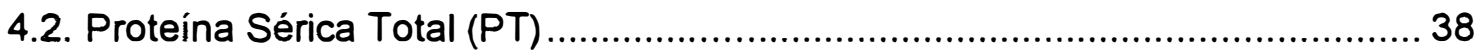

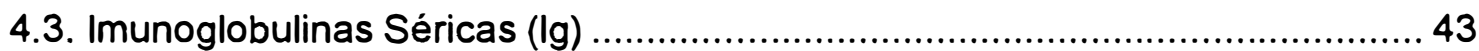

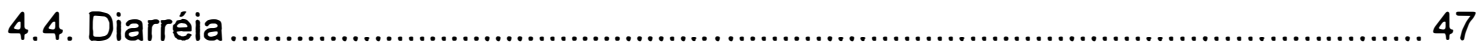

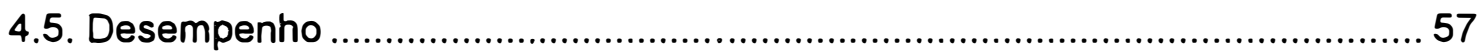

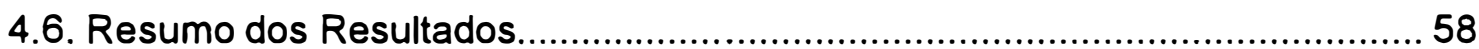

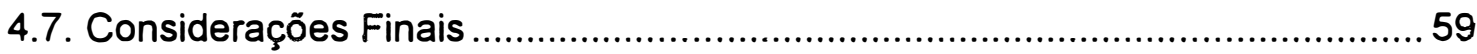

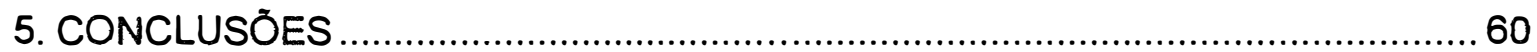

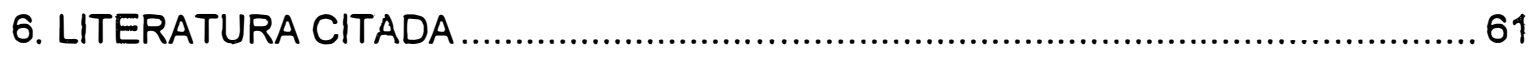




\section{LISTA DE TABELAS}

TABELA

PÁGINA

1. Atividade relativa de tocoferóis e tocotrienóis.

2. Médias de tratamentos da concentração sérica de vitamina $E(\mu \mathrm{mol} / \mathrm{l})$ e atividade de glutationa peroxidase GSHPx (unidades $/ \mathrm{ml}$ de eritrócitos) de bezerros aos 2 dias de idade. 39

3. Concentração média de proteina total sérica $(\mathrm{g} / 100 \mathrm{ml})$ nos tratamentos. 39

4. Concentração média de imunoglobulinas séricas $(\mathrm{g} / 100 \mathrm{ml})$ nos tratamentos.

5. Notas médias diárias de cor fecal durante 30 dias nos tratamentos. 48

6. Notas médias diárias de consistência fecal durante 30 dias nos tratamentos.

7. Peso médio $(\mathrm{kg})$ dos animais de cada tratamento, do nascimento aos 70 dias de idade. 


\section{LISTA DE FIGURAS}

FIGURA

PÁGINA

1. Estrutura química genérica da vitamina $E$ .18

2. Mecanismo catalítico da enzima GSHPX.

3. Flutuação da concentração de proteina total sérica $(\mathrm{g} / 100 \mathrm{ml})$ nos tratamentos.

4. Flutuação da concentração de imunoglobulinas séricas $(g / 100 \mathrm{ml})$ nos tratamentos.

5. Frequência de notas de cor de fezes no periodo de 2 a 30 dias nos tratamentos.

6. Frequência de notas de cor de fezes no periodo de 2 a 10 dias nos tratamentos.

7. Frequência de notas de cor de fezes no periodo de 11 a 20 dias nos tratamentos.

8. Frequência de notas de cor de fezes no periodo de 21 a 30 dias nos tratamentos.

9. Frequência de notas de consistência de fezes no periodo de 2 a 30 dias nos tratamentos.

10. Frequência de notas de consistência de fezes no periodo de 2 a 10 dias nos tratamentos.

11. Frequência de notas de consistência de fezes no periodo de 11 a 20 dias nos tratamentos.

12. Frequência de notas de consistência de fezes no periodo de 21 a 30 dias nos tratamentos. 


\section{LISTA DE APÊNDICES}

1. Composição da ração fornecida aos bezerros...........................................77

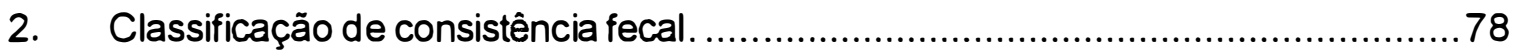

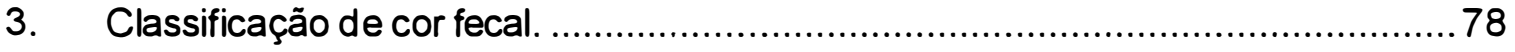

4. Classificação de presença de muco nas fezes. ..................................................79

5. Classificação de presença de sangue nas fezes..................................................79

6. Concentração de vitamina $E$ sérica $(\mu \mathrm{mol} / \mathrm{i})$ de bezerros aos 2 dias de

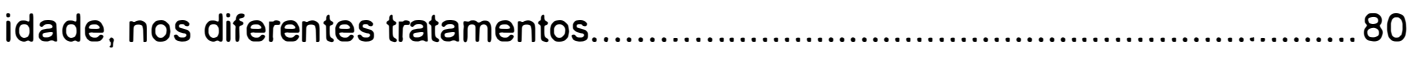

7. Atividade de glutationa peroxidase (unidades $/ \mathrm{ml}$ de eritrócitos) de bezerros aos 2 dias de idade, nos diferentes tratamentos.............................. 80

8. Concentração de proteína total sérica $(\mathrm{g} / 100 \mathrm{ml})$ nas 8 unidades experimentais do tratamento $\mathrm{T} 1$.

9. Concentração de proteína total sérica $(\mathrm{g} / 100 \mathrm{ml})$ nas 8 unidades experimentais do $\mathrm{T} 2$.

10. Concentração de proteína total sérica $(\mathrm{g} / 100 \mathrm{ml})$ nas 8 unidades experimentais do $\mathrm{T} 3$

11. Concentração de proteína total sérica $(\mathrm{g} / 100 \mathrm{ml})$ nas 8 unidades experimentais do $\mathrm{T} 4$

12. Concentração de proteína total sérica $(\mathrm{g} / 100 \mathrm{ml})$ nas 4 unidades experimentais do T5.

13. Concentração de proteína total sérica $(\mathrm{g} / 100 \mathrm{ml})$ nas 4 unidades experimentais do $\mathrm{T} 6$.

14. Valores de ZST (absorbância $\times 100$ ) observados nos bezerros às $24 \mathrm{~h}$ de vida, nos diferentes tratamentos.

15. Concentração de imunoglobulinas séricas $(\mathrm{g} / 100 \mathrm{ml})$ nas 8 unidades experimentais do $\mathrm{T} 1$

16. Concentração de imunoglobulinas séricas $(\mathrm{g} / 100 \mathrm{ml})$ nas 8 unidades experimentais do $\mathrm{T} 2$ 
17. Concentração de imunoglobulinas séricas $(\mathrm{g} / 100 \mathrm{ml})$ nas 8 unidades experimentais do T3

18. Concentração de imunoglobulinas séricas $(\mathrm{g} / 100 \mathrm{ml})$ nas 8 unidades experimentais do T4

19. Concentração de imunoglobulinas séricas $(\mathrm{g} / 100 \mathrm{ml})$ nas 4 unidades experimentais do T5.

20. Concentração de imunoglobulinas séricas $(\mathrm{g} / 100 \mathrm{ml})$ nas 4 unidades experimentais do T5. 87

21. Notas de consistência de fezes nas 8 unidades experimentais do T1. 88

22. Notas de consistência de fezes nas 8 unidades experimentais do T2. 89

23. Notas de consistência de fezes nas 8 unidades experimentais do T3 90

24. Notas de consistência de fezes nas 8 unidades experimentais do T4. 91

25. Notas de consistência de fezes nas 4 unidades experimentais do T5. 92

26. Notas de consistência de fezes nas 4 unidades experimentais do T6. .93

27. Notas de cor de fezes nas 8 unidades experimentais do T1 .94

28. Notas de cor de fezes nas 8 unidades experimentais do T2. 95

29. Notas de cor de fezes nas 8 unidades experimentais do T3. .96

30. Notas de cor de fezes nas 8 unidades experimentais do T4. 97

31. Notas de cor de fezes nas 4 unidades experimentais do T5. 98

32. Notas de cor de fezes nas 4 unidades experimentais do T6. 99

33. Pesos $(\mathrm{kg})$ das 8 unidades experimentais do T1 100

34. Pesos $(\mathrm{kg})$ das 8 unidades experimentais do T2 100

35. Pesos $(\mathrm{kg})$ das 8 unidades experimentais do T3 101

36. Pesos $(\mathrm{kg})$ das 8 unidades experimentais do T4 101

37. Pesos $(\mathrm{kg})$ das 4 unidades experimentais do T5. 102

38. Pesos $(\mathrm{kg})$ das 4 unidades experimentais do T6 102 


\section{EFEITO DE SELÊNIO E VITAMINA E SOBRE O DESENVOLVIMENTO IMUNOLÓGICO DE BEZERROS}

Autora: Rosana Bessi

Orientador: Prof. Dr. Raul Machado Neto

\section{RESUMO}

Comportamento imunológico e desempenho foram avaliados em 40 bezerros de ambos os sexos das raças Holandesa, Jersey, Gernsey e Pardo Suiça. Após ingestão do colostro, os animais foram alocados nos seguintes tratamentos: T1: animais com alto nivel inicial de imunoglobulinas passivas, que receberam vitamina $E$ e selênio; T2: animais com alto nível inicial de imunoglobulinas passivas, controle; T3: animais com alto nivel inicial de imunoglobulinas passivas, que receberam selênio; T4: animais com alto nível inicial de imunoglobulinas passivas, que receberam vitamina $E$; T5: animais com baixo nivel inicial de imunoglobulinas passivas, que receberam vitamina $E$ e selênio e T6: animais com baixo nível inicial de imunoglobulinas passivas, controle. O delineamento experimental empregado foi 0 de parcelas subdivididas no tempo, sendo os efeitos de nivel de anticorpos maternos e suplementação de selênio e vitamina $E$ aplicados às parcelas e as medidas repetidas no tempo consideradas subparcelas. Avaliaram-se as concentrações de proteína total e imunoglobulinas séricas, as variáveis fecais cor e consistência, além de peso e ganho de peso dos animais nos primeiros 70 dias de vida. A suplementação de vitamina $E$ e selênio determinaram o estabelecimento mais precoce da imunocompetência em bezerros com baixa concentração de anticorpos maternos, bem como proporciona melhor higidez no período de maior incidência de diarréia. 


\section{EFFECT OF SELENIUM AND VITAMIN E ON IMMUNOLOGICAL DEVELOPMENT OF NEWBORN DAIRY CALVES}

Author: Rosana Bessi

Adviser: Prof. Dr. Raul Machado Neto

\section{SUMMARY}

The immunological status and performance were evaluated in forty dairy calves. After feeding colostrum, calves were alloted randomly to the treatments described as follows: T1: animals with high levels of passive immunity that received vitamin $E$ and selenium supplementation; T2: animals with high levels of passive immunity that received no vitamin $E$ and selenium supplementation; T3: animals with high levels of passive immunity that received selenium supplementation; T4: animals with high levels of passive immunity that received vitamin $E$ supplementation; T5: animals with low levels of passive immunity that received vitamin $E$ and selenium supplementation and T6: animals with low levels of passive immunity that received no vitamin $E$ and selenium supplementation. The experimental period comprised the first seventy days of life and the following parameters were analysed: total serum protein, serum immunoglobulin, body weight and qualitative data about diarrhea caracteristics. Vitamin $E$ and selenium supplementation determinated earlier establishment of immunocompetence in calves with low concentrations of maternal antibodies. These supplemented animals had also the health performance improved in the period of highest incidence of diarrhea. 


\section{INTRODUÇÃO}

O fornecimento de colostro imediatamente após o nascimento é prática fundamental no manejo de bezerros, porque os ruminantes nascem praticamente sem anticorpos circulantes e o colostro se constitui na única fonte para aquisição de imunidade nesses animais. Essa imunidade é dita passiva por ser transmitida da mãe para 0 filho sem que este participe da sua sintese.

As imunoglobulinas presentes no colostro são absorvidas intactas pelas células epiteliais do intestino delgado durante um curto periodo após o nascimento, observando-se uma concentração sérica máxima dessas proteinas entre 24 e $48 \mathrm{~h}$ de vida. Após esse periodo, o neonato enfrenta um periodo de transição, em que deixa de se beneficiar dos anticorpos adquiridos e passa a responder ativamente ao desafios do seu meio. $\dot{E}$ exatamente nesta fase, caracterizada pela alta suscetibilidade dos bezerros a doenças respiratórias e gastrointestinais, que a nutrição pode ter um papel significativo nas funções do sistema imunológico.

Há evidências de que os níveis de determinados nutrientes podem afetar todos os componentes do sistema imunológico, modulando a resposta especifica humoral e a mediada por células, e também as respostas não especificas. A influência de dois nutrientes, vitamina $E$ e selênio, na proteção de animais domésticos vem sendo exaustivamente estudada. Embora a redução da incidência de mastite e de desordens reprodutivas em vacas sejam os efeitos mais conhecidos em bovinos leiteiros, demonstrou-se também que a suplementação de bezerros com vitamina $E$ e selênio afeta a resposta imunológica e a resistência a doenças. Esses nutrientes são necessários durante o periodo de rápido crescimento dos animais, os quais podem se tornar deficientes poucas semanas após o nascimento se dietas adequadas não forem fornecidas.

Diversos estudos foram feitos para se determinar a necessidade de vitamina $E$ e selênio pelos bezerros, utilizando-se como critérios não apenas a 
ausência de sintomas clinicos de deficiência mas, também, a higidez e a competência imunológica.

Este trabalho teve por objetivo estudar o efeito de vitamina $E$ e selênio suplementares sobre o desenvolvimento imunológico sérico no período de transição da imunidade passiva para ativa, bem como a relação de variáveis séricas com higidez em bezerros recém-nascidos de raças leiteiras. 


\section{REVISÃO DE LITERATURA}

\subsection{Imunidade Passiva}

\subsubsection{Absorção de anticorpos}

A capacidade do sistema imunológico do ruminante recém-nascido de responder ativamente a estímulos antigênicos é praticamente nula. Desta maneira, é elevada a relação entre morbidez e mortalidade de bezerros e o processo de aquisição de imunidade passiva. Autores relatam altas taxas de mortalidade e incidência de diarréia em animais com falha na transferência de imunoglobulinas maternas (Gay et al., 1965; Penhale et al., 1970; Selman et al., 1971; Brignole \& Stott, 1980; Ribeiro et al., 1983; Nocek et al., 1984).

A placenta sindesmocorial, presente em ruminantes, impede a passagem de anticorpos da circulação materna para a fetal, fazendo com que os bezerros nasçam com niveis insignificantes de imunoglobulinas no soro (McCoy et al., 1970; Tizard, 1985). No entanto, células epiteliais ainda imaturas no intestino delgado permitem a transferência de macromoléculas intactas do lume para a circulação sanguinea (Kruse, 1983). Neste processo estão envolvidos pinocitose das imunoglobulinas, na membrana plasmática apical da célula epitelial, e transporte das proteinas em pequenas vesiculas para os espaços intercelulares, na membrana lateral ou basal. As proteinas passam, a seguir, por dutos lactiferos antes de atingirem o sangue. O processo de absorção ocorre principalmente nas células das porções jejuno e ileo, sendo desprezivel a contribuição das células do duodeno (James et al., 1979). 
Segundo Kruse (1983) apenas durante algumas horas após o nascimento existem condições ideais para a absorção de anticorpos pelo bezerro, tais como: pequena produção de $\mathrm{HCl}$ no estômago; atividade minima da pepsina gástrica; presença de um fator inibidor de tripsina no colostro, que protege os anticorpos da digestão por enzimas pancreáticas; e baixa atividade proteolítica da mucosa intestinal. A expressão "fechamento intestinal" (Lecce \& Morgan, 1962) é utilizada para definir o término da transferência de macromoléculas do intestino para o sangue em recémnascidos que ocorre antes das primeiras 36-48 h de vida em ungulados (Brambell, 1958). Segundo Jeffcott (1972), o mecanismo exato que desencadeia o fechamento não é conhecido, mas sabe-se que os fatores presentes no colostro, a substituição das células epiteliais absortivas do intestino delgado, mecanismos endócrinos, estresse, prematuridade, restrição alimentar, desenvolvimento gástrico e início da ingestão de sólidos estão intimamente relacionados.

\subsubsection{Níveis de imunoglobulinas séricas}

Bezerros pré-colostrais apresentam pequenas quantidades de imunoglobulinas séricas. Níveis médios de $0,2 \mathrm{mg} / \mathrm{ml}$ foram registrados por McCoy et al. (1970) e Bush et al. (1971). Após a ingestāo do colostro, a concentração dessas proteínas aumenta significativamente (McCoy et al., 1970; Machado Neto \& Packer, 1986).

Logan et al. (1978) verificaram que 50\% da massa de imunoglobulina $G$ (lgG) fornecida na primeira refeição foi absorvida $6 \mathrm{~h}$ após o nascimento. Após duas refeições, $45 \%$ das imunoglobulinas consumidas estavam presentes no soro de bezerros com $24 \mathrm{~h}$ de vida (Bush et al., 1971).

Os valores máximos de absorção de imunoglobulinas do colostro, encontrados por diferentes autores, ocorreram entre 12 e 48 horas de vida. De acordo com Bush et al. (1971), Husband et al. (1972) e Ribeiro et al. (1983), a concentração máxima de imunoglobulinas séricas foi atingida por volta de $24 \mathrm{~h}$ após o nascimento. Já Klaus et al., (1969) observaram o pico de concentração de IgG e IgM às 48 h de vida, enquanto Logan et al., (1978) observaram valores entre 15 e 48 h, dependendo da classe da imunoglobulina. 
O nivel de anticorpos adquirido pelo recém-nascido após a ingestão do colostro é muito variável. Segundo Edwards et al. (1982), não há evidências de que os animais difiram fisiologicamente quanto à capacidade de absorção. Assim, o que determina o sucesso do processo de transferência é o bom manejo de recémnascidos. Stott et al. (1979d) constataram que bezerros que permaneceram com as mães para o consumo de colostro apresentam maior variabilidade nos níveis de imunoglobulinas adquiridas passivamente. Após aleitamento natural, concentrações que variaram de 0 a $63 \mathrm{mg}$ de $\mathrm{lgG} / \mathrm{ml}$ e de 0 a $15 \mathrm{mg} \mathrm{lgM} / \mathrm{ml}$ foram observadas em bezerros leiteiros com $24 \mathrm{~h}$ de vida (Brignole \& Stott, 1980). Variação maior foi observadas por Robison et al. (1988), em bezerros que permanecendo com as mães por $24 \mathrm{~h}$ após o nascimento apresentaram nível médio de imunoglobulinas séricas igual a $25,71 \pm 19,06 \mathrm{mg} / \mathrm{ml}$ entre 24 e $48 \mathrm{~h}$ de vida, com variação de 0,05 a 108,27 $\mathrm{mg} / \mathrm{ml}$.

Ainda quanto à forma de fornecimento de colostro, Besser et al. (1991) detectaram falha na transferência passiva (nivel menor que $10 \mathrm{mg} / \mathrm{ml}$ de lgG $_{1}$ sérica às $46 \mathrm{~h}$ de vida) em $61,4 \%$ dos bezerros que mamaram nas mães, quando comparada à transferência em bezerros alimentados artificialmente (por mamadeira: 19,3\%; por sonda esofagiana: 10,8\%). Os autores recomendaram o fornecimento de $100 \mathrm{~g}$ de $\operatorname{lgG}_{1}$, independente do método de aleitamento.

Um fator muito importante no manejo do bezerro neonato é a idade com que os animais recebem o primeiro colostro. Com o aumento da idade, há um progressivo decréscimo da taxa de absorção, que pode estar associado a substituicão das células epiteliais responsáveis pela transferência de imunoglobulinas do colostro (Stott et al., 1979b). Stott et al. (1979a) observaram que 50\% dos bezerros que receberam colostro às $24 \mathrm{~h}$ de vida falharam em absorver imunoglobulinas, o que não foi verificado em animais que mamaram antes das $12 \mathrm{~h}$. Verificou-se também, uma relação inversa entre nível máximo de imunoglobulinas séricas e idade da primeira refeição, uma vez que o atraso no fornecimento de colostro resultou em progressiva diminuição da concentração sérica de imunoglobulinas (Stott et al., 1979c).

Outro fator que determina a quantidade de imunoglobulinas absorvida é a sua concentração no colostro. Bush et al. (1971) observaram que $68 \%$ da variação nas imunoglobulinas séricas de bezerros pode ser atribuida a diferenças na 
quantidade consumida por unidade de peso, enfatizando a necessidade de se avaliar o colostro fornecido.

Stott et al. (1979c) forneceram diferentes volumes de colostro e verificaram que animais recebendo 2 I de colostro no nascimento atingiram maiores níveis séricos de IgG que animais recebendo 0,5 ou 1 I. No entanto, Stott \& Fellah (1983) verificaram que a absorção de imunoglobulinas em colostro de boa qualidade foi mais eficiente quando uma determinada massa de imunoglobulinas foi fornecida em 1 I que igual massa em 2 I. Quando colostro de baixa qualidade foi fornecido, o volume não influenciou na absorção. Desse modo, parece que a concentração de imunoglobulinas do colostro tem maior importância do que a quantidade total de colostro fornecida.

Verificou-se também, que proteínas como a albumina sérica bovina, interferem na absorção, diminuindo a eficiência. Essa interferência é consistente com a hipótese de que o sistema de transporte de macromoléculas no intestino do bezerro apresenta uma capacidade limitada, que é esgotada por proteínas, imunoglobulinas ou não (Besser \& Osborn, 1993).

Besser et al. (1990) citaram, ainda, a estação do ano, o estresse, a presença da mãe, o "status" endócrino do bezerro, o peso ao nascer e o "status" ácido-base do bezerro como fatores adicionais que podem interferir na eficiência com que diferentes bezerros absorvem imunoglobulinas do colostro.

Após atingir a concentração máxima, as proteínas absorvidas sofrem catabolismo ou são transferidas para outros "pools" metabólicos, fazendo com que o nivel sérico de imunoglobulinas caia gradativamente (Tennant et al., 1969; Bush et al., 1971; Husband al., 1972; Ribeiro et al., 1983; Machado Neto \& Packer, 1986 e Daniele et al., 1994). Porter (1972) constatou que a vida média das imunoglobulinas adquiridas passivamente é de 20 dias para $\lg G, 4$ dias para $\operatorname{lgM}$ e 2 dias para $\lg A$. Husband et al. (1972) encontraram resultados semelhantes, estimando a vida média de $\operatorname{lgG}_{1}$ em 16 dias, de $\operatorname{lgG}_{2}$ em 32 dias, de IgM em 4 dias e de IgA em 2 dias e meio.

Ribeiro et al. (1983) verificaram que o decréscimo de anticorpos séricos em bezerros holandeses continuou até os 21 dias de idade, enquanto Machado Neto \& Packer (1986) registraram uma queda linear da concentração de imunoglobulinas séricas no período de 0 a 30 dias em bezerros holandeses. Já Daniele et al. (1994 a), 
trabalhando com animais que atingiram alta concentração sérica de imunoglobulinas passivas (média de $40 \mathrm{mg} / \mathrm{ml}$ ), verificaram um prolongado periodo de declínio, com menores valores (média de $23 \mathrm{mg} / \mathrm{ml}$ ) entre 40 e 60 dias de idade.

A sintese endógena determina que, progressivamente, estabeleça-se no recém-nascido uma elevação da concentração sérica das imunoglobulinas. Segundo Husband et al. (1972), a produção endógena de IgG e lgM inicia-se entre 8 e 16 dias após o nascimento e a de $\operatorname{lgA}$ em torno de 64 dias. No entanto, Devery et al. (1979) verificaram que o bezerro já apresenta capacidade de produção endógena de IgG1 nas 3 primeiras semanas de vida. A taxa de produção não é grande, aproximadamente $1 \mathrm{~g}$ de $\lg _{1} /$ dia, e provavelmente depende do estresse antigênico a que o bezerro é submetido, mas a quantidade acumulada pode ser importante para a proteção do animal no início da vida.

Vários autores, como Husband \& Lascelles (1975), Logan et al. (1974) e Ribeiro et al. (1983), observaram que bezerros que adquiriram uma maior quantidade de anticorpos passivos maternos retardaram a fase endógena, sugerindo um efeito inibidor das imunoglobulinas maternas sobre o sistema imunológico do bezerro recém-nascido. Igualmente, Baracat (1993) constatou que animais com baixa concentração de lgG materna apresentaram pontos de concentração mínima de lgG e a idades de ocorrência desses valores diferentes dos animais com alta concentração.

A proteína sérica em bezerros, a partir do nascimento, segue um padrão semelhante ao das imunoglobulinas. Ao nascer, o bezerro apresenta os níveis mais baixos de proteína total, mas esses niveis atingem um pico de concentração aos 4 dias de vida com a ingestão do colostro, para em seguida diminuir gradativamente até se estabilizar (Tennant et al., 1969; Fagliari et al., 1983; Nocek et al., 1984; Daniele et al.,1994). Assim, Naylor et al. (1977) verificaram que a concentração de proteína total plasmática possibilita um bom prognóstico da mortalidade (principalmente devido a diarréia) em bezerros na primeira semana de vida. Esses autores constataram que animais com níveis superiores a $6 \mathrm{~g}$ de proteína/100ml de soro apresentaram menor incidência de doenças e recomendaram, para que essa concentração fosse atingida, a ingestão de uma quantidade de colostro equivalente a $5 \%$ do peso vivo nas primeiras $4 \mathrm{~h}$ de vida ou a permanência com as mães por $24 \mathrm{~h}$ após o nascimento. 


\subsection{Vitamina E e Selênio}

Evans \& Bishop (1922) constataram que ratas mantidas em dieta purificada, embora suplementadas com vitaminas $A$ e $B$, apresentavam desordens reprodutivas que culminavam com a morte e reabsorção de fetos. Os autores verificaram que um fator presente em folhas verdes de alface e folhas desidratadas de alfafa previnia a esterilidade. Esse fator foi reconhecido como uma nova vitamina por Sure (1924), que propôs a adoção do termo vitamina E. Já o termo $\alpha$-tocoferol surgiu quando Evans et al. (1936) isolaram um álcool de uma fração não-saponificável de óleo de germe de trigo que apresentava a mesma atividade biológica da vitamina $E$.

Estudos com diversas espécies animais seguiram-se à descoberta dessa vitamina, relacionando a sua deficiência a uma série de condiçōes patológicas, como por exemplo diátese exsudativa e encefalomalácia em aves, distrofia muscular e cardiomiopatia em bezerros (Rice \& Kennedy, 1988).

Na década de 30 verificou-se que a fração insaponificável de alguns óleos vegetais exibiam marcadas propriedades antioxidantes. Olcott \& Mattill (1931) isolaram de lipídios de alface uma fração de natureza fenólica com efeito antioxidante. Verificou-se que frações isoladas de óleo de germe de trigo e óleo de semente de algodão continham grandes concentraçōes de vitamina $E$, das quais o antioxidante não podia ser separado. Olcott \& Emerson (1937) observaram que a fração insaponificável de óleo de alface inibiu a oxidação de banha, sendo os compostos $\alpha, \beta$ e $\gamma$ tocoferóis antioxidantes eficientes. Após inúmeros estudos concluiu-se que a função biológica da vitamina $E$ é previnir a conversão oxidativa de ácidos poliinsaturados de membranas e lipoproteínas em hidroperóxido de lipídios.

No inicio da década de 50, investigou-se um agente presente em dietas a base da levedura Torula desidratada e deficientes em vitamina E. Esse agente desconhecido da dieta foi chamado de Fator 3 e apresentou-se tão efetivo quanto a vitamina $E$ em previnir necrose de fígado e diátese exsudativa em aves. Selênio (Se) foi isolado de materiais orgânicos que continham o Fator 3 e observou-se que sais inorgânicos de Se protegiam ratos da degeneração hepática. Schwarz \& Foltz (1957) sugeriram que Se era um nutriente essencial, podendo participar de reaçōes de óxidoredução. 
Informações anteriores à década de 50, com respeito aos efeitos biológicos de Se, são relacionadas exclusivamente à toxicidade do elemento, principalmente em animais que utilizaram plantas seleniferas como forragem. Deste modo, a suplementação da dieta com Se foi proibida por um longo tempo, mesmo comprovando-se sua essencialidade para mamiferos, aves e várias bactérias (Stadtman, 1991).

Como Se e vitamina $\mathrm{E}$ apresentavam a mesma resposta nutricional em diferentes espécies e a função antioxidante da vitamina $E$ já era conhecida, sugeriu-se que selênio desempenhava papel semelhante (Caldwell \& Tappel, 1964). Verificou-se que este nutriente era incorporado a proteinas dos tecidos (Hamilton \& Tappel, 1963), em consequência estudos foram conduzidos para avaliar a atividade antioxidante de selenoaminoácidos e selenoproteinas (Olcott et al., 1961; Hamilton \& Tappel, 1963; Caldwell \& Tappel, 1964; Shimazu \& Tappel, 1964; Caldwell \& Tappel, 1965).

Trabalhando com aminoácidos cristalinos para obter uma dieta rigorosamente sem Se, Thompson \& Scott (1969) observaram que é necessário uma grande ingestão de vitamina E (100 a 1000 ppm) para previnir sinais clínicos de doença em aves deficientes em selênio, excedendo consideravelmente ao requerimento normal. Os autores estabeleceram definitivamente que o Se não era um substituto para vitamina $E$, mas que a vitamina reduzia o requerimento de selênio. Investigação subsequente demonstrou que aves deficientes em Se não retinham quantidades normais de vitamina $E$ em consequencia da baixa absorção de lipídios. Essa condição foi determinada pela baixa produção de enzimas pancreáticas, em animais que apresentavam severa degeneração e fibrose do pâncreas (Thompson \& Scott, 1970).

Embora reconhecidos como essenciais, existiam evidências de que as funções de vitamina $E$ e Se se sobrepunham. Verificou-se que Se, na ausência de vitamina $E$ na dieta, diminuiu a hemólise de eritrócitos e a extensão da oxidação de hemoglobina em ratos. Os efeitos foram mais evidentes quando glucose foi adicionada ao meio de incubação. Por outro lado, vitamina $E$ na dieta também diminuiu a hemólise de eritrócitos, mesmo na ausência de $\mathrm{Se}$, mas não protegeu hemoglobina de danos oxidativos, em virtude de sua localização nas membranas. Havia evidências de que a glucose participava desse mecanismo através de sua habilidade de gerar glutationa reduzida (GSH) pela ação combinada das enzimas glucose 6-fosfato desidrogenase e 
glutationa redutase. Observou-se que glucose mantinha o nivel de GSH mesmo em eritrócitos de animais deficientes em Se e que a concentração de GSH celular aumentava nesses animais. A utilização prejudicada de $\mathrm{GSH}$ indicava para a presença de uma enzima envolvida na proteção a danos oxidativos e que requeria Se para sua expressão (Rotruck et al., 1972). Enquanto vitamina E protegia somente a membrana, o sistema Seglucose-GSH agia na preservação da membrana celular, da hemoglobina e de outras proteinas celulares suscetiveis a danos oxidativos.

Paralela a essa linha de pesquisa, seguia outra, também iniciada na década de 50, que caracterizou uma glutationa peroxidase presente em eritrócitos. Essa enzima destruia $\mathrm{H}_{2} \mathrm{O}_{2}$, com GSH servindo como doador de hidrogênio. Sugeriu-se que o sistema GSH - enzima era de primordial importância fisiológica na proteção de hemoglobina, provendo uma explicação para a notável estabilidade da hemoglobina de eritrócitos intactos (Mills, 1957). A atividade da enzima dependia da manutenção de glutationa no estado reduzido, ligando o mecanismo protetor ao metabolismo da glucose (Mills \& Randall, 1958; Cohen \& Hochstein, 1961).

Rotruck et al. (1973) ligaram as duas linhas de pesquisas, ao propor que Se era um componente da enzima glutationa peroxidase (GSHPx), permitindo uma explicação plausivel para sua relação com a vitamina $E$.

A equação que expressa a atividade da enzima foi assim proposta:

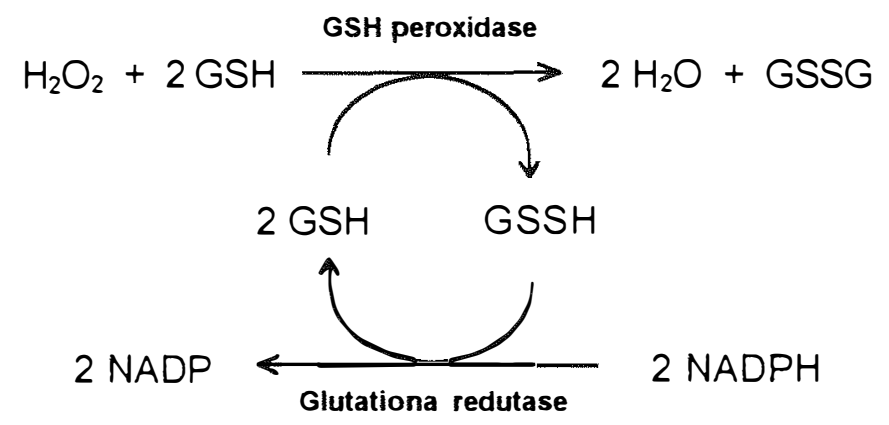

Em adição à GSHPx clássica, Ursini et al. (1985) isolaram outra enzima glutationa peroxidase dependente de $\mathrm{Se}$, que atua especificamente sobre hidroperóxidos de lipidios. Comprovou-se também, que a enzima GSHPx plasmática difere estrutural e antigenicamente da GSHPx celular. Um estudo conduzido por Avissar et al. (1989) determinou que células hepáticas, endoteliais e linfócitos sintetisam GSHPx celular, a qual 
é encontrada somente intracelularmente. GSHPx plasmática foi produzida e secretada apenas pelas células hepáticas.

Entre 33 e $40 \%$ do Se total do organismo de um mamífero está na forma de GSHPx. Entretanto, há funções metabólicas do Se que não podem ser atribuídas a GSHPx, exercendo sua função como constituinte de outros proteinas. Selenoproteina $P$ foi a segunda selenoproteina plasmática caracterizada em mamiferos, apresentando como característica marcante o alto conteúdo de Se. Enquanto GSHPx e outras selenoproteinas bacterianas contém 1 átomo de Se como selenocisteina por cadeia polipeptídica, selenoproteina $P$ contém aproximadamente 8 selenocisteinas na sua cadeia polipeptídica (Read et al., 1990; Hill et al., 1991). Em ratos mantidos em dietas nutricionalmente adequadas, aproximadamente $60 \%$ do Se plasmático está na forma de selenoproteina $P$, o que representa $8 \%$ do Se corporal. Verificou-se também que a meiavida dessa proteina no plasma é de aproximadamente 4 horas. Sua função não é conhecida, mas parece desempenhar um importante papel no metabolismo de Se, uma vez que representa uma fração significativa do Se corporal com rápido tumover, o que indica alta taxa de utilização de Se (Hill et al., 1991).

Por um longo periodo, GSHPx foi a única enzima que apresentava Se como parte integral descrita em eucariotos. Recentemente, constatou-se que a enzima iodotironina 5' -deiodinase tipo I continha Se (Stadtman, 1991). Berry et al. (1991) relataram que a enzima iodotironina 5 '-deiodinase tipo I, encontrada principalmente no fígado e rins contém selenocisteína. Essa enzima catalisa a conversão de tiroxina, o principal produto secretado pela glândula tireóide, para sua forma ativa 3,3',5 triiodotíronina. A atividade da enzima é menor em animais deficientes em Se (Berry et al., 1991) afetando significativamente o crescimento de cobaias (Cammack et al., 1995). Da mesma forma, outros processos dependentes da regulação pelos hormômios da tireóide, como regulação da composição corporal, temperatura corporal e utilização de energia podem ser afetados pela ingestão de Se (Cammack et al., 1995).

Thompson et al. (1995) também verificaram que a deficiência de Se prejudicou o crescimento de ratos e diminuiu o nivel de triiodotironina plasmático. Entretanto, a infusão constante do hormônio em ratos deficientes em Se não restabeleceu a taxa de crescimento, sugerindo que o decréscimo dos níveis de 
triiodotironina plasmático não é a causa do crescimento prejudicado em animais severamente deficientes em Se.

\subsection{Atividade Antioxidante de Vitamina E e Selênio}

Vitamina $E$ e Se fazem parte de um sistema que evita ou inibe efeitos deletérios provocados por radicais livres e seus produtos tóxicos. Os componentes desse sistema podem ser classificados como preventivos ou quebradores de reação em cadeia. O Se, como componente de GSHPx, se enquadra na primeira categoria, já que a enzima remove precursores de radicais livres. As enzimas superóxido dismutase e catalase, além de quelatores de metais também estão nessa categoria. Quando os radicais livres são formados a despeito dos mecanismos de ação preventiva, os antioxidantes quebradores de reação em cadeia podem diminuir a extensão dos danos causados por radicais livres, reagindo diretamente com eles e convertendo-os em produtos mais estáveis. Essa categoria inclui agentes hidrossolúveis, como ascorbato, glutationa (GSH) e urato, e lipossolúveis, tais como $\alpha$-tocoferol, ubiquinona, ácido retinóico e $\beta$-caroteno (Slater et al., 1987; Burton, 1994; Miller et al., 1993). De acordo com Halliwell \& Chirico (1993) esse sistema não é completamente efetivo, já que alguns metabólitos derivadas de oxigênio são biologicamente úteis.

\subsubsection{Radicais livres}

Os elétrons dentro de átomos e moléculas ocupam regiões de espaço chamadas orbitais. Cada orbital carrega no máximo 2 elétrons, mas se apenas 1 elétron ocupa um orbital, ele é chamado elétron não pareado. Radical livre é uma espécie química que possui um ou mais elétrons não pareados. Essa condição é encontrada por exemplo no átomo de hidrogênio (com 1 elétron), nos metais de transição e no oxigênio molecular $\left(\mathrm{O}_{2}\right)$. O símbolo usado para representar o elétron não pareado é um ponto $\left({ }^{\circ}\right)$ superescrito (Halliwell \& Gutteridge, 1984; Slater et al., 1987; Halliwell, 1994).

Normalmente, a presença de elétrons não pareados está associada ao aumento de reatividade. Alguns radicais não são muito reativos, mas outros são muito 
reativos, sendo possivelmente $\mathrm{OH}^{\circ}$ o radical mais ativo formado em organismos vivos (Halliwell, 1987).

Radicais livres e outras espécies derivadas de oxigênio são constantemente geradas nos organismos vivos, por "acidentes químicos" ou por processos metabólicos específicos (Halliwell, 1994). Além disso, sabe-se que fatores exógenos, como radiação solar, micotoxinas e agrotóxicos podem incrementar marcadamente a sua produção (Miller et al., 1993). Os processos envolvidos na formação de radicais livres são fissão homolítica de ligações e reação de transferência de elétrons. Em geral, tais processos originam-se da absorção de radiação (ionizante, ultravioleta, visivel ou térmica) ou por reações de oxirredução, como reações não enzimáticas de transferência de elétrons, reações catalizadas por metais ou processos catalizados por enzimas (Slater, 1984).

Embora essencial a todos os organismos aeróbicos, há evidências de que mesmo na concentração atmosférica (21\%), o oxigênio apresenta efeitos danosos aos organismos, que variam consideravelmente com a espécie, idade, estado fisiológico e dieta desses organismos (Halliwell, 1984). Gerschman et al. (1954) propuseram que muitos dos efeitos tóxicos do $\mathrm{O}_{2}$ poderiam ser atribuídos a formação de radicais livres de $\mathrm{O}_{2}$.

O oxigênio molecular $\left(\mathrm{O}_{2}\right)$ apresenta um par de elétrons compartilhados (ligação covalente), mas há também 2 elétrons não pareados, alocados em diferentes orbitais, com mesmo número quântico "spin". Assim, se $\mathrm{O}_{2}$ oxidar outro átomo ou molécula recebendo um par de elétrons, estes devem ser de "spin" paralelo para ocupar os espaços vagos nos orbitais, já que, de acordo com o princípio de Pauli, em um orbital podem existir no máximo 2 elétrons e isto somente se os dois apresentaraem spins opostos $(+1 / 2,-1 / 2)$. Isso impõe uma restrição sobre a oxidação por $\mathrm{O}_{2}$, que tende a receber 1 elétron por vez e diminui a velocidade de reação com outras espécies não radicais (Halliwell \& Gutteridge, 1984; Halliwell, 1994).

Se um simples elétron é aceito por $\mathrm{O}_{2}, 0$ radical superóxido, $\mathrm{O}_{2}^{-} \cdot \dot{e}$ formado (Halliwell \& Gutteridge, 1984). Uma importante fonte de $\mathrm{O}_{2}^{-}$é a bomba respiratória de células fagocíticas ativadas, quando em contato com partículas estranhas, e em menor extensão por diferentes tipos de células como fibroblastos e linfócitos. 
Também parte do ânion superóxido produzido "in vivo" deve-se a reações de autoxidação e ao "vazamento" de elétrons da cadeia respiratória (Halliwell, 1994).

Em solução aquosa $\mathrm{O}_{2}{ }^{*}$ é pouco reativo, agindo como um agente redutor e lentamente sofrendo reação de dismutação, pela qual peróxido de hidrogênio $\left(\mathrm{H}_{2} \mathrm{O}_{2}\right)$, um metabólito não radical, é formado. A reação de dismutação ocorre em etapas, $\mathrm{com}^{-}$ ' combinando-se primeiro com 1 próton para produzir o radical hidroperoxil, $\mathrm{HO}_{2}{ }^{-\bullet}$.

$$
\begin{gathered}
\mathrm{O}_{2}^{-\bullet}+\mathrm{H}^{+} \longrightarrow \mathrm{HO}_{2}^{-\bullet} \\
\mathrm{HO}_{2}^{-\bullet}+\mathrm{O}_{2}^{\cdot \bullet}+\mathrm{H}^{+} \longrightarrow \mathrm{H}_{2} \mathrm{O}_{2}+\mathrm{O}_{2} \\
\hline 2 \mathrm{O}_{2}^{\cdot \bullet}+2 \mathrm{H}^{+} \longrightarrow \mathrm{H}_{2} \mathrm{O}_{2}+\mathrm{O}_{2}
\end{gathered}
$$

Segundo Halliwell (1987), surgiu nos anos 70, a teoria de que os efeitos deletérios de $\mathrm{O}_{2}$ eram causados por um aumento na formação de radical superóxido dentro das células. Embora não completamente provada, ela é suportada por evidências de 3 linhas de pesquisa. Primeiro foi demonstrado que $\mathrm{O}_{2}{ }^{-\bullet}$ pode ser gerado por vários sistemas presentes em organismos vivos. Em geral, a taxa de $\mathrm{O}_{2}{ }^{\bullet}$ produzido aumenta proporcionalmente ao aumento da concentração de $\mathrm{O}_{2}$.

A teoria superóxido também, é suportada por estudos que constataram danos biológicos causados por sistemas geradores de $\mathrm{O}_{2}{ }^{\bullet}$, como a degradação de DNA e ácido hialurônico quando expostos $\mathrm{a}_{2}{ }^{*}$.

Finalmente, a descoberta da enzima superóxido desmutase é a terceira evidência. Essa enzima é encontrada em quase todas as células aeróbicas e seu único substrato conhecido é $\mathrm{O}_{2} \vec{*}$, catalizando especificamente a reação de dismutação. Em tecidos de mamíferos essa enzima é principalmente intracelular.

$\mathrm{O}_{2} \mathrm{O}_{2}$ produzido é removido pela ação de outras enzimas, das quais há duas em tecidos de mamiferos: catalase e glutationa peroxidase. Sob condições normais a mais importante dessas duas enzimas é GSHPx. Isso provavelmente devido à diferente localização celular das enzimas. A catalase é encontrada em peroxissomas, enquanto GSHPx está nas mitocôndrias e no citossol, uma distribuição similar a da superóxido dismutase (Halliwell, 1994). Entretanto, de acordo com Halliwell \& Chirico (1993), $\mathrm{O}_{2}^{\bullet}$ e $\mathrm{H}_{2} \mathrm{O}_{2}$ apresentam uma reatividade limitada, não reagindo diretamente com DNA ou lipidios das membranas. Beauchamp \& Fridovich (1970) propuseram que a toxicidade de $\mathrm{O}_{2} \bullet$ e $\mathrm{H}_{2} \mathrm{O}_{2}$ poderia estar ligada à conversão destes metabólitos a $\mathrm{OH}^{*}$. 
A fissão homolítica da ligação $0-\mathrm{O}$ em $\mathrm{H}_{2} \mathrm{O}_{2}$ produz dois radicais hidroxil, $\mathrm{OH}^{*}$. A reação pode ser obtida por calor ou radiação ionizante, mas a simples mistura de um sal de ferro com $\mathrm{H}_{2} \mathrm{O}_{2}$ pode provocar uma série de reações com radicais, como foi observado por Fenton em 1894:

$$
\begin{gathered}
\mathrm{O}_{2}^{\cdot \bullet}+\mathrm{Fe}^{+3} \longrightarrow \mathrm{Fe}^{+2}+\mathrm{O}_{2} \\
\mathrm{Fe}^{+2}+\mathrm{H}_{2} \mathrm{O}_{2} \longrightarrow \mathrm{Fe}^{+3}+\mathrm{OH}^{\bullet}+\mathrm{OH}^{-}
\end{gathered}
$$

A soma geral dessas equações, a menos que outro reagente seja adicionado para interceptar $\mathrm{OH}^{\circ}$, é uma decomposição de $\mathrm{H}_{2} \mathrm{O}_{2}$ catalizada por $\mathrm{Fe}$ (Halliwell \& Gutteridge, 1984; Halliwell, 1994).

O radical hidroxil reage com constantes extremamente altas com quase todas as moléculas encontradas em células vivas: carboidratos, aminoácidos, fosfolipidios, bases nitrogenadas e ácidos orgânicos. A reatividade dos radicais $\mathrm{OH}^{\bullet}$ é tão alta que se formados em sistemas vivos, reagirão imediatamente com qualquer molécula biológica que esteja nas proximidades, produzindo radicais de reatividade variável (Halliwell \& Gutteridge, 1984).

O metal mais estudado como promotor da formação de $\mathrm{OH}^{\bullet}$ é o ferro. As células normalmente são protegidas dos efeitos de $\mathrm{Fe}$, pela formação de complexos em grandes moléculas compartimentalizadas longe dos sítios suscetíveis a danos. Sais de titânio, cobalto e cobre também, promovem a formação de $\mathrm{OH}^{\bullet}$ (Halliwell \& Gutteridge, 1984; Halliwell, 1987; Halliwell, 1994).

A difusão de $\mathrm{OH}^{\bullet}$ de seu sítio de formação é limitada por causa de sua alta reatividade. Portanto, o que determina a natureza dos danos é a localização do ion metálico, que promoverá a formação de $\mathrm{OH}^{\bullet}$. Se houver ions metálicos ligados a DNA e

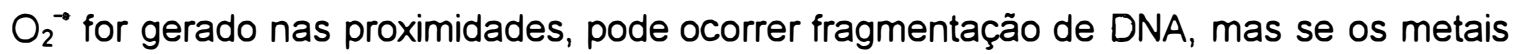
estiverem próximos a lipidios das membranas pode haver o desencadeamento da peroxidação de lipídios.

Sendo uma espécie menos reativa, $\mathrm{O}_{2} \bullet$ pode se difundir e sofrer conversão para espécies mais reativas, produzindo danos a distância do sítio inicial de formação (Slater et a!., 1987):

$$
\mathrm{O}_{2} \stackrel{\text { difusão }}{\longrightarrow} \mathrm{O}_{2} \longrightarrow \mathrm{H}_{2} \mathrm{O}_{2} \stackrel{\mathrm{Fe}}{\longrightarrow} \mathrm{OH}^{*} \longrightarrow \text { danos }
$$


A deficiência de substâncias protetoras ou excesso de exposição a agentes estimuladores podem resultar em estresse oxidativo, que ocorre quando próoxidantes superam a capacidade dos antioxidantes (Miller et al., 1993). Estudos têm demonstrado que radicais livres são capazes de produzir modificações e danificar proteínas, lipídios, carboidratos e nucleotídeos. Se o radical é formado próximo a ácidos nucléicos, pode produzir uma mudança na estrutura, resultando em mutação, com consequente risco de carcinogênese (Slater, 1984). O ataque de radicais livres a proteínas têm recebido menor atenção, mas é claro que modificações em aminoácidos próximos ao sítio ativo de uma proteína podem alterar vias metabólicas (Diplock, 1992). A inativação peroxidativa de enzimas esteroidogênicas pode prejudicar a reprodução animal (Miller et al., 1993).

A maior parte dos trabalhos se referem aos danos produzidos por radicais livres aos ácidos graxos polinsaturados (PUFA) das membranas (Diplock, 1992). Muitos tipos de injúria celular, provocadas por intermediários radicais livres, apresentam como principal característica a peroxidação de PUFA, especialmente $C_{20: 4}$ e $C_{22: 6}$ (Slater, 1984). $O$ início da peroxidação numa membrana ocorre pelo ataque de qualquer espécie que possa retirar um átomo de $\mathrm{H}$ da cadeia de carbono do PUFA. Quanto maior o número de duplas ligações, mais fácil é a remoção do átomo de $\mathrm{H}$. Radical hidroxil e possivelmente $\mathrm{HO}_{2}{ }^{\bullet}$ podem fazer isto, mas $\mathrm{O}_{2}{ }^{-\bullet}$ e $\mathrm{H}_{2} \mathrm{O}_{2}$, não. Desde que o átomo de $\mathrm{H}$ possui somente 1 elétron, se esse elétron é removido, o átomo de $C$ fica com um elétron não pareado.

$$
-\mathrm{CH}+\mathrm{R}^{\cdot} \longrightarrow-\mathrm{C}^{\bullet}+\mathrm{RH}
$$

O radical resultante sofre um rearranjo molecular e combina-se rapidamente com $\mathrm{O}_{2}$, formando um radical peroxil. Radicais peroxil são capazes de retirar átomos de $\mathrm{H}$ de outros ácidos graxos e assim estabelecer uma reação em cadeia, que continua até que os ácidos graxos da membrana estejam completamente oxidados a hidroperóxidos:

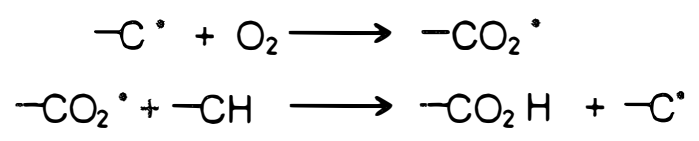

A reação que originalmente é reduzida espacialmente, pode produzir uma onda de efeitos secundários posteriores que difundem os distúrbios por toda a célula, até mesmo para domínios extracelulares (Slater, 1984). 
Peróxidos de lipidios desestabilizam membranas, diminuindo a fluidez dos lipídios e afetando funções metabólicas que dependem da estrutura da membrana. Os radicais podem atacar também, proteinas das membranas, inativando enzimas e receptores, além de modificar a permeabilidade da membrana a ions (Slater et al., 1987; Halliwell, 1994). A extensão da propagação depende de muitos fatores, como relação lipidio-proteina nas membranas, a composição de ácidos graxos e a presença de antioxidantes que interrompam a reação (Halliwell \& Chirico, 1993).

Transportando esses efeitos para as células imunocompetentes, podem ser alteradas as funções que dependem da integridade da membrana, como reconhecimento de antígenos, ligação de agentes mitogênicos, liberação de mediadores solúveis, ligação e lise de células estranhas, transmissão de sinais para o interior da célula (Kiremidjian-Schumacher \& Stotzky, 1987).

Cabe ressaltar ainda que linfócitos normalmente, apresentam uma concentração maior de ácidos graxos livres do que outras células (Kigoshl \& Ito, 1973), o que os toma muito mais dependentes de mecanismos antioxidantes para a integridade da membrana e a manutenção da sua atividade.

\subsubsection{Modo de ação da vitamina E e selênio}

A estrutura quimica genérica da vitamina $E$ está representada na Figura 1. É um anel aromático 2-metil-6-cromanol ao qual uma cadeia fitol de 16 carbonos se liga ao carbono C-2. Foram identificados oito compostos lipossolúveis, estruturalmente similares, que dividem-se em 2 grupos, tocoferóis e tocotrienóis, de acordo com a saturação da cadeia fitol. Enquanto a cadeia lateral é saturada nos tocoferóis, tocotrienóis apresentam três duplas ligações nas posições 3', 7' e 11'. Já o grau de metilação do anel cromanol define os quatro diferentes membros de cada grupo, isto é, $\alpha, \beta, \gamma$ e $\delta$ (Figura 1). Todas as formas agem como antioxidantes em vários graus, sendo o grupo tocoferol o que apresenta maior atividade biológica (Rice \& Kennedy, 1988; Lynch, 1991).

Quanto à atividade dos diferentes compostos, devem ser observadas as características do anel aromático e da cadeia lateral da molécula (Kasparek ${ }^{1}$, citado por Lynch, 1991). A presença de grupamentos metil no anel aromático é de

\footnotetext{
${ }^{1}$ KASPAREK, S. Chemistry of tocopherols and tocotrienols. In: MACHLIN, L.J. Vitamin E: a complete treatise. New York: Marcel Decker Inc., 1980.
} 
grande importância, uma vez que removidos não é mais verificada a atividade de vitamina $E$. O composto $\alpha$-tocoferol, o mais ativo, é completamente metilado nas posições 5,7 e 8 (Tabela 1). A perda de um ou dois grupos metil, nas posições 5 ou 7 do anel, reduz a atividade dos compostos e a posição desses grupamentos também, influencia a atividade da molécula, como verificado entre as formas $\beta$ e $\gamma$. Já as duplas ligações presentes nas posições 3', 7' e 11' da cadeia fitol reduzem a atividade dos tocotrienóis (Lynch, 1991).

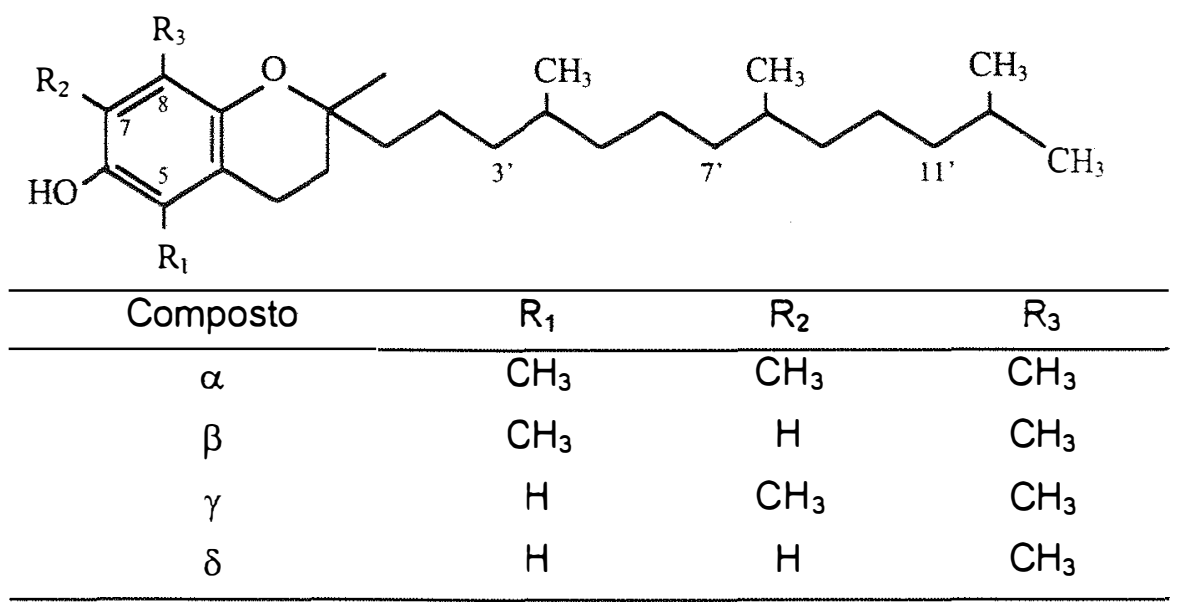

Fonte: RICE \& KENNEDY (1988)

Figura 1. Estrutura química genérica da vitamina $E$.

Tabela 1. Atividade relativa de tocoferóis e tocotrienóis.

\begin{tabular}{cc}
\hline$d$ - $\alpha$-tocoferol & $100 \%$ \\
$d$ - $\beta$-tocoferol & $14-40 \%$ \\
$d$ - $\gamma$-tocoferol & $1-20 \%$ \\
$d$ - $\delta$-tocoferol & $1 \%$ \\
$d$ - $\alpha$-tocotrienol & $15-30 \%$ \\
$d$ - $\beta$-tocotrienol & $1-5 \%$ \\
$d-\gamma$-tocotrienol & $1 \%$ \\
$d$ - $\delta$ - tocotrienol & $1 \%$ \\
\hline
\end{tabular}

Fonte: LYNCH (1991) 
Comparando quantitativamente as concentrações de vitamina $E$ e antioxidantes totais, Burton et al. (1983) verificaram que vitamina $E$ é o principal e provavelmemte o único antioxidante lipossolúvel quebrador de cadeia presente em tecidos e plasma de mamiferos, sendo predominante a ação de $\alpha$-tocoferol. A maior parte do $\alpha$-tocoferol presente nos tecidos animais está localizado nas frações altamente insaturadas das membranas celulares (Taylor et al., $1976^{2}$ citados por Rice \& Kennedy, 1988). Isso porque a cadeia fitol permite que a vitamina tome-se parte integrante das membranas, permanecendo nas proximidades dos PUFA, evitando, assim, que reações de oxidação continuem. $\alpha$-Tocoferol é o único que parece tomar-se parte integral da membrana enquanto exerce sua função.

A cadeia lateral pode também, ser importante para posicionar adequadamente a vitamina $E$ na membrana para capturar radicais peroxil. Niki et al. (1985) demonstraram que a longa cadeia lateral tem pouco efeito sobre sua atividade antioxidante, mas que essa cadeia aumenta a retenção de vitamina $E$ em lipossomas $e$, consequentemente, suprime a habilidade de a vitamina movimentar-se entre as membranas. Sugeriu-se, também, que $\alpha$-tocoferol tende a estabilizar as membranas, formando complexos com ácidos graxos e fosfolipídios (Kagan \& Quinn, 1988).

Já o grupamento hidroxila do anel aromático confere a propriedade antioxidante, doando o hidrogênio fenólico para um radical formado durante a peroxidação dos ácidos graxos (Rice \& Kennedy, 1988). Fukuzawa \& Gebicki (1983) mediram a taxa de oxidação de $\alpha$-tocoferol pelos radicais livres hidroxil e superóxido. Os autores concluiram que $\alpha$-tocoferol pode ser vulnerável à destruição por radicais livres de oxigênio, sendo $\mathrm{OH}^{*}$ potencialmente o oxidante mais eficiente. $\mathrm{O}_{2}{ }^{*}$ não pode oxidar lipídios, mas pode participar de processos degradativos reagindo com vitamina $E$.

A vitamina $(\mathrm{PhOH})$ reduz o radical peroxil que foi formado nas membranas, convertendo-o a hidroperóxido de lipídio. No processo, $\alpha$-tocoferol é oxidado para um radical relativamente estável, $\alpha$-tocoferoxil (um radical fenoxil, $\mathrm{PhO} 0^{\circ}$ ):

$$
\mathrm{LOO}+\mathrm{PhOH} \longrightarrow \mathrm{LOOH}+\mathrm{PhO}^{\circ}
$$

A reação de $\alpha$-tocoferol com o radical peroxil é rápida quando comparada à reação do radical com outro PUFA. Assim, uma pequena quantidade de $\alpha$-tocoferol

\footnotetext{
${ }^{2}$ TAYLOR, S.L.; LAMDEN, M.P.; TAPPEL, A.L. Lipids, v.2, p.530, 1976.
} 
pode proteger uma grande quantidade de PUFA. Eventualmente, o radical $\mathrm{PhO} \cdot$ pode reagir com outro radical $\mathrm{PhO}{ }^{*}$ ou um radical peroxil, formando produtos não radicais:

$\mathrm{PhO}^{\circ}+\mathrm{PhO}^{*}\left(\mathrm{LOO}^{\circ}, \mathrm{LO}^{\circ}\right) \longrightarrow$ produtos não radicais

Bowry et al. (1992), seguindo o consumo de ubiquinol-10 (coenzima $Q$ reduzida) endógeno sob um fluxo constante de radicais, verificaram que radical peroxil pode acelerar a peroxidacão de lipoproteínas de baixa densidade (LDL) ou outras pequenas partículas lipídicas em dispersão aquosa. Isso ocorre porque a cadeia fitil mantém o radical tocoferoxil dentro da partícula lipídica $(\mathrm{LH})$, diminuindo a taxa da reação de eliminação do radical e levando à reação:

$$
\mathrm{PhO}^{\bullet}+\mathrm{LH} \longrightarrow \mathrm{PhOH}+\mathrm{LOO}^{\circ}
$$

Sob essas condições, a vitamina $E$ pode agir como pró-oxidante, iniciando reação em cadeia, sendo essencial a presença de agentes que reduzam os radicais tocoferoxil formados (Burton, 1994). Três vias são consideradas fisiologicamente importantes para a redução do radical $\alpha$-tocoferoxil: ácido ascórbico, ubiquinol-10 e processos de transporte de elétrons em mitocôndrias (Stoyanovsky et al., 1995).

Quando vitamina C está presente, $\alpha$-tocoferol é regenerado em membranas e lipoproteínas. O radical de vitamina $C$ pode ser enzimaticamente reduzido por um sistema dependente de $\mathrm{NADH}$. Isto permite reparar um radical orgânico $R^{*}$ potencialmente deletério e ligá-lo a oxidação de $\mathrm{NADH}$ e a uma grande faixa de processos bioquímicos normais (Packer et al., 1979).

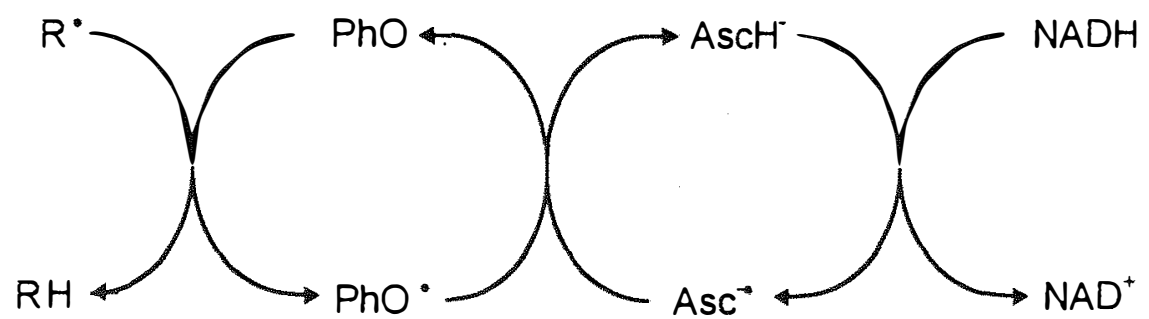

Stoyanovsky et al. (1995) sugeriram que em sistemas em que há uma constante geração de íons superóxido, redução de ubiquinona-10 $\left(\mathrm{Q}_{10} \mathrm{H}_{2}\right)$ por um elétron para ubisemiquinona $\left(\mathrm{Q}_{10} \mathrm{H}^{\circ}\right)$ regenera radicais $\alpha$-tocoferoxil.

$$
\mathrm{PhO}^{\circ}+\mathrm{Q}_{10} \mathrm{H}_{2} \longrightarrow \mathrm{PhOH}+\mathrm{Q}_{10} \mathrm{H}^{\circ}
$$

Um estudo conduzido por Maguire et al. (1989) demonstrou que NADH, succinato e citocromo $\mathrm{c}$ reduziram o radical tocoferoxil, prevenindo o acúmulo do radical e 
o consumo de vitamina $E$. Os autores sugeriram que na mitocôndria não há uma enzima específica para reduzir o radical tocoferoxil, mas que sítios de redução estão ligados a vários componentes que transportam elétrons na cadeia respiratória.

Selênio na GSHPx está na forma de selenocisteina e esse aminoácido está no sítio catalítico da enzima (Forstrom et al., 1978). Ladenstein et al. (1979) purificaram GSHPx de eritrócitos bovinos e verificaram que a enzima é formada por quatro unidades quimicamente indistinguiveis. O mapa da densidade elétrica mostrou que as subunidades têm uma forma esférica, com uma depressão plana na região do centro ativo. Cada centro ativo provavelmente é formado por segmentos de duas subunidades, já que os sítios ativos estão localizados nas vizinhanças das regiões de contato. $A$ enzima tetramérica contém quatro átomos-grama Se por mol ( $\mathrm{Mr}=84000)$. O monômero é uma cadeia peptídica simples de 178 residuos de aminoácidos.

O mecanismo catalítico da GSHPx não está completamente estabelecido, mas sabe-se que o mecanismo é do tipo "pingue-pongue" e que o Se ligado à enzima ocorre em diferentes estádios de oxidação, nas diferentes fases da reação. O mecanismo "pingue-pongue" caracteriza-se pela liberação do produto de uma interação enzimasubstrato antes que um segundo substrato reaja com a enzima (Combs \& Combs, 1986).

Epp et al. (1983), estudando GSHPx de eritrócitos bovinos, propuseram um modelo do mecanismo de reação, baseado em dados funcionais e estruturais, apresentado na Figura 2.

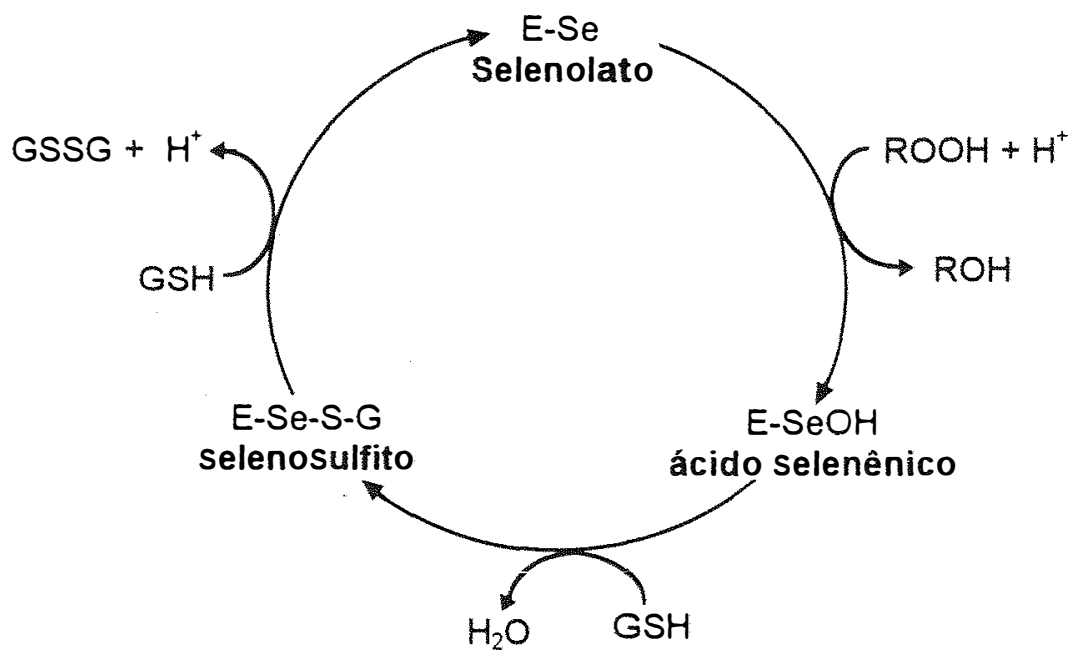

Figura 2. Mecanismo catalítico da enzima GSHPx. 
A forma selenolato (E-Se) do resíduo de selenocisteina reduz o substrato peróxido a um álcool, sendo oxidado a ácido selenênico ( $\mathrm{E}-\mathrm{SeOH}$ ). A reação com glutationa produz a forma selenosulfito (E-Se-S-G) que, em seguida, é atacada por uma segunda glutationa, regenerando a forma ativa da enzima. Os mesmos autores sugeriram que a forma ácido selenênico é transitória, sofrendo redução pelo excesso de GSH normalmente presente na célula.

Chaudiere et al. (1984) concordaram que selenolato está presente na forma reduzida da enzima em concentrações fisiológicas de GSH. Entretanto, os autores utilizando inibidores para caracterizar o ciclo da enzima GSHPx, demonstraram que ácido selenênico não pode ser uma das três formas da enzima.

2.3.3. Suplementação de selênio e vitamina $E$

Apesar de o selênio ser amplamente distribuido nos solos, as concentrações e disponibilidade são muito variáveis. A necessidade de suplementação adquiriu maior importância quando verificaram-se grandes áreas deficientes nesse mineral. Há regiões em que o nivel do mineral nos alimentos não é adequado e a suplementação é necessária para garantir a produção animal (Ulrey, 1992). No Brasil, Lucci et al. (1984 a,b) avaliaram o nivel de Se em forragens e no soro sanguíneo de bovinos leiteiros de diversas regiões do estado de São Paulo e verificaram que $78 \%$ das vacas encontravam-se com niveis séricos do mineral considerados deficientes $(0,04 \mathrm{ppm}$ ou menos), uma vez que as forragens consumidas eram pobres em Se.

As forragens são a principal fonte de vitamina $E$ na dieta de animais leiteiros. O conteúdo da vitamina é alto na forragem fresca, mas decresce significativamente em forragens conservadas (Schingoethe et al., 1978; Smith et al., 1991). Em muitos rebanhos, forragem fresca não pode ser fornecida durante todo o ano, o que pode resultar numa ingestão sub-ótima de vitamina $E$ (Miller et al., 1993).

Problemas causados pela deficiência de vitamina $E$ e Se se manifestam durante o periodo perinatal, quando a suplementação desses nutrientes é especialmente crítica. Nesse período é comum uma menor ingestão de matéria 
seca e consequente menor consumo de vitamina $E$ e Se. Além disso, a mobilização desses nutrientes para o feto e colostro influenciam o "status" materno (Weiss et al., 1990).

Justifica-se, portanto, o grande interesse na suplementação de vacas gestantes, principalmente durante o periodo seco, e também de bezerros recémnascidos, não apenas para evitar as condições clínicas de má nutrição, mas também pelo efeito já demonstrado desses nutrientes em aspectos como higidez e competência imunológica (NRC, 1988).

\subsubsection{Suplementação materna}

Os bezerros nascem com concentrações de Se similares às das mães, indicando transferência de Se através da placenta (Hidiroglou \& Batra, 1994).

De acordo com Van Saun et al. (1989) a concentração de Se sérico materno mantém-se superior à concentração sérica do feto em média até oito meses e meio de gestação, quando o nivel materno declina rapidamente. Já o nível hepático de Se em fetos é superior ao materno durante toda a gestação, podendo inclusive compensar parcialmente a deficiência da mãe (Koller et al., 1984; Van Saun et al., 1989; Campbell et al., 1990; Kirk et al., 1995). O nivel de Se sérico fetal é semelhante aos verificados em animais pré-colostrais (Van Saun et al., 1989).

Niveis superiores a $2,2 \mu \mathrm{g}$ de $\mathrm{Se} / \mathrm{g}$ de matéria seca do figado e maiores que $120 \mathrm{ng}$ de $\mathrm{Se} / \mathrm{ml}$ de sangue foram considerados adequados em fetos bovinos por Van Saun et al. (1989). Baseando-se em equações preditoras, para atingir esses valores nos fetos o nivel mínimo de Se no fígado materno deve variar entre 0,95 a $1,0 \mu \mathrm{g}$ de $\mathrm{Se} / \mathrm{g}$ de peso seco. Niveis hepáticos menores que 1,0 $\mu \mathrm{g}$ de $\mathrm{Se} / \mathrm{g}$ em fetos foram associados a lesões miodegenerativas.

Koller et al. (1984) verificaram que bezerros filhos de vacas suplementadas oralmente com Se, na forma de selenito de sódio, apresentaram maior concentração de Se sérico e maior atividade de GSHPx no nascimento. Esses resultados confirmaram os obtidos por Perry et al. (1978), em que bezerros de vacas recebendo suplementação de $5 \mathrm{mg}$ Se/dia apresentaram maior nível sérico de Se ao 
nascer. Outras formas de suplementação foram avaliadas. A administração oral, parenteral ou em péletes intraruminais foram eficientes na suplementação de vacas prenhas, aumentando a concentração de Se no sangue das vacas no parto e, no sangue, soro ou fígado dos bezerros (Jenkins et al., 1974; Little et al., 1979; Weiss et al., 1984; de Toledo \& Perry, 1985; Stowe et al., 1988; Campbell et al., 1990; Hidiroglou \& Batra, 1994; Abdelrahman \& Kincaid, 1995).

Animais avaliados por Weiss et al. (1990) apresentaram, no início do período seco, concentrações médias de Se no plasma e no sangue de 0,088 e 0,257 $\mu \mathrm{g} \mathrm{Se} / \mathrm{ml}$ respectivamente, valores considerados adequados. Dentre esses animais, um grupo não suplementado, recebendo 0,1 ppm de Se na dieta, apresentou marcado declínio dessas variáveis, tornando-se deficiente no parto e início da lactação. Já animais suplementados com 0,3 ppm, mais uma injeção de $50 \mathrm{mg}, 21$ dias antes do parto estimado, mantiveram os niveis de Se plasmático e sanguíneo.

Estudando, também, o comportamento de Se no período seco, Abdelrahman \& Kincaid (1995) confirmaram esses resultados, verificando ainda que o fornecimento de 0,3 ppm às vacas aumentou a concentração de Se no fígado de bezerros no nascimento e aos 42 dias de idade. Entretanto, Stowe et al. (1988) recomendaram niveis mais elevados de Se durante o periodo seco, de 0,5 a 0,7 ppm, para prover concentrações séricas de no minimo 70 a 80 ng/ml.

Com relação a $\alpha$-tocoferol, Hidiroglou et al. (1994) relataram a sua pequena transferência pela placenta, já que o nível plasmático das mãe é superior ao do bezerro recém-nascido. Desse modo, o fornecimento suplementar de vitamina $E$ às mães não afeta o nivel sérico desta vitamina nos bezerros pré-colostrais ((Stowe et al., 1988; Hidiroglou, 1989), o que toma a transferência através do colostro muito importante. Os animais apresentaram niveis baixos de $\alpha$-tocoferol ao nascer, mas após a ingestão de colostro, os níveis são significativamente superiores entre os 7 e 10 dias de idade (Stowe et al., 1988; Hidiroglou \& Batra, 1994).

Goff \& Stabel (1990) registraram um marcado declínio na concentração de $\alpha$-tocoferol plasmático próximo ao parto, como resultado da produção e secreção do colostro. Quando os animais progrediram no periodo de lactação, $\alpha$-tocoferol plasmático aumentou, provavelmente devido à maior ingestão de matéria seca (Weiss et al., 1990; Goff \& Stabel, 1990; Hidiroglou et al., 1994). Entretanto, Stowe et 
al. (1988) observaram que a suplementação de vacas no periodo seco com 500 UI vitamina $E$ /dia, com ou sem Se suplementar, manteve o nivel sérico de $\alpha$-tocoferol entre 2 e $4 \mu \mathrm{g} / \mathrm{ml}$, o que os autores consideraram apropriado para vacas leiteiras.

\subsubsection{Vitamina E e selênio no colostro e leite}

O colostro é uma excelente fonte de Se, apresentando concentrações relativamente altas e proporcionais à dieta (Koller et al., 1984; Stowe et al., 1988; CAMPBELL et al., 1990).

Com respeito à presença de Se na secreção láctea que se segue ao colostro, existem inúmeras informações na literatura. Jenkins et al. (1974) e Little et al. (1979), trabalhando com animais recebendo dietas deficientes em Se, verificaram que a suplementação aumentou o nivel de Se no leite. Trabalhos posteriores (Perry et al., 1977; Conrad \& Moxon,1979; Hidiroglou et al., 1987) esclareceram que a concentração de Se no leite é baixa e é difícil aumentar seu nivel substancialmente, através do fornecimento de Se às vacas. O fornecimento de $0,1,2$ ou $5 \mathrm{mg}$ de Se/dia a vacas Hereford não alterou a concentração de Se no leite (Perry et al., 1977). Já Conrad \& Moxon (1979) verificaram que 4,8\% de Se suplementar foi transferido para o leite quando animais foram alimentados com dietas deficientes, mas que somente $0,9 \%$ do Se suplementar foi tranferido para o leite de vacas consumindo dietas adequadas em Se.

De acordo com Maus et al. (1980), a flutuação da concentração de Se no plasma e no leite apresentam o mesmo comportamento com o aumento do Se consumido. Com o aumento da ingestão de 2 para $6 \mathrm{mg}$ de Se/dia, os níveis do mineral no plasma e leite aumentam linearmente. Quando a ingestão chega a aproximadamente $6 \mathrm{mg} /$ dia, há uma inflexão da curva de resposta tanto para plasma quanto para leite. A partir desse ponto, a taxa e a extensão da resposta são limitadas. A curva de concentração de Se atinge um platô em $0,12 \mu \mathrm{g} / \mathrm{ml}$ de plasma e $0,05 \mu \mathrm{g} / \mathrm{ml}$ de leite, mudando pouco com o aumento da ingesão após a inflexão. Por outro lado, quando a ingestão de Se é moderada (6-12 mg/dia) a glândula mamária aparentemente secreta somente uma quantidade limitada de Se no leite, ou, mais 
provavelmente, a absorção líquida de Se do intestino é controlada com o aumento da ingestão para previnir acúmulo excessivo nos tecidos. Somente quando a concentração e ingestão de Se tornam-se altas (5 mg/kg ou $50 \mathrm{mg} / \mathrm{dia})$, a habilidade do mecanismo de proteção é excedida e a sua toxidez manifesta-se.

O conteúdo de vitamina $E$ do colostro é de especial importância para 0 ruminante recém-nascido, porque ao nascer apresenta pequenas quantidades da vitamina em seus tecidos. Hidiroglou (1989) analisou o leite bovino no início da lactação quanto ao nivel de vitamina E. A maior concentração de $\alpha$-tocoferol $(1,91$ $\mu \mathrm{g} / \mathrm{ml}$ ) foi verificada no colostro obtido na primeira ordenha e a média do primeiro mês de lactação foi de $0,30 \mu \mathrm{g}$ de $\alpha$-tocoferol $/ \mathrm{ml}$. A adminstração intraperitonial de $5 \mathrm{~g}$ de dl- $\alpha$-acetato de tocoferol ao final do primeiro mês de lactação, aumentou a concentração de vitamina $E$ no plasma e no leite, medida 12 horas após a adminstração. As concentrações de vitamina $E$ no plasma e no leite permaneceram mais elevadas que as concentrações do controle por quatro e seis dias, respectivamente. Weiss et al. (1990) verificaram que o fornecimento de vitamina $E$ durante o periodo seco aumentou o nivel de vitamina $E$ no colostro, o que pode ser importante para a higidez do bezerro.

Schingoethe et al. (1978) verificaram uma variação sazonal no nivel de $\alpha$-tocoferol no leite de vacas mantidas em pastagens. A concentração aumentou de aproximadamente $20 \mu \mathrm{g} / \mathrm{g}$ de gordura na primavera para $50 \mu \mathrm{g} / \mathrm{g}$ de gordura no verão, declinando para $30 \mu \mathrm{g} / \mathrm{g}$ de gordura no inverno. Já animais que foram alimentados com forragens conservadas apresentaram um nivel estável de $25 \mu \mathrm{g} / \mathrm{g}$ de gordura. Miller et al. (1995) confirmaram esses resultados.

\subsubsection{Suplementação do bezerro recém-nascido}

Enquanto no colostro a concentração de Se é relativamente alta e proporcional à dieta, sua concentração no leite cai consideravelmente 1 semana após o parto. Maus et al. (1980) observaram que bezerros consumindo dietas lácteas não suplementadas apresentaram concentrações de Se no sangue de 0,1 ppm ao nascer, 
mas sofreram depleção atingindo 0,06 ppm na terceira semana de vida. Em animais avaliados por Weiss et al. (1983), o nivel de Se sérico de bezerros não suplementados decresceu linearmente de $0,024 \mathrm{ppm}$ no nascimento para $0,0188 \mathrm{ppb}$ no $56^{\circ}$ dia Os autores sugeriram que os animais apresentam uma necessidade crescente de Se para incorporação na enzima GSHPx durante a eritropoiese.

Ao fornecer uma alta dose de Se (1 ppm) na dieta, Kincaid et al. (1977) verificaram um aumento significativo dos niveis de Se no fígado, coração e sangue de bezerros, mas a atividade especifica de ${ }^{75} \mathrm{Se}$ foi reduzida nos mesmos tecidos, sugerindo que a homeostase no bezerro é muito efetiva para moderar a absorção de Se. Esses resultados foram confirmados por Weiss et al. (1984). Os bezerros, filhos de vacas não suplementadas, que receberam Se na forma de uma ou duas injeções, apresentaram maior concentração sérica de Se, que os não injetados. No entanto, Se sérico de bezerros de vacas que receberam $5 \mathrm{mg}$ diariamente no periodo seco não responderam à suplementação por injeção. Nesse estudo, a concentração de Se sérico atingiu um platô de $50 \mathrm{ng} / \mathrm{ml}$ em bezerros filhos de vacas suplementadas com 5 ppm de Se/dia, não aumentando quando Se adicional foi injetado.

Por outro lado, Kincaid \& Hodgson (1989) afirmaram que Se suplementar no nascimento provê uma reserva endógena no bezerro para ser utilizada quando $o$ animal crescer e a exigencia aumentar. Os autores trabalharam com bezerros filhos de mães suplementadas e nascidos com concentrações adequadas de Se (aproximadamente $0,15 \mu \mathrm{g}$ de Se/ml de sangue). Não houve mudanças nos niveis de Se pelo menos até a terceira semana de vida dos bezerros de vacas com concentrações adequadas de Se. Entretanto, houve um aumento de Se no sangue na décima semana de idade, quando bezerros foram injetados com Se no nascimento $(0,0825 \mathrm{mg}$ de Se/kg de peso vivo).

A diagnose de deficiências subclínicas de Se em ruminantes pode ser realizada pela avaliação da atividade de GSHPx. De acordo com Siddons \& Mills (1981), esta determinação apresenta vantagens sobre a medição da concentração de Se no sangue como indicador do "status" de Se, já que a metodologia para sua detecção é mais simples e não está sujeita a erros por contaminação das amostras.

A atividade da GSHPx no sangue não aumenta rapidamente após a suplementação como a concentração sérica de Se. Há um intervalo de 4 a 5 
semanas entre o aumento de Se sérico e o aumento da atividade da enzima, o que está relacionado ao "tumover" normal dos eritrócitos. Animais avaliados por Weiss et al. (1983) apresentaram atividade média de 14,9 unidades/mg de hemoglobina ao nascer. $A$ atividade aumentou quadraticamente após uma injeção subcutânea de Se e vitamina $E$, atingindo o nível máximo de 30,8 unidades/mg de hemoglobina 35 dias após o nascimento. De acordo com os autores, à medida que os animais crescem e o volume total de sangue aumenta, Se sérico foi tornando-se limitado, e menos Se estava disponivel para incorporação na GSHPx durante a eritropoiese.

Koller et al. (1984) verificaram que a atividade da GSHPX no sangue decresceu entre o nascimento e a oitava semana de idade, mas filhos de mães suplementadas apresentaram uma queda menos acentuada por causa da grande disponibilidade de Se no colostro.

O bezerro recém-nascido depende da ingestão de colostro como sua fonte de vitamina $E$. Ao nascer, bezerros apresentaram baixa concentração de $\alpha$ tocoferol $(0,14 \mu \mathrm{g} / \mathrm{ml})$. Após a ingestão do colostro, a concentração aumentou para $1,04 \mu \mathrm{g} / \mathrm{ml}$ no décimo dia, mas declinou para $0,80 \mu \mathrm{g} / \mathrm{ml} 30$ dias após o nascimento (Hidiroglou \& Batra, 1994). Em animais não suplementados, o nivel decresceu para $0,35 \mu \mathrm{g} / \mathrm{ml}$ na décima semana (Reddy et al., 1985).

De acordo com Reddy et al. (1985), diversos fatores afetam a necessidade de vitamina $E$ em bezerros, como estresse pelo confinamento, doenças, desmama e interrelações com outros nutrientes como Se e PUFA. Os autores sugeriram que os animais podem não conseguir vitamina $E$ suficiente de rações iniciais convencionais $(21,6$ UI vitamina $E / \mathrm{kg})$ e a suplemtentação pode ser essencial para obter máximo desempenho.

Tanto a suplementação oral quanto a parenteral aumentaram as concentrações séricas de $\alpha$-tocoferol de bezerros. Reddy et al. (1987) verificaram que o fornecimento diário de 125 a 250 UI de vitamina $E$ foi benéfico, melhorando o desempenho dos animais. No entanto, os autores sugeriram que para manter constante a concentração de $\alpha$-tocoferol no sangue, a suplementação deve aumentar com a idade, recomendando-se com base no peso corporal. 


\subsection{Selênio e Vitamina E e Resposta Imunológica em Bovinos}

O desenvolvimento de uma resposta imunológica adequada depende da integridade funcional de vários tipos de células imunocompetentes. Da mesma maneira que são responsáveis pela manutenção da integridade das membranas de eritrócitos, vitamina $\mathrm{E}$ e Se podem ser associados à degradação de metabólitos derivados de oxigênio em células linfóides (Sheffy \& Schultz, 1979). No entanto, o efeito imunoestimulatório desses nutrientes pode não se restringir apenas à ação antioxidante. A maior fração do Se corporal está na forma de compostos não bem caracterizados, como peptideos, nucleotideos e outros produtos metabólicos, enquanto a vitamina $E$ está envolvida no metabolismo de prostaglandinas. Assim, podem existir outras vias ainda pouco estudadas para explicar o efeito destes nutrientes sobre a resposta imunológica (Kiremidjian-Schumacher \& Stotzky, 1987; Sheffy \& Schultz, 1979).

A resposta humoral e a mediada por células em bezerros leiteiros avaliados por Cipriano et al. (1982) não foram alteradas quando a dieta desses animais foi suplementada com a adição diária de $1 \mathrm{~g}$ de dl- $\alpha$-acetato de tocoferol ao leite. Nesse trabalho problemas com a gordura emulsificada da dieta podem ter mascarado o efeito da suplementação, além do que a resposta imunológica poderia ter sido estimulada por quantidades menores da vitamina.

Em trabalhos posteriores, realizados por Reddy et al. (1986) e Reddy et al. (1987), verificou-se um aumento na proliferação de linfócitos $T$ e $B$ e na concentração de IgM em animais suplementados. Reddy et al. (1986) optaram por suplementação semanal, fornecendo vitamina $E$ oralmente ou através de injeção intramuscular, enquanto Reddy et al. (1987) utilizaram apenas doses orais e diárias.

Reffett et al. (1988) observaram que a deficiência de Se pode deprimir a resposta imunológica de bezerros desafiados por um patógeno, uma vez que o nivel de IgM sérico e o titulo de anticorpos para IBRV (Bovine Rhinotracheitus Virus) foram superiores em bezerros suplementados. Nesses animais constatou-se, também, que a atividade da GSHPx no sangue e plasma aumentaram após o desafio viral. Esse acréscimo pode ter sido causado pela maior produção de metabólitos 
derivados de oxigênio durante a atividade de macrófagos e neutrófilos, e consequente necessidade de eliminá-los do sistema.

Droke \& Loerch (1989), utilizando novilhos de corte que receberam vitamina $E$ e Se por injeção intramuscular, constataram melhora na competência imunológica, evidenciada pelo aumento no título de lgG sérico em resposta à vacinação com Pasteurella haemolytica. Entretanto, não houve efeito sobre desempenho ou saúde.

Ainda com Pasteurella haemolytica como desafio, mas em animais submetidos a estresse, Stabel et al. (1989) não encontraram diferenças consistentes na concentração de imunoglobulinas, em bezerros com niveis deficientes ou adequados em Se. Assim como foi verificado por Reffett et al. (1988), a atividade de GSHPx plasmática aumentou em animais com niveis adequados ou ligeiramente deficientes de Se em resposta à doença infecciosa, o que pode ser reflexo dos danos oxidativos nos tecidos.

Resposta humoral positiva foi verificada por Swecker, Jr. et al. (1989) após o fornecimento de mistura mineral com 80 a $120 \mathrm{mg}$ de Se/kg. Essa suplementação aumentou e manteve a concentração de Se no sangue em niveis superiores a $100 \mu \mathrm{g} / \mathrm{l}$, concentração associada a produção ótima de anticorpos para lisozima. Quando animais gestantes receberam mistura mineral contendo $120 \mathrm{mg}$ de Se/kg, consumindo em média $6 \mathrm{mg}$ de Se/dia, observou-se que a concentração total de IgG colostral e, também, o nivel de lgG sérico dos bezerros às $24 \mathrm{~h}$ de vida aumentaram (Swecker et al., 1995). 


\section{MATERIAL E MÉTODOS}

A fase de campo deste trabalho foi realizada entre outubro de 1992 e outubro de 1993 no Departamento de Zootecnia, da Escola Superior de Agricultura "Luiz de Queiroz" , município de Piracicaba, Estado de São Paulo.

As análises laboratoriais foram realizadas no Laboratório de Anatomia e Fisiologia Animal (LAFA) do Departamento de Zoologia da Escola Superior de Agricultura "Luiz de Queiroz" , município de Piracicaba, Estado de São Paulo.

\subsection{Animais}

Nesse experimento foram utilizados bezerros recém-nascidos, machos e fêmeas das raças Holandesa, Jersey, Pardo-Suiça e Guemsey. Logo após o nascimento, esses animais foram separados das mães e encaminhados ao bezerreiro, onde permaneceram em baias individuais até a desmama.

Os bezerros receberam colostro matemo durante os 2 primeiros dias de vida, através de mamadeira. A seguir receberam 4 I de leite integral divididos em duas refeiçöes diárias, oferecidas em balde. Além dessa dieta líquida, os animais tinham a disposição água e feno desde o primeiro dia de vida e ração inicial a partir do sétimo dia. A composição dessa ração é apresentada na tabela 1 do Apêndice.

Os animais com diarréia foram tratados com solução salina para hidratação oral e se restringiu o leite da dieta. Apenas em casos graves fomeceu-se antibióticos.

A desmama abrupta foi efetuada aproximadamente aos 45 dias de vida, de acordo com o consumo da ração inicial. Os animais foram então agrupados em baias coletivas na mesma instalação. 


\subsection{Tratamentos}

Considerando o fato de que o nivel de imunoglobulinas séricas em bezerros nas primeiras 24-48 horas de vida é muito variável (Brignole \& Stott, 1980; Robison et al., 1988), estabeleceu-se previamente que os animais seriam divididos em dois grupos experimentais de acordo com a concentração inicial de imunoglobulinas séricas adquiridas passivamente. Esse procedimento foi adotado para diminuir a variação entre as parcelas experimentais.

Nesse trabalho adotou-se o nivel de 20 unidades ZST (Zinc Sulphate Turbidity) como referência para a separação dos animais, procurando-se com isto formar um grupo em que a transferência de imunoglobulinas fosse deficiente. Para essa avaliação, coletou-se sangue de cada animal no segundo dia de vida (após a ingestão de colostro) e determinou-se o nível de imunoglobulinas séricas pelo método de ZST, descrito por McEvan et al. (1970). A partir destes resultados, classificou-se os animais em dois grupos:

Alto: animais que às 48 horas de vida apresentaram niveis de lg adquiridas passivamente superiores a 20 unidades ZST;

Baixo: animais que apresentaram valores inferiores a 20 unidades ZST.

As 20 unidades ZST correspondem, de acordo com avaliações efetuadas no LAFA, a uma concentração de imunoglobulinas séricas de $15,06 \mathrm{mg} / \mathrm{ml}$.

Após essa avaliação preliminar os animais reberam vitamina $E$ e/ou selênio através de injeção intramuscular no terceiro dia de vida. A ordem previamente estabelecida por sorteio, ficou assim determinada:

A. Vitamina E + Selênio: cada animal recebeu 2200 Ul de vitamina E e 0,15 mg de Se/kg PV;

B. Controle: cada animal recebeu $4 \mathrm{ml}$ de solução salina;

C. Selênio: cada animal recebeu 0,15 mg de Se/kg PV;

D. Vitamina E: cada animal recebeu 2200 Ul de vitamina $E$.

Em função da disponibilidade de animais e condições foram estabelecidos os seguintes tratamentos: 
T1: animais do grupo alto que receberam vitamina $\mathrm{E}$ e Se;

T2: animais do grupo alto controle;

T3: animais do grupo alto que receberam selênio;

T4: animais do grupo alto que receberam vitamina $\mathrm{E}$;

T5: animais do grupo baixo que receberam vitamina $\mathrm{E}$ e Se;

T6: animais do grupo baixo controle.

Foram utilizados 8 animais em cada tratamento com bezerros apresentando alta imunidade passiva e 4 em cada tratamento apresentando baixa imunidade passiva, totalizando 40 unidades experimentais. Em função da necessidade de se usar animais com proteção passiva baixa, fora dos padrões da atividade da Fazenda Experimental, somente foi possivel estabelecer os tratamentos T5 e T6, com 4 repetições cada, para animais dessas condições.

Utilizou-se nos tratamentos T1, T4 e T5 vitamina $E$ na forma de $\alpha$-dltocoferol (Merck), diluída em veículo oleoso. A atividade de $2200 \mathrm{UI}$ de vitamina E equivale a $2 \mathrm{~g}$ de $\alpha$-dl-tocoferol. Já o selênio aplicado aos tratamentos T1, T3 e T5 estava na forma de selenito de sódio (Labsynth), e foi diluído em água destilada.

\subsection{Amostragem de Sangue}

Coletou-se de cada animal aproximadamente $10 \mathrm{ml}$ de sangue da veia jugular aos $2,5,10,15,17,20,25,30,35,40,50,70$ dias de idade. $O$ soro separado por centrifugação foi transferido para 3 frascos devidamente identificados, e mantido a $-20^{\circ} \mathrm{C}$ até o processamento das amostras.

Para a avaliação da atividade da enzima GSHPx em eritrócitos, coletou-se sangue no segundo dia de vida em tubo de centrífuga contendo $1 \mathrm{ml}$ de EDTA $10 \%$. Centrifugou-se a amostra, eliminou-se o plasma e após a leitura do hematócrito, promoveu-se a hemólise das células pela adição de água deionizada. As células lisadas foram mantidas em frascos a $-20^{\circ} \mathrm{C}$ por um periodo máximo de 1 mês pré-análise. 


\subsection{Amostragem de Fezes}

As amostras de fezes foram coletadas e avaliadas diariamente no periodo de 2 a 30 dias de idade. Classificaram-se as fezes quanto a cor, consistência, presença de muco e sangue para assim identificar diarréia através das tabelas $2,3,4$ e 5 do Apêndice, utilizadas pelo AFRC (Agricultural and Food Research Council - Inglaterra), que são apresentadas no Apêndice.

A classificação utilizada para determinação da condição de diarréia segue o sistema empregado por De Leeuw et al. (1980) e Tsunemitsu et al. (1989), que a definiram como quando as fezes se apresentam pelo menos semi-líquidas e de cor bege ou amarela, com grande quantidade de muco.

\subsection{Comportamento e Desempenho}

Foram avaliadas diariamente, no periodo entre 2 e 30 dias, as condiçōes corporais dos animais, através das variáveis disposição, hidratação e apetite.

O peso corporal dos bezerros foi registrado ao nascer e aos 5, 10, 15, 20, $25,30,35,40,45,50,70$ dias de idade.

\subsection{Análise das Amostras de Sangue}

A concentração de imunoglobulinas séricas no segundo dia de vida foi determinada pelo método descrito por McEvan et al. (1970). É um método baseado na avaliação da turvação obtida pela reação entre imunoglobulinas e o sulfato de zinco, $\mathrm{ZnSO}_{4} .7 \mathrm{H}_{2} \mathrm{O}$. Uma solução de sulfato de zinco (208 mg ZnSO $\left.4.7 \mathrm{H}_{2} \mathrm{O} / \mathrm{l}\right)$ foi preparada com água destilada que permaneceu em ebulição por 20 minutos, para remover dióxido de carbono dissolvido. O dióxido de carbono afeta a turvação e consequentemente a densidade óptica. Assim, essa solução foi mantida em um sistema fechado, no qual todo - ar consumido borbulhava em solução de $\mathrm{NaOH}$. Previamente mantendo-se a temperatura ambiente entre $21-23^{\circ} \mathrm{C}$, misturou-se $100 \mu \mathrm{l}$ da amostra de soro a $6 \mathrm{ml}$ da 
solução de $\mathrm{ZnSO}_{4} .7 \mathrm{H}_{2} \mathrm{O}$ e após incubar por 60 minutos, procedeu-se a leitura da absorbância no espectrofotômetro, em comprimento de onda $660 \mathrm{~nm}$. As amostras foram analisadas em duplicata para se obter o valor médio.

Para a quantificação da proteína sérica total utilizou-se o método de biureto (Reinhold, 1953). Misturou-se $100 \mathrm{ml}$ da amostra de soro a 4,9 ml de $\mathrm{NaOH}(0,75$ $\mathrm{N})$ e $1 \mathrm{ml}$ de reagente de biureto. Após incubação por 20 minutos, procedeu-se a leitura da absorbância no espectrofotômetro em comprimento de onda $545 \mathrm{~nm}$. Para cada bateria de amostras, estabeleceu-se uma curva padrão que relacionava concentrações conhecidas de proteina (albumina bovina - Sigma Chemical Co.) a valores de absorbância. As amostras foram analisadas em duplicata, sendo o valor médio utilizado para se obter a concentração de proteína sérica em g/100 ml de soro.

As amostras de soro foram submetidas a eletroforese para a separação e posterior quantificação das frações protéicas albumina e globulina. Utilizou-se um sistema de eletroforese vertical em tubos de vidro preenchidos por gel de poliacrilamida $7 \%$. 0 soro foi diluído (1:50) em tampão PBS + sacarose (10\%), aplicado sobre o gel e o sistema submetido a uma amperagem de 1,2 $\mathrm{mA}$ por tubo durante $1 \mathrm{~h}$. $\mathrm{O}$ gel foi colorido com amido black (1\% em ácido acético $7 \%$ ) por $1 \mathrm{~h}$ e descolorido com ácido acético $7 \%$, através de sucessivas lavagens (Brewer \& Ashworth, 1969). A leitura do gel revelado foi feita utilizando-se um densitômetro Canalco - mod. $K$, obtendo-se o gráfico correspondente e as áreas fracionadas. Para identificação precisa da área correspondente às imunoglobulinas foram realizados vários procedimentos eletroforéticos utilizando soro de bezerros pré-colostrais e a dição de imunoglobulina pura padrão (Sigma Chemical Company - USA). A proteina total determinada por biureto foi utilizada para a quantificacão de albumina, globulina e imunoglobulina em g/100 ml de soro.

Avaliou-se, também, a atividade da enzima GSHPx nos eritrócitos pelo método de Paglia \& Valentine (1967) modificado. Nesse método a concentração de glutationa reduzida (GSH) é mantida constante pela adição da enzima glutationa redutase e de NADPH, que convertem imediatamente toda glutationa oxidada (GSSG) a forma reduzida. Avalia-se a produção de GSSG pelo decréscimo em absorbância quando NADPH é convertido a NADP. As amostras de células lisadas foram descongeladas e diluídas a 1:40 em água deionozada. A cada $0,05 \mathrm{ml}$ da amostra adicionou-se $1,4 \mathrm{ml}$ do reagente principal, que contém glutationa redutase e NADPH (Sigma Chemical Company - USA). Misturou-se por Vortex e incubou-se por $3 \mathrm{~min}$ a $30^{\circ} \mathrm{C}$. Adicionou-se $0,05 \mathrm{ml}$ de 
cumene hidroperóxido (Sigma Chemical Company - USA) e utilizando-se espectrofotômetro avaliou-se a mudança na densidade óptica em $340 \mathrm{~nm}$ nos tempos de $0,30,60$ e 90 s. A leitura das amostras foi corrigida pela leitura de um branco, no qual água deionizada substituiu a amostra. Considerando a porcentagem de hematócrito, calculou-se a atividade da enzima em unidades por $\mathrm{ml}$ de eritrócitos.

Enviou-se amostras de soro, dos animais aos 2 dias de idade, ao Departamento de Clínica Médica da Faculdade de Ribeirão Preto, Universidade de São Paulo, para determinação da concentração de $\alpha$-tocoferol. Empregou-se o método de cromatografia líquida de alta eficiência (HPLC) descrito por Amaud et al. (1991).

\subsection{Delineamento Experimental e Análise Estatística}

O delineamento experimental adotado foi em parcelas subdivididas no tempo, sendo os efeitos do nivel inicial de imunoglobulinas e do fornecimento suplementar de vitamina $E$ e selênio aplicados às parcelas e as medidas repetidas no tempo consideradas como subparcelas. O modelo utilizado para a análise foi:

$$
Y_{i j}=\mu+T_{i}+P_{j}+T_{i} \times P_{j}+e_{i j}
$$

sendo: $Y_{i j}$ as medidas observadas nas unidades experimentais; $\mu$ a média geral; $T_{i} 0$ efeito de tratamento; $P_{j} \circ$ efeito das datas experimentais; $T_{i} \times P_{j}$ a interação entre tratamento e datas experimentais e $e_{i j}$ o erro experimental.

As variáveis séricas e de desempenho foram submetidos à análise de variância para tal delineamento, procedendo-se, posteriormente, a análise de variância dentro de cada data experimental. Nesse caso, o modelo utilizado para a análise foi:

$$
Y_{i}=\mu+T_{i}++e_{i}
$$

sendo: $Y_{i}$ as medidas observadas nas unidades experimentais; $\mu$ a média geral; $T_{i} 0$ efeito de tratamento e $e_{i}$ o erro experimental. Quando necessário, estabeleceu-se um conjunto de contrastes ortogonais para a comparação das médias de tratamentos, de acordo com a estrutura dos tratamentos. A variável imunoglobulina (lg) sofreu transformação logaritmica. 
Para as variáveis peso e ganho de peso foram feitas análises de variância utilizando-se o peso ao nascer e a concentração inicial de imunoglobulinas séricas como covariáveis.

$\mathrm{Na}$ análise estatística da variável cor fecal agrupou-se os dados em duas categorias, de acordo com as notas recebidas:

$$
\begin{aligned}
& \text { fezes normais } \rightarrow \text { notas } 0,0 \text { a } 1,5 \\
& \text { fezes diarréicas } \rightarrow \text { notas } 2,0 \text { a } 3,0
\end{aligned}
$$

Procedeu-se da mesma forma para a variável consistência fecal, utilizando-se o seguinte critério:

$$
\begin{aligned}
& \text { fezes normais } \rightarrow \text { notas } 0,0 \text { a } 1,0 \\
& \text { fezes diarréicas } \rightarrow \text { notas } 1,5 \text { a } 4,0 .
\end{aligned}
$$

Aplicou-se, a seguir, o teste não-paramétrico $\chi^{2}$, pelo qual a frequência com que os animais apresentaram fezes normais ou diarréicas foi associada aos tratamentos. Desta forma, não foram avaliadas as notas diárias, mas a incidência de diarréia durante o período experimental. Inicialmente analisou-se essas variáveis no periodo total, de 2 a 30 dias, dividindo-se em seguida em três subperiodos: 2 a 10, 11 a 20 e 21 a 30 dias.

Utilizou-se na análise estatística dos dados o programa SAS (1989). 


\section{RESULTADOS E DISCUSSÃO}

\subsection{Condição Inicial de Vitamina E e Selênio}

A concentração sérica média de vitamina $E$ e a atividade média de GSHPx em eritrócitos dos animais aos 2 dias de idade são apresentadas na Tabela 2. Os dados originais são apresentados nas tabelas 6 e 7 do Apêndice. Cipriano et al. (1982) e Reddy et al. (1985) relataram níveis que variaram de 1,92 a 2,7 $\mu \mathrm{mol} / \mathrm{l}$ em bezerros entre 24 e $48 \mathrm{~h}$ de vida, sendo inferiores aos valores médios de vitamina $\mathrm{E}$ observados nesse experimento. Embora a concentração de vitamina $E$ no colostro fornecido aos animais não tenha sido avaliada, e, considerando que o bezerro recémnascido recebe essa vitamina principalmente através do colostro, fatores que afetam a formação e transferência desse alimento ao recém-nascido podem explicar essas variações.

De acordo com Davies (1984), animais com atividade da GSHPx inferior a 15 unidades $/ \mathrm{ml}$ de eritrócitos podem ser deficientes em selênio. As atividades observadas foram superiores a esse valor, com apenas 2 exceções, animal 1 do T3 e animal 4 do T6, indicando que a suplementação materna de Se manteve níveis adequados do mineral nos animais recém-nascidos.

\subsection{Proteina Sérica Total (PT)}

Os níveis médios de proteína sérica total (PT) dos bezerros, nas diferentes idades, são apresentados na Tabela 3 e ilustrados na Figura 3. Os dados originais são apresentados nas Tabelas 8 a 13 do Apêndice. No tratamento T4 0 animal 1 morreu ao completar 35 dias de idade, não sendo substituído e considerando-se para análise apenas 7 animais nesse tratamento após a referida data. 
Tabela 2. Médias de tratamentos da concentração sérica de vitamina $E(\mu \mathrm{mol} / \mathrm{l})$ e atividade de glutationa peroxidase GSHPx (unidades/ml de eritrócitos) de bezerros aos 2 dias de idade.

\begin{tabular}{cccc}
\hline \multirow{2}{*}{ Tratamentos } & Vitamina $E(\mu \mathrm{mol} / \mathrm{l})$ & & GSHPx(U/ml eritrócitos) \\
\cline { 2 - 2 } T1 & Média $\pm \mathrm{DP}$ & & Média $\pm \mathrm{DP}$ \\
T2 & $5,69 \pm 3,88$ & & $40,05 \pm 16,95$ \\
T3 & $8,04 \pm 2,30$ & & $38,17 \pm 8,86$ \\
T4 & $3,36 \pm 1,40$ & & $39,71 \pm 17,34$ \\
T5 & $5,83 \pm 2,01$ & & $50,90 \pm 15,48$ \\
T6 & $5,20 \pm 1,09$ & & $60,38 \pm 24,28$ \\
\hline
\end{tabular}

Tabela 3. Concentração média de proteína total sérica $(\mathrm{g} / 100 \mathrm{ml})$ nos tratamentos.

\begin{tabular}{ccccccc}
\hline $\begin{array}{c}\text { Idade } \\
\text { (dias) }\end{array}$ & Média \pm DP & Média \pm DP & Média \pm DP & Média \pm DP & Média \pm DP & Média \pm DP \\
\hline 2 & $8,87 \pm 0,45$ & $9,18 \pm 0,20$ & $8,65 \pm 0,42$ & $9,04 \pm 0,47$ & $7,27 \pm 0,51$ & $6,92 \pm 0,30$ \\
5 & $8,49 \pm 0,47$ & $8,64 \pm 0,28$ & $8,12 \pm 0,35$ & $8,43 \pm 0,44$ & $6,65 \pm 0,70$ & $6,91 \pm 0,24$ \\
10 & $8,38 \pm 0,36$ & $8,51 \pm 0,17$ & $7,78 \pm 0,30$ & $8,02 \pm 0,31$ & $6,96 \pm 0,56$ & $6,75 \pm 0,03$ \\
15 & $8,17 \pm 0,21$ & $8,04 \pm 0,18$ & $7,28 \pm 0,28$ & $7,69 \pm 0,28$ & $6,61 \pm 0,35$ & $6,25 \pm 0,35$ \\
17 & $7,81 \pm 0,31$ & $7,74 \pm 0,37$ & $7,35 \pm 0,32$ & $7,53 \pm 0,58$ & $6,25 \pm 0,43$ & $6,38 \pm 0,33$ \\
20 & $7,57 \pm 0,27$ & $7,61 \pm 0,22$ & $7,14 \pm 0,21$ & $7,80 \pm 0,42$ & $6,51 \pm 0,36$ & $6,16 \pm 0,19$ \\
25 & $7,25 \pm 0,30$ & $7,11 \pm 0,36$ & $7,03 \pm 0,34$ & $7,16 \pm 0,26$ & $6,31 \pm 0,40$ & $6,08 \pm 0,29$ \\
30 & $7,22 \pm 0,34$ & $7,28 \pm 0,20$ & $7,12 \pm 0,22$ & $7,48 \pm 0,36$ & $6,52 \pm 0,29$ & $5,87 \pm 0,34$ \\
35 & $7,25 \pm 0,20$ & $7,22 \pm 0,30$ & $7,27 \pm 0,23$ & $7,42 \pm 0,38$ & $6,21 \pm 0,25$ & $5,86 \pm 0,34$ \\
40 & $7,39 \pm 0,26$ & $7,66 \pm 0,33$ & $7,42 \pm 0,21$ & $7,64 \pm 0,31$ & $7,21 \pm 0,74$ & $6,19 \pm 0,42$ \\
50 & $7,76 \pm 0,27$ & $7,61 \pm 0,29$ & $7,94 \pm 0,18$ & $7,73 \pm 0,29$ & $7,29 \pm 0,35$ & $6,11 \pm 0,39$ \\
70 & $7,87 \pm 0,30$ & $7,98 \pm 0,28$ & $8,21 \pm 0,21$ & $8,21 \pm 0,41$ & $7,88 \pm 0,33$ & $7,05 \pm 0,45$ \\
\hline
\end{tabular}

T1: Vitamina $\mathrm{E}+$ Selênio - nível alto de lg

T2: Controle - nivel alto de lg

T3: Selênio - nivel alto de lg

T4: Vitamina $E$ - nivel alto de lg

T5: Vitamina $E$ + Selênio - nível baixo de lg

T6: Controle - nível baixo de lg

DP: Desvio Padrão 
Os valores médios de PT observados nas diferentes datas experimentais estão de acordo com os verificados por Machado Neto et al. (1986) e Daniele et al. (1994b).

Através da análise de variância para o delineamento experimental em parcelas subdivididas observou-se que as médias de PT diferiram significativamente $(p<0,002)$ entre tratamentos, e, também, entre as idades ao longo do período experimental $(p<0,0001)$. No entanto, a interação tratamento $x$ idade não foi significativa, indicando um comportamento similar dos tratamentos nas diferentes idades. Na primeira data experimental, 2 dias, verificou-se que as concentrações médias de PT foram significativamente superiores $(p<0,0001)$ nos animais separados para formar os grupos de tratamentos com alta e baixa imunidade passiva inicial. Essa diferença que se manteve até os 50 dias de idade, não foi mais observada aos 70 dias. Este comportamento já era esperado, uma vez que os grupos foram separados pela concentração inicial de imunoglobulinas, fração protéica que no início da vida do animal perfaz de 20 a $40 \%$ da PT.

Os tratamentos do grupo alto (T1, T2, T3 e T4) não diferiram quando comparados nas datas experimentais avaliadas, enquanto, nos tratamentos do grupo baixo (T5 e T6), os animais que receberam vitamina $E$ e selênio suplementares apresentaram concentração média de PT superior $(p<0,0276)$ à do animais controle aos 50 dias de idade.

A concentração de PT foi avaliada por outros autores (Cipriano et al., 1982; Reddy et al., 1985; Reddy et al., 1986; Reddy et al., 1987a) que suplementaram bezerros com vitamina $E$. Nesses trabalhos, os animais apresentavam concentrações adequadas de imunoglobulinas séricas, após a ingestão do colostro, e o fornecimento suplementar da vitamina não influenciou o nível de PT sérica.

A concentração de PT decresceu no primeiro mês de vida dos animais de todos os tratamentos, comportamento que já foi relatado por outros autores (Tennant et al., 1969; Machado Neto et al., 1986; Daniele et al., 1994 b). Essa queda é atribuida ao catabolismo dos anticorpos adquiridos passivamente do colostro. Os valores mínimos médios calculados por tratamento foram $6,72 \pm 0,59 \mathrm{~g} / 100 \mathrm{ml}$ para $\mathrm{T} 1 ; 6,61 \pm 0,86 \mathrm{~g} / 100 \mathrm{ml}$ para T2; $6,46 \pm 0,47 \mathrm{~g} / 100 \mathrm{ml}$ para T3; $6,54 \pm 1,29 \mathrm{~g} / 100 \mathrm{ml}$ para T4; 5,88 $\pm 0,68 \mathrm{~g} / 100 \mathrm{ml}$ para T5 e 5,72 $\pm 0,68 \mathrm{~g} / 100 \mathrm{ml}$ para T6. Não houve 
diferença entre os tratamentos para a concentração mínima, mas as médias dos grupos com alta e baixa imunidade inicial diferiram significativamente $(p<0,026)$. Nos animais do grupo alto observou-se uma concentração minima média de 6,447 $\mathrm{g} / 100 \mathrm{ml}$, enquanto os animais do grupo baixo apresentaram 5,804 g/100ml. A data de ocorrência dos valores minimos foram $34,375 \pm 15,68$ dias para $T 1 ; 31,25 \pm 6,94$ dias para T2; $22,75 \pm 7,78$ dias para T3; $29,25 \pm 18,45$ dias para T4; $20,50 \pm 12,69$ dias para T5 e 30,00 $\pm 9,13$ dias para T6. Os grupos não diferiram, o mesmo ocorrendo para os tratamentos do grupo alto. No entanto, houve uma tendência $(p<0,0966)$ de 0 tratamento T6 apresentar um ponto de inflexão mais precoce, aos 20,5 dias de idade.

Após a data de ocorrência do valor mínimo, verificou-se que a concentração de PT aumentou em todos os tratamentos, marcando a fase endógena, na qual a produção de anticorpos pelo próprio bezerro torna-se mais evidente. Nessa fase, o aumento da sintese de outras proteinas séricas também pode contribuir para 0 incremento de PT (Husband et al., 1972).

Foram encontradas correlações positivas entre as concentrações de PT e imunoglobulinas séricas no segundo dia de idade: $r=0,983(p<0,0001)$ para o T1; $r=0,826(p<0,0115)$ para o T2; $r=0,93(p<0,008)$ para o T3; $r=0,966(p<0,0001)$ para 0 T4; $r=0,991$ ( $p<0,0085)$ para o T5. A correlação entre essas duas variáveis só não foi significativa nessa data para o tratamento T6. Os valores observados estão de acordo com Nocek et al. (1984), Machado Neto et al. (1986) e Daniele et al. (1994). A correlação descresceu, mas manteve-se significativa nas demais datas experimentais para todos os tratamentos. As variáveis PT e imunoglobulinas séricas, também, foram significativamente correlacionadas $(p<0,0001)$ considerando-se 0 periodo experimental total, com valores de $r=0,897$ para $T 1, r=0,859$ para $T 2, r=0,877$ para $T 3$, $r=0,882$ ) para $T 4, r=0,844$ para T5 e $r=0,695$ para T6. Esse comportamento correlacionado entre PT e lg ocorre em função da fração lg representar entre 20 e $40 \%$ da PT e, por ser essa a fração mais variável nesse periodo estudado. 


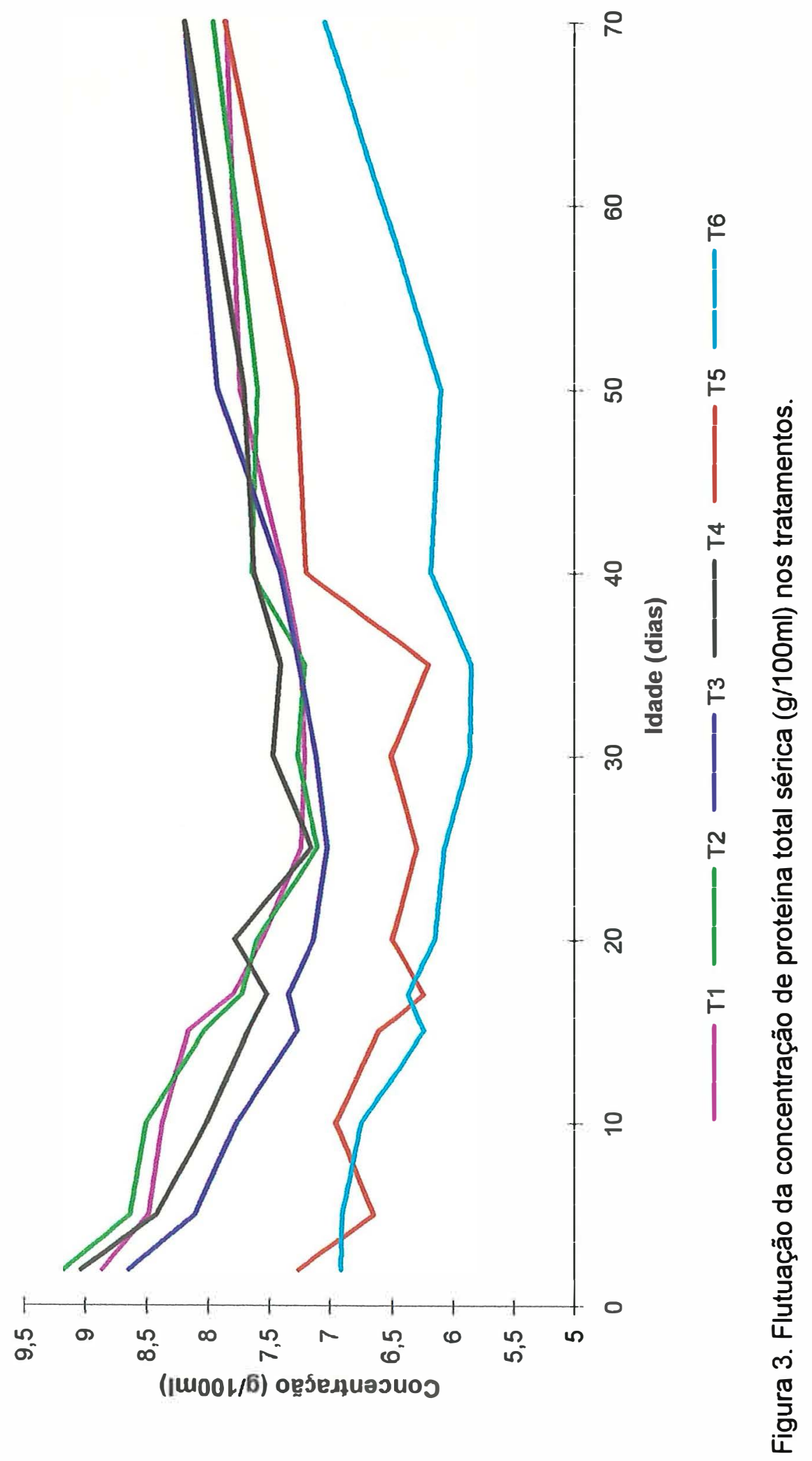




\subsection{Imunoglobulinas Séricas (lg)}

Os niveis médios de lg nas diferentes idades e tratamentos são apresentados na Tabela 4 e a flutuação dessa variável, durante a fase experimental, é mostrada na Figura 5. Os dados originais da concentração de lg sérica no segundo dia de vida, avaliada pelo método de ZST, são apresentados na tabela 14 do Apêndice, enquanto os níveis avaliados por eletroforese são apresentados nas tabelas 15 a 20 do Apêndice.

Tabela 4. Concentração média de imunoglobulinas séricas $(g / 100 \mathrm{ml})$ nos tratamentos.

\begin{tabular}{ccccccc}
\hline $\begin{array}{c}\text { Idade } \\
\text { (dias) }\end{array}$ & Média \pm DP & Média \pm DP & Média \pm DP & Média \pm DP & Média \pm DP & Média \pm DP \\
\hline 2 & $3,66 \pm 0,51$ & $4,23 \pm 0,22$ & $3,50 \pm 0,34$ & $3,88 \pm 0,49$ & $1,98 \pm 0,36$ & $2,05 \pm 0,21$ \\
5 & $3,12 \pm 0,46$ & $3,57 \pm 0,27$ & $2,87 \pm 0,28$ & $3,34 \pm 0,42$ & $1,48 \pm 0,37$ & $1,96 \pm 0,33$ \\
10 & $2,87 \pm 0,43$ & $3,37 \pm 0,14$ & $2,55 \pm 0,30$ & $2,92 \pm 0,29$ & $2,09 \pm 0,41$ & $1,65 \pm 0,17$ \\
15 & $2,80 \pm 0,37$ & $2,95 \pm 0,11$ & $2,36 \pm 0,19$ & $2,44 \pm 0,25$ & $1,69 \pm 0,54$ & $1,44 \pm 0,16$ \\
17 & $2,52 \pm 0,33$ & $2,87 \pm 0,23$ & $2,40 \pm 0,34$ & $2,42 \pm 0,29$ & $1,44 \pm 0,24$ & $1,51 \pm 0,13$ \\
20 & $2,42 \pm 0,31$ & $2,60 \pm 0,14$ & $2,00 \pm 0,11$ & $2,43 \pm 0,33$ & $1,40 \pm 0,23$ & $1,39 \pm 0,17$ \\
25 & $2,12 \pm 0,23$ & $2,28 \pm 0,19$ & $1,97 \pm 0,21$ & $2,03 \pm 0,18$ & $1,59 \pm 0,47$ & $1,26 \pm 0,16$ \\
30 & $2,04 \pm 0,22$ & $2,29 \pm 0,18$ & $2,01 \pm 0,15$ & $2,30 \pm 0,33$ & $1,75 \pm 0,27$ & $1,17 \pm 0,19$ \\
35 & $1,99 \pm 0,15$ & $2,15 \pm 0,16$ & $2,05 \pm 0,12$ & $2,25 \pm 0,32$ & $1,77 \pm 0,24$ & $1,23 \pm 0,20$ \\
40 & $2,08 \pm 0,23$ & $2,30 \pm 0,23$ & $2,13 \pm 0,13$ & $2,25 \pm 0,20$ & $1,87 \pm 0,42$ & $1,33 \pm 0,21$ \\
50 & $2,28 \pm 0,25$ & $2,40 \pm 0,26$ & $2,22 \pm 0,22$ & $1,85 \pm 0,24$ & $1,85 \pm 0,24$ & $1,19 \pm 0,22$ \\
70 & $2,30 \pm 0,26$ & $2,46 \pm 0,28$ & $2,69 \pm 0,22$ & $2,40 \pm 0,23$ & $2,34 \pm 0,31$ & $1,79 \pm 0,12$ \\
\hline
\end{tabular}

T1: Vitamina E + Selênio - nível alto de lg

T2: Controle - nível alto de lg

T3: Selênio - nivel alto de lg

T4: Vitamina $E$ - nivel alto de lg

T5: Vitamina $E$ + Selênio - nível baixo de lg

T6: Controle - nivel baixo de lg

DP: Desvio Padrão

Os valores máximos de lg séricas foram observados nas primeiras $48 \mathrm{~h}$ de vida, em função da absorção de anticorpos do colostro (McCoy et al., 1970; Husband et al., 1970; Ribeiro et al., 1983). Os níveis observados nos animais desse 
experimento estão de acordo com os verificados por Machado Neto \& Packer (1986) e Daniele et al. (1994 a).

Pela análise de variância para o delineamento experimental em parcelas subdivididas observou-se que a interação tratamento $x$ idade foi significativa $(p<0,0014)$. Dessa forma, analisou-se o efeito de tratamento, dentro de cada data experimental, sobre o nivel de imunoglobulinas séricas.

As concentrações médias de lg observadas no grupo de alto (T1, T2, T3 e T4) foram superiores às do grupo baixo (T5 e T6) dos 2 aos 50 dias de idade, não diferindo, no entanto, na última data avaliada, 70 dias. Esse resultado salienta a influência das imunoglobulinas passivas sobre PT, uma vez que foi verificada condição semelhante para essa variável.

Dentro do grupo alto, as concentrações médias de lg não diferiram entre os 4 tratamentos nas diferentes idades do periodo experimental. Quanto aos dois tratamentos do grupo baixo, os niveis médios observados dos 2 aos 25 dias não diferiram entre si, sendo, no entanto, as médias de T5 significativamente superiores às de T6 aos 30 ( $p<0,0605), 35(p<0,0559)$ e $50(p<0,0298)$ dias de idade. Aos 40 dias de idade houve uma tendência de as médias diferirem $(p<0,1210)$. Já aos 70 dias, essa diferença não foi mais observada ( $p<0,2029)$.

As diferenças significativas entre tratamentos dos grupos alto e baixo revelam uma absorção diferenciada de $\mathrm{lg}$ do colostro nas primeiras horas de vida. $A$ variação no nivel de anticorpos absorvidos do colostro entre animais pode ser muito grande, devido a vários fatores inerentes ao próprio colostro, ao bezerro e/ou manejo (Edwards et al., 1982; Donovan et al., 1986; Robison et al., 1988).

No periodo de 2 a 25 dias, as concentrações de lg não diferiram nos tratamentos T5 e T6 mas, no periodo seguinte, 25 a 50 dias, os animais suplementados do grupo baixo apresentaram concentrações de lg superiores às dos animais controle. Essa condição pode estar relacionada a um efeito positivo da suplementação de vitamina $E$ e selênio sobre a concentração de lg, quando os animais apresentam uma situação inicial baixa. Considerando os tratamentos do grupo alto, verifica-se ausência de diferença, provavelmente como consequência do bom estado imunológico do recém-nascido, que toma a influência de vitamina $E$ e Se menos efetiva ou detectável. Droke \& Loerch (1990), também, verificaram que 
vitamina $E$ e selênio só influenciaram a concentração de lgG quando administrados em conjunto, sugerindo um sinergismo na atuação destes nutrientes.

$\mathrm{Na}$ literatura há relatos de aumento do nivel de anticorpos séricos e maior resposta da proliferação de linfócitos após a suplementação de bezerros com vitamina E e selênio (Reddy et al., 1986; Reffett et al., 1988; Droke \& Loerch, 1989). Por outro lado, Cipriano et al., (1982) e Nemec et al., (1990) não verificaram resposta positiva quando utilizaram estes nutrientes.

Quanto aos animais do grupo alto, a elevada concentração de imunoglobulinas passivas maternas pode ter exercido um efeito inibitório sobre o desenvolvimento do sistema imunológico, como já proposto por outros autores (Logan et al., 1974; Ribeiro et al., 1983; Machado Neto \& Packer, 1986), e, nesse caso, não houve efeito de vitamina $E$ e selênio suplementares.

Como na variável PT, a concentração de Ig decresceu no primeiro mês de vida, resultado do catabolismo dessas proteinas adquiridas do colostro. Foram calculados os valores mínimos da concentração de $\lg$ e as datas de ocorrência desses valores. As concentrações minimas médias foram 1,70 $\pm 0,43 \mathrm{~g} / 100 \mathrm{ml}$ para $\mathrm{T} 1 ; 1,89 \pm 0,38 \mathrm{~g} / 100 \mathrm{ml}$ para T2; $1,51 \pm 0,33 \mathrm{~g} / 100 \mathrm{ml}$ para T3; 1,80 $\pm 0,58 \mathrm{~g} / 100 \mathrm{ml}$ para $\mathrm{T} 4 ; 1,23 \pm 0,53 \mathrm{~g} / 100 \mathrm{ml}$ para T5 e 1,05 $\pm 0,35 \mathrm{~g} / 100 \mathrm{ml}$ para T6. Dentro dos grupos, os tratamentos não diferiram, mas houve diferença entre os grupos com alta $e$ baixa imunidades passiva inicial $(p<0,0021)$. As médias calculadas dos grupos foram: $1,728 \mathrm{~g} / 100 \mathrm{ml}$ para o grupo alto e $1,1425 \mathrm{~g} / 100 \mathrm{ml}$ para o grupo baixo. Esse resultado também foi observado por Baracat (1993), que relatou concentrações minimas de 2,253 e 1,52 g/100ml para os grupo alto e baixo, respectivamente. As datas de ocorrência desses valores foram 42,125 $\pm 19,79$ dias para T1; 40,625 \pm 14,50 dias para $\mathrm{T} 2 ; 23,00 \pm 11,93$ dias para $\mathrm{T} 3 ; 32,50 \pm 8,86$ dias para $\mathrm{T} 4 ; 25,00 \pm$ 10,80 dias para T5 e 35,00 $\pm 10,80$ dias para T6. Esses valores não diferiram entre os grupos alto e baixo e, ainda, dentro do grupo baixo, mas houve uma tendência $(p<0,0927)$ dos tratamentos diferirem dentro do grupo alto.

Como ocorreu nos trabalhos de Ribeiro et al. (1983) e Machado Neto \& Packer (1986), após o ponto de concentração mínima verificou-se um aumento na concentração de Ig sérica. Assim, a flutuação de lg sérica é resultado da interação do catabolismo dos anticorpos adquiridos passivamente, da transferência dos anticorpos sistêmicos para outros 'pools' metabólicos e da produção endógena, a qual se acentua a partir do $20^{\circ}$ ao $30^{\circ}$ dias de idade (Bush et al., 1971; Husband et al., 1972; Machado Neto \& Packer, 1986). 


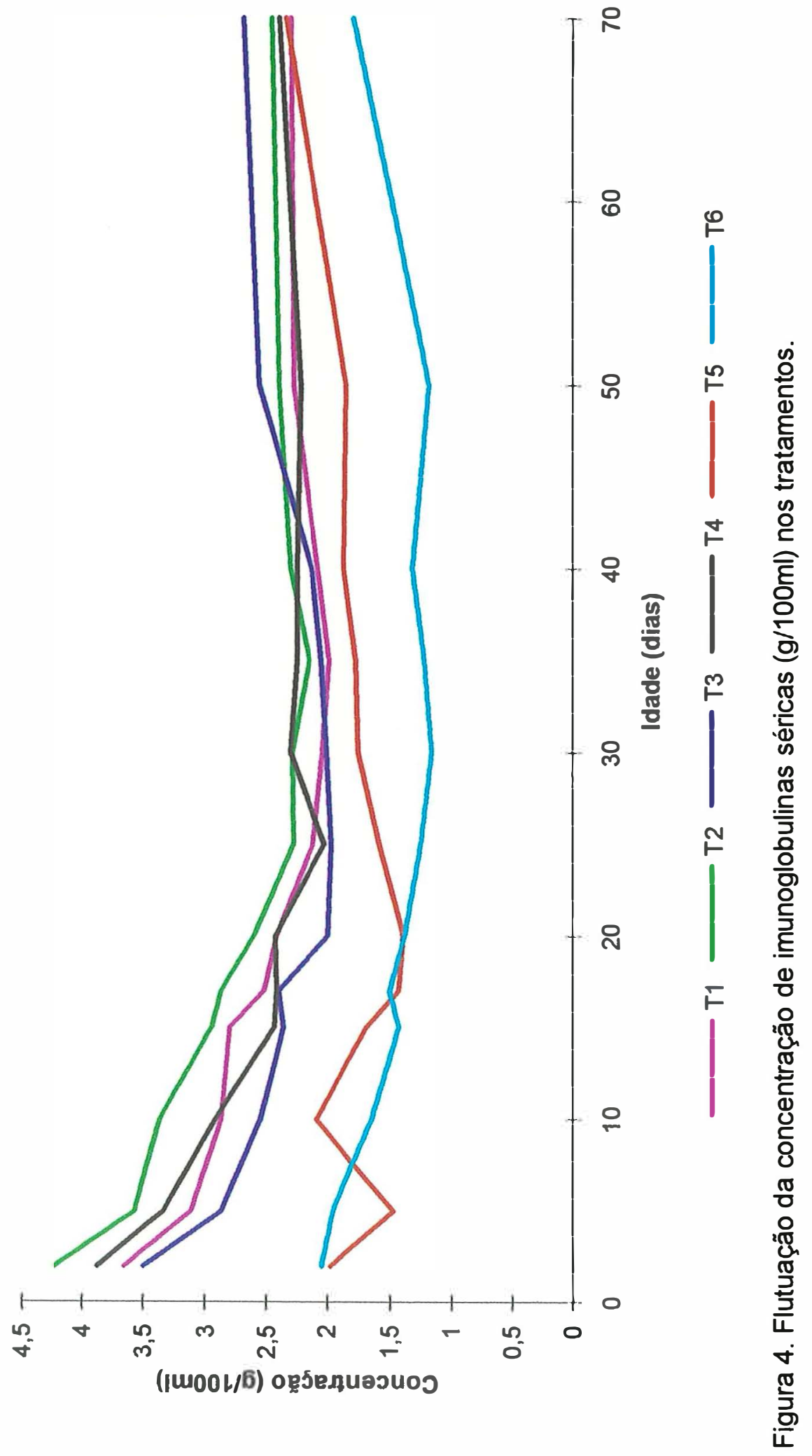




\subsection{Diarréia}

Os resultados relativos às notas médias diárias de cor e consistência das fezes dos animais estão apresentados nas Tabelas 5 e 6 . Os dados originais são apresentados nas tabelas 21 a 32 do Apêndice.

Para a análise da variável cor de fezes, de acordo com o exposto na metodologia, notas acima de 2,0 foram consideradas como uma condição de diarréia. Através do teste $\chi^{2}$ testou-se a hipótese $h_{0}$ de que não havia associação entre tratamentos e frequência das notas de cor fecal. Essa hipótese foi rejeitada para a variável cor, observando-se que houve diferença significativa entre tratamentos $(p<0,0001)$. Dividiu-se a seguir as tabelas contingência para se comparar os grupos alto e baixo e, também, os tratamentos dentro de cada grupo. Comparando-se a frequência de fezes normais ou diarréicas (Figura 5), verificou-se que houve uma tendência de os grupos diferirem $(p<0,093)$, com maior frequência de diarréia nos animais com baixa imunidade passiva inicial $(36,09 \%$ das notas de cor) que nos animais do grupo alto $(30,35 \%)$.

Dentro do grupo alto os tratamentos, também, diferiram ( $p<0,0001)$. T4 apresentou maior frequência de fezes diarréicas $(40,69 \%$ das notas), enquanto a menor frequência foi verificada no T2 (22,94\% das notas). Constatou-se, ainda, que a frequência das notas de cor fecal não estava associada aos tratamentos 5 e 6 , na análise que abrange todo o periodo experimental ( 2 a 30 dias de idade).

Também, dividiu-se o periodo experimental total em três subperiodos: 2 a 10 (Figura 6), 11 a 20 (Figura 7) e 21 a 30 (Figura 8) dias de idade e procedeu-se a análise de $\chi^{2}$. No subperiodo de 2 a 10 dias para a variável cor, os tratamentos não estavam associados à frequência de notas normais ou diarréicas. Já no subperíodo de 11 a 20 dias, rejeitou-se $h_{0}$, ocorrendo diferenças entre tratamentos $(p<0,004)$. Dividindo-se as tabelas de contingência, observou-se que grupo baixo apresentou maior frequência de fezes diarréicas $(52,56 \%$ das notas) que o grupo alto $(37,81 \%)$. Entre os tratamentos do grupo alto, a frequência das notas não diferiu, mas dentro do grupo baixo, os animais suplementados apresentaram menor incidência $(p<0,006)$ de diarréia $(37,50 \%)$ que os animais controle $(68,42 \%)$. A alto incidência de diarréia nos animais do T6 fez com que os grupos diferissem, já que a a frequência de fezes diarréicas do T5 é semelhante à observada nos tratamentos do grupo alto. No terceiro subperiodo estudado, 21 a 30 dias, também foram verificadas diferenças 
Tabela 5. Notas médias diárias de cor fecal durante 30 dias nos tratamentos.

\begin{tabular}{ccccccc}
\hline $\begin{array}{c}\text { Tdade } \\
\text { (dias) }\end{array}$ & Média DP & Média DP & Média DP & Média DP & Média DP & Média DP \\
\hline 2 & $0,69 \pm 0,27$ & $0,50 \pm 0,00$ & $0,44 \pm 0,06$ & $0,50 \pm 0,00$ & $0,50 \pm 0,00$ & $0,38 \pm 0,12$ \\
3 & $0,62 \pm 0,20$ & $0,69 \pm 0,19$ & $0,38 \pm 0,08$ & $0,56 \pm 0,22$ & $0,38 \pm 0,12$ & $0,88 \pm 0,38$ \\
4 & $0,56 \pm 0,22$ & $0,50 \pm 0,23$ & $0,88 \pm 0,39$ & $0,88 \pm 024$ & $0,62 \pm 0,47$ & $0,25 \pm 0,14$ \\
5 & $0,44 \pm 0,24$ & $0,88 \pm 0,34$ & $0,56 \pm 0,27$ & $0,81 \pm 0,40$ & $0,62 \pm 0,47$ & $0,50 \pm 0,50$ \\
6 & $0,75 \pm 0,34$ & $0,69 \pm 0,30$ & $0,88 \pm 0,34$ & $0,29 \pm 0,29$ & $0,12 \pm 0,12$ & $0,00 \pm 0,00$ \\
7 & $0,81 \pm 0,39$ & $0,25 \pm 0,25$ & $0,94 \pm 0,33$ & $1,06 \pm 0,40$ & $0,50 \pm 0,50$ & $0,62 \pm 0,47$ \\
8 & $0,69 \pm 0,35$ & $0,50 \pm 0,33$ & $0,31 \pm 0,31$ & $0,94 \pm 0,37$ & $1,00 \pm 0,58$ & $1,38 \pm 0,80$ \\
9 & $0,94 \pm 0,37$ & $0,75 \pm 0,37$ & $0,31 \pm 0,31$ & $1,31 \pm 0,40$ & $0,00 \pm 0,00$ & $1,50 \pm 0,54$ \\
10 & $0,75 \pm 0,37$ & $1,19 \pm 0,46$ & $0,81 \pm 0,40$ & $1,06 \pm 0,40$ & $1,00 \pm 0,58$ & $1,88 \pm 0,47$ \\
11 & $1,12 \pm 0,39$ & $1,00 \pm 0,49$ & $1,31 \pm 0,39$ & $1,06 \pm 0,36$ & $0,62 \pm 0,47$ & $2,12 \pm 0,12$ \\
12 & $1,00 \pm 0,39$ & $0,50 \pm 0,33$ & $1,38 \pm 0,41$ & $1,12 \pm 0,35$ & $1,50 \pm 0,50$ & $2,25 \pm 0,14$ \\
13 & $1,44 \pm 0,44$ & $0,69 \pm 0,34$ & $1,12 \pm 0,43$ & $1,00 \pm 0,38$ & $0,50 \pm 0,50$ & $2,00 \pm 0,00$ \\
14 & $1,25 \pm 0,38$ & $1,12 \pm 0,44$ & $1,00 \pm 0,39$ & $0,75 \pm 0,37$ & $1,25 \pm 0,75$ & $1,62 \pm 0,55$ \\
15 & $0,94 \pm 0,36$ & $0,38 \pm 0,38$ & $1,00 \pm 0,39$ & $1,25 \pm 0,37$ & $1,00 \pm 0,58$ & $0,67 \pm 0,67$ \\
16 & $1,44 \pm 0,32$ & $0,50 \pm 0,33$ & $0,50 \pm 0,33$ & $0,81 \pm 0,35$ & $0,62 \pm 0,62$ & $0,50 \pm 0,50$ \\
17 & $0,69 \pm 0,41$ & $0,75 \pm 0,37$ & $1,25 \pm 0,37$ & $0,75 \pm 0,37$ & $0,00 \pm 0,00$ & $1,00 \pm 0,58$ \\
18 & $0,81 \pm 0,40$ & $0,25 \pm 0,25$ & $1,06 \pm 0,32$ & $0,06 \pm 0,06$ & $0,50 \pm 0,50$ & $2,12 \pm 0,12$ \\
19 & $0,56 \pm 0,37$ & $0,50 \pm 0,33$ & $0,62 \pm 0,32$ & $1,00 \pm 0,39$ & $0,50 \pm 0,50$ & $1,62 \pm 0,55$ \\
20 & $0,31 \pm 0,25$ & $1,19 \pm 0,35$ & $0,50 \pm 0,33$ & $0,75 \pm 0,37$ & $1,00 \pm 0,58$ & $0,88 \pm 0,51$ \\
21 & $0,25 \pm 0,25$ & $1,00 \pm 0,38$ & $0,50 \pm 0,33$ & $0,75 \pm 0,37$ & $1,50 \pm 0,50$ & $0,88 \pm 0,51$ \\
22 & $0,50 \pm 0,33$ & $0,50 \pm 0,33$ & $0,69 \pm 0,34$ & $1,00 \pm 0,38$ & $0,88 \pm 0,51$ & $0,88 \pm 0,51$ \\
23 & $0,44 \pm 0,29$ & $0,25 \pm 0,25$ & $0,50 \pm 0,33$ & $1,00 \pm 0,38$ & $0,50 \pm 0,50$ & $0,50 \pm 0,50$ \\
24 & $1,12 \pm 0,44$ & $0,25 \pm 0,25$ & $0,25 \pm 0,25$ & $1,25 \pm 0,37$ & $1,00 \pm 0,58$ & $0,50 \pm 0,50$ \\
25 & $0,81 \pm 0,40$ & $0,00 \pm 0,00$ & $0,25 \pm 0,25$ & $1,50 \pm 0,34$ & $0,00 \pm 0,00$ & $0,50 \pm 0,50$ \\
26 & $1,00 \pm 0,38$ & $0,50 \pm 0,33$ & $0,69 \pm 0,34$ & $1,19 \pm 0,35$ & $0,50 \pm 0,50$ & $0,50 \pm 0,50$ \\
27 & $0,56 \pm 0,37$ & $0,00 \pm 0,00$ & $0,50 \pm 0,33$ & $1,25 \pm 0,37$ & $1,00 \pm 0,58$ & $0,50 \pm 0,50$ \\
28 & $0,60 \pm 0,34$ & $0,44 \pm 0,29$ & $0,62 \pm 0,32$ & $1,25 \pm 0,37$ & $1,00 \pm 0,58$ & $0,50 \pm 0,50$ \\
29 & $0,44 \pm 0,29$ & $0,25 \pm 0,25$ & $0,50 \pm 0,33$ & $0,25 \pm 0,25$ & $0,50 \pm 0,50$ & $1,00 \pm 0,58$ \\
30 & $0,25 \pm 0,25$ & $0,00 \pm 0,00$ & $0,25 \pm 0,25$ & $1,00 \pm 0,38$ & $1,00 \pm 0,58$ & $0,00 \pm 0,00$ \\
\hline
\end{tabular}

T1: Vitamina E + Selênio - nível alto de lg

T2: Controle - nivel alto de ig

T3: Selênio - nivel alto de lg

T4: Vitamina $E$ - nivel alto de lg

T5: Vitamina E + Selênio - nível baixo de lg

T6: Controle - nível baixo de lg

DP: Desvio Padrão 
Tabela 6. Notas médias diárias de consistência fecal durante 30 dias nos tratamentos.

\begin{tabular}{ccccccc}
\hline $\begin{array}{c}\text { Idade } \\
\text { ddias) }\end{array}$ & Média DP & Média DP & Média DP & Média DP & Média DP & Média DP \\
\hline 2 & $0,69 \pm 0,35$ & $0,31 \pm 0,13$ & $0,44 \pm 0,20$ & $0,38 \pm 0,18$ & $0,62 \pm 0,24$ & $0,12 \pm 0,12$ \\
3 & $0,50 \pm 0,22$ & $0,69 \pm 0,19$ & $0,50 \pm 0,23$ & $0,75 \pm 0,46$ & $0,38 \pm 0,24$ & $0,62 \pm 0,24$ \\
4 & $0,56 \pm 0,29$ & $0,56 \pm 0,27$ & $0,56 \pm 0,18$ & $0,50 \pm 0,31$ & $0,38 \pm 0,24$ & $0,62 \pm 0,31$ \\
5 & $0,62 \pm 0,21$ & $0,38 \pm 0,16$ & $0,69 \pm 0,16$ & $1,00 \pm 0,37$ & $0,25 \pm 0,25$ & $0,50 \pm 0,50$ \\
6 & $0,75 \pm 0,40$ & $0,44 \pm 0,15$ & $0,56 \pm 0,20$ & $0,38 \pm 0,16$ & $0,12 \pm 0,12$ & $0,38 \pm 0,24$ \\
7 & $0,62 \pm 0,24$ & $0,75 \pm 0,14$ & $0,38 \pm 0,12$ & $1,12 \pm 0,54$ & $0,50 \pm 0,35$ & $0,38 \pm 0,38$ \\
8 & $0,69 \pm 0,35$ & $0,50 \pm 0,21$ & $0,31 \pm 0,19$ & $0,31 \pm 0,48$ & $0,75 \pm 0,25$ & $2,12 \pm 0,97$ \\
9 & $0,94 \pm 0,32$ & $0,44 \pm 0,26$ & $0,69 \pm 0,38$ & $1,44 \pm 0,26$ & $0,62 \pm 0,24$ & $1,00 \pm 0,20$ \\
10 & $0,50 \pm 0,21$ & $0,94 \pm 0,38$ & $0,94 \pm 0,35$ & $1,19 \pm 0,37$ & $1,38 \pm 0,72$ & $2,00 \pm 0,79$ \\
11 & $0,81 \pm 0,48$ & $1,06 \pm 0,55$ & $1,31 \pm 0,43$ & $1,00 \pm 0,35$ & $1,75 \pm 0,78$ & $2,25 \pm 0,32$ \\
12 & $0,81 \pm 0,45$ & $0,50 \pm 0,25$ & $2,06 \pm 0,48$ & $0,62 \pm 0,18$ & $1,50 \pm 0,46$ & $1,88 \pm 0,75$ \\
13 & $0,94 \pm 0,37$ & $0,31 \pm 0,19$ & $1,44 \pm 0,53$ & $1,50 \pm 0,52$ & $1,38 \pm 0,75$ & $1,50 \pm 0,35$ \\
14 & $1,06 \pm 0,49$ & $1,31 \pm 0,52$ & $0,88 \pm 0,39$ & $0,69 \pm 0,28$ & $0,88 \pm 0,38$ & $2,00 \pm 0,35$ \\
15 & $1,06 \pm 0,33$ & $0,75 \pm 0,50$ & $0,94 \pm 0,35$ & $1,00 \pm 0,51$ & $1,12 \pm 0,55$ & $1,33 \pm 0,88$ \\
16 & $0,75 \pm 0,41$ & $0,50 \pm 0,31$ & $0,56 \pm 0,29$ & $0,62 \pm 0,31$ & $0,25 \pm 0,14$ & $1,00 \pm 0,54$ \\
17 & $0,75 \pm 0,28$ & $0,94 \pm 0,37$ & $0,94 \pm 0,35$ & $0,44 \pm 0,22$ & $0,25 \pm 0,14$ & $0,50 \pm 0,35$ \\
18 & $1,31 \pm 0,52$ & $0,38 \pm 0,20$ & $1,06 \pm 0,44$ & $0,44 \pm 0,28$ & $0,38 \pm 0,24$ & $2,12 \pm 0,77$ \\
19 & $0,81 \pm 0,34$ & $0,38 \pm 0,16$ & $1,25 \pm 0,46$ & $0,12 \pm 0,08$ & $0,25 \pm 0,25$ & $1,50 \pm 0,54$ \\
20 & $0,75 \pm 0,33$ & $0,31 \pm 0,13$ & $0,38 \pm 0,16$ & $0,88 \pm 0,38$ & $0,75 \pm 0,43$ & $0,62 \pm 0,38$ \\
21 & $0,56 \pm 0,37$ & $0,81 \pm 0,53$ & $0,50 \pm 0,31$ & $0,50 \pm 0,19$ & $0,62 \pm 0,38$ & $0,38 \pm 0,24$ \\
22 & $0,75 \pm 0,31$ & $0,56 \pm 0,33$ & $0,62 \pm 0,31$ & $0,75 \pm 0,33$ & $0,25 \pm 0,25$ & $0,62 \pm 0,24$ \\
23 & $0,94 \pm 0,39$ & $0,69 \pm 0,38$ & $0,69 \pm 0,19$ & $0,94 \pm 0,37$ & $0,88 \pm 0,43$ & $0,25 \pm 0,14$ \\
24 & $0,94 \pm 0,48$ & $0,25 \pm 0,19$ & $0,31 \pm 0,16$ & $0,12 \pm 0,51$ & $1,50 \pm 0,61$ & $0,62 \pm 0,38$ \\
25 & $1,00 \pm 0,40$ & $0,31 \pm 0,29$ & $0,31 \pm 0,21$ & $1,75 \pm 0,55$ & $1,00 \pm 0,71$ & $0,75 \pm 0,32$ \\
26 & $1,31 \pm 0,48$ & $0,44 \pm 0,11$ & $0,62 \pm 0,36$ & $1,50 \pm 0,57$ & $1,75 \pm 1,01$ & $1,00 \pm 0,54$ \\
27 & $1,06 \pm 0,32$ & $0,50 \pm 0,28$ & $0,25 \pm 0,16$ & $1,31 \pm 0,27$ & $1,12 \pm 0,12$ & $0,62 \pm 0,31$ \\
28 & $0,75 \pm 0,30$ & $0,38 \pm 0,20$ & $1,31 \pm 0,47$ & $1,38 \pm 0,35$ & $1,12 \pm 0,83$ & $1,62 \pm 0,62$ \\
29 & $0,62 \pm 0,32$ & $0,50 \pm 0,21$ & $0,31 \pm 0,21$ & $1,44 \pm 0,49$ & $1,88 \pm 0,72$ & $1,38 \pm 0,80$ \\
30 & $0,31 \pm 0,25$ & $0,19 \pm 0,13$ & $0,25 \pm 0,16$ & $1,86 \pm 0,39$ & $1,25 \pm 0,43$ & $1,00 \pm 0,68$ \\
\hline
\end{tabular}

T1: Vitamina E + Selênio - nível alto de lg

T2: Controle - nivel alto de lg

T3: Selênio - nivel alto de lg

T4: Vitamina $E$ - nível alto de lg

T5: Vitamina $E$ + Selênio - nível baixo de lg

T6: Controle - nível baixo de lg

DP: Desvio Padrão 


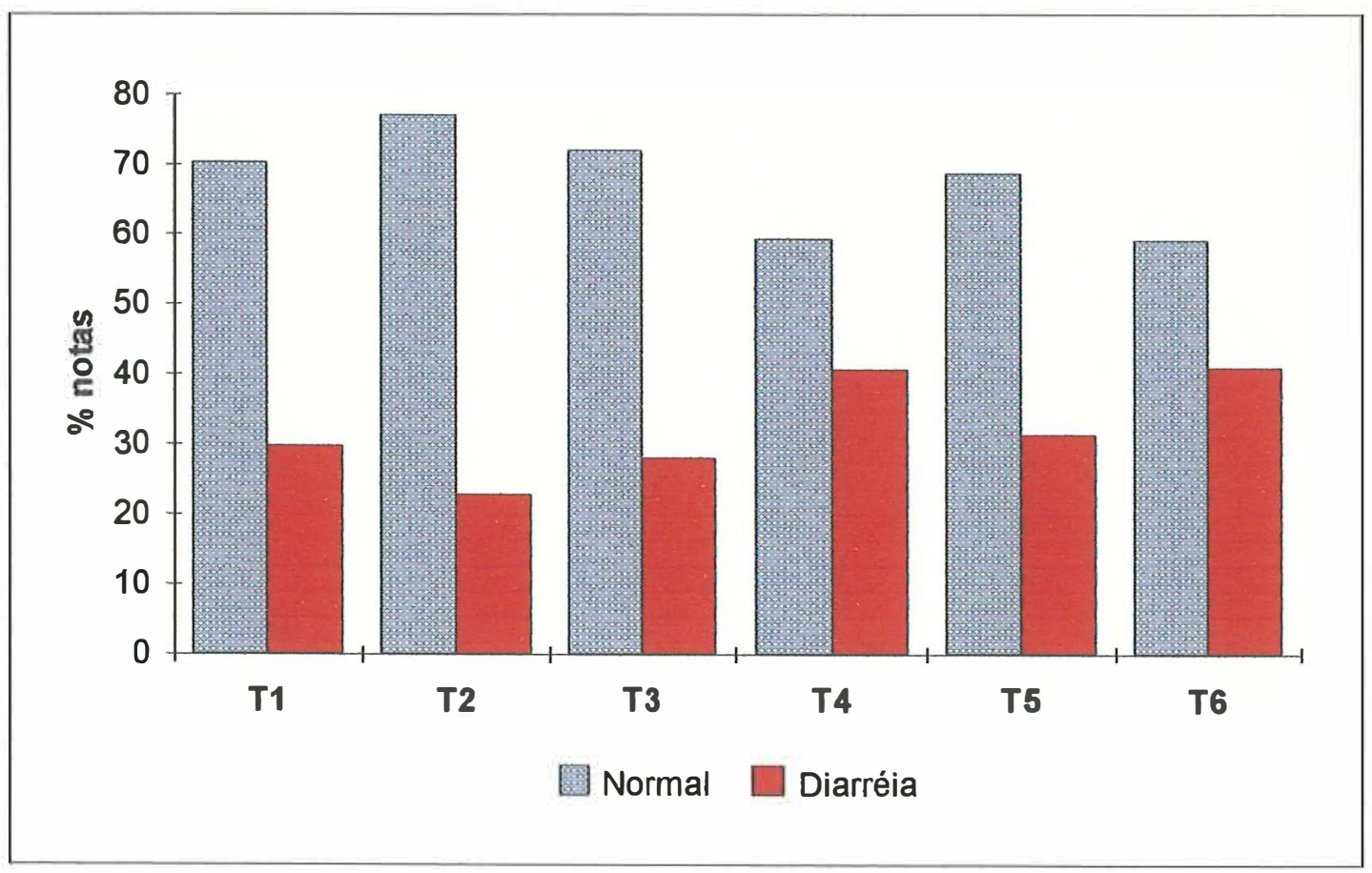

Figura 5. Frequência de notas de cor de fezes no periodo de 2 a 30 dias nos tratamentos.

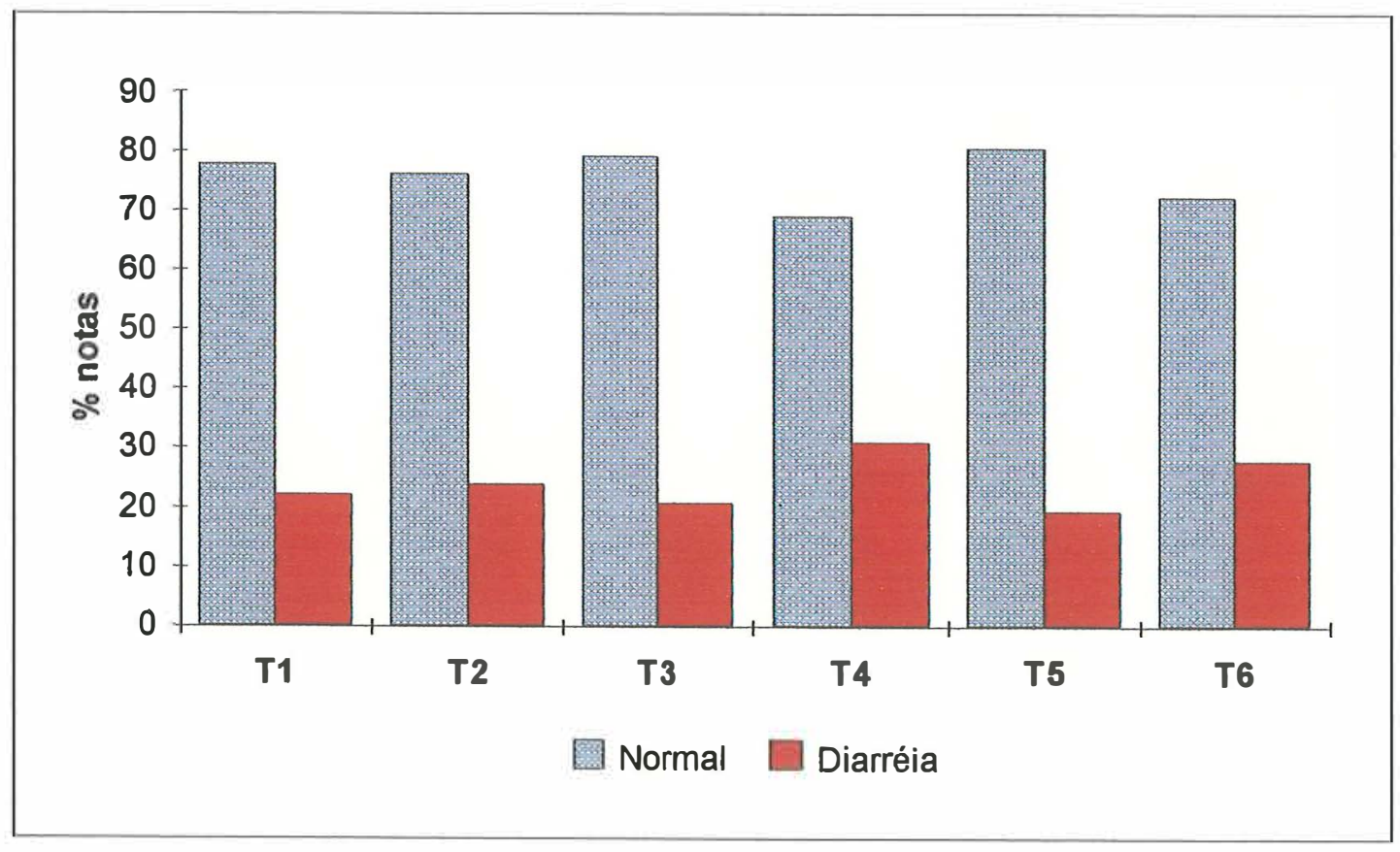

Figura 6. Frequência de notas de cor de fezes no período de 2 a 10 dias nos tratamentos. 


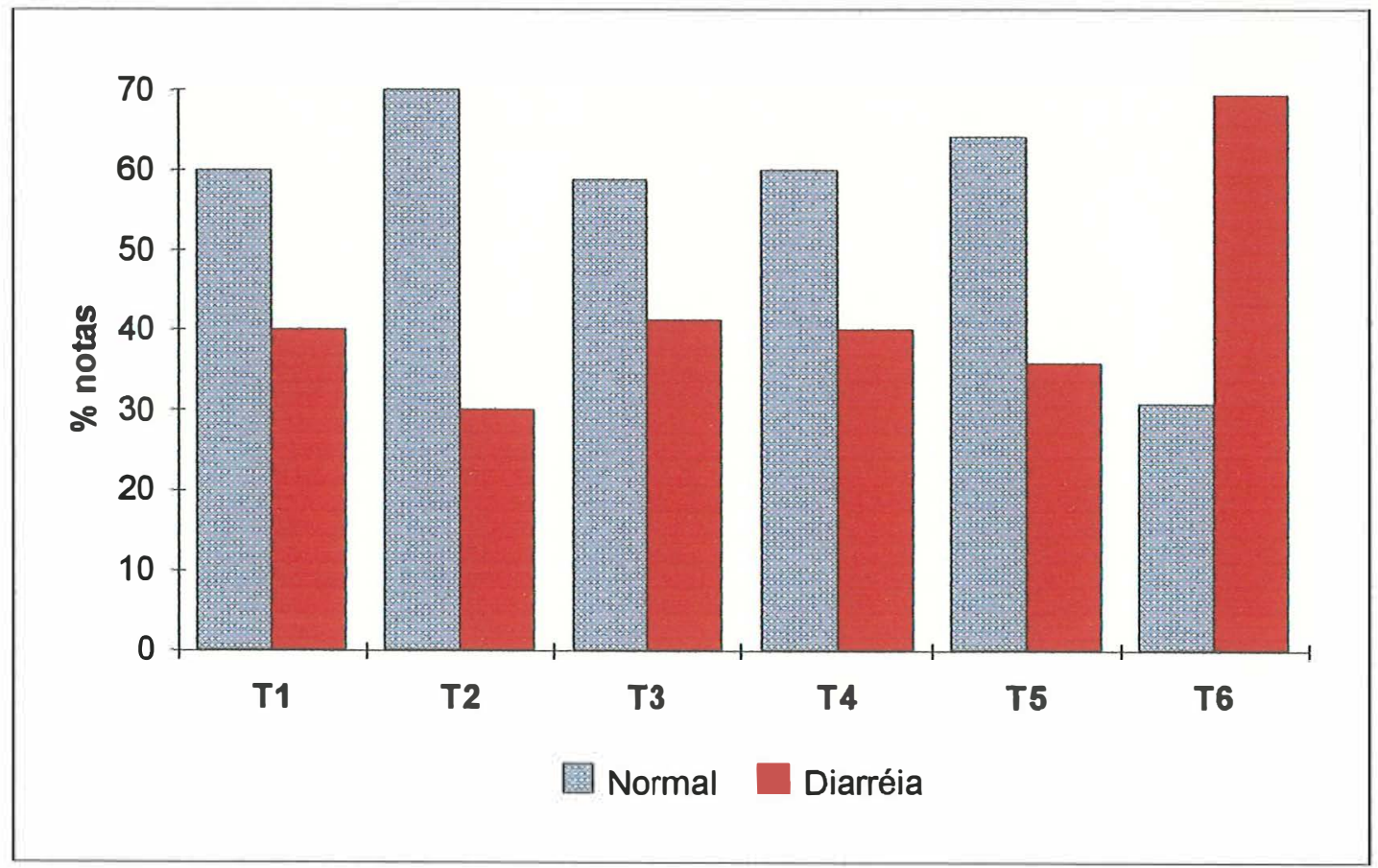

Figura 7. Frequência de notas de cor de fezes no período de 11 a 20 dias nos tratamentos.

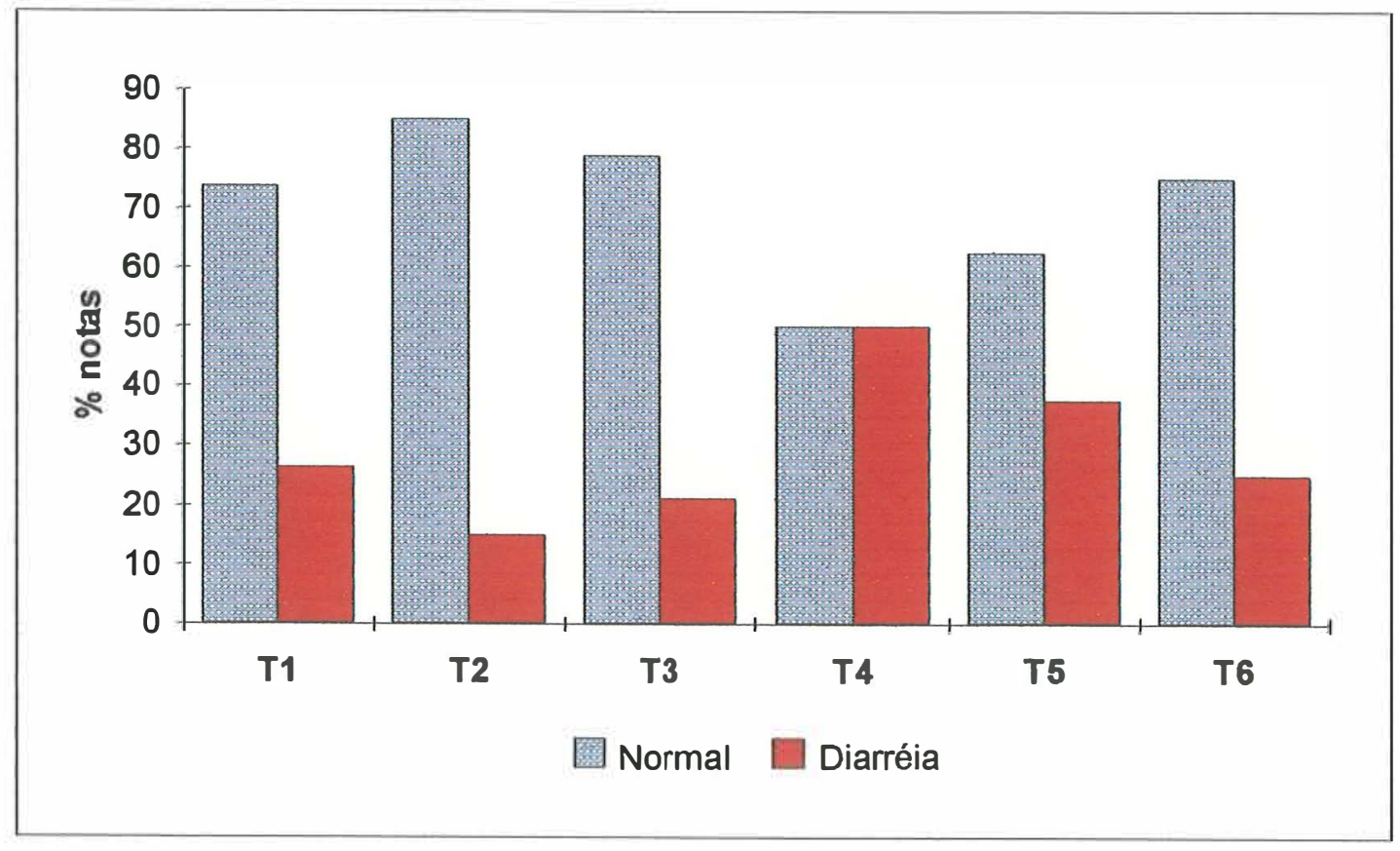

Figura 8. Frequência de notas de cor de fezes no período de 21 a 30 dias nos tratamentos. 
entre tratamentos $(p<0,0001)$. Não houve diferença entre os grupos alto e baixo $(p<0,581)$, bem como entre os tratamentos do grupo baixo $(p<0,228)$. No entanto, dentro do grupo alto, houve diferença $(p<0,0001)$, com o tratamento 4 apresentando $50 \%$ das notas correspondentes a fezes diarréicas.

Foram avaliados, ainda, inicio e duração de diarréia para cor fecal. Não houve efeito de tratamento para o início de diarréia, com os tratamentos apresentando as médias: T1: $10,25 \pm 7,34$ dias; T2: $10,5 \pm 5,73$ dias; T3: $8,75 \pm 5,77$ dias; T4: 5,00 \pm 3,02 dias; T5: 7,75 $\pm 2,87$ dias; T6: $8,00 \pm 3,56$ dias. A grande variação verificada entre animais nas datas de inicio de diarréia pode ter influenciado essa análise, não permitindo que diferenças entre tratamentos fossem detectadas. Para duração de diarréia, considerando-se o periodo total de 2 a 30 dias, não houve efeito de tratamento. Mas, houve uma tendência $(p<0,0774)$ de o T6 diferir do T5 apresentando maior duração de diarréia no segundo subperiodo, com médias de 3,50 $\pm 2,64$ dias para o T5 e 6,75 $\pm 0,96$ dias para o T6.

Para a variável cor, a alta incidência de diarréia no T4, durante o último subperiodo estudado, influenciou o resultado geral do grupo alto. Em parte esse resultado pode ser explicado por um quadro atípico de diarréia severa e prolongada que ocorreu em alguns animais, o que pode ter influenciado os resultados. A alta incidência de diarréia do T6 no segundo subperiodo não modificou o resultado geral do grupo baixo. Os animais desse tratamento apresentaram menor nivel de anticorpos adquiridos passivamente, condição que pode ter prejudicado a proteção contra patógenos intestinais no periodo de 11 a 20 dias. Outros autores, como Penhale et al. (1973), Brignole \& Stott (1980) e Ribeiro et al. (1983), também verificaram maiores problemas de saúde em bezerros que apresentaram baixo nivel de lg no soro. Já nos animais do $T 5$, suplementados com vitamina $E$ e selênio, que também apresentaram baixo nivel inicial de lg, observou-se menor incidência de diarréia, assim como se tornaram, com base na flutuação de Ig sérica, imunocompetentes mais precocemente (Tabela 4).

Para a variável consistência considerou-se notas superiores a 1,5 como uma condição de diarréia. A análise de $\chi^{2}$ para o periodo de 2 a 30 dias de coletas (Figura 9) de amostras fecais demonstrou que $h_{0}$ foi rejeitada $(p<0,01)$. Dividindo-se as tabelas de contingência observou-se que os grupos alto e baixo diferiram $(p<0,008)$, com menor incidência de diarréia nos animais do grupo alto, o qual 
apresentou uma frequência de notas de fezes diarréicas de $22,03 \%$, enquanto no grupo baixo verificou-se essa condição em $30,30 \%$ das notas. Dentro do grupo alto os tratamentos também diferiram, sendo o T4 o que apresentou maior incidência de diarréia $(29,87 \%$ das notas), enquanto no grupo baixo o tratamento suplementado com vitamina $E$ e selênio apresentou menor frequência de notas de fezes diarréicas $(23,28 \%)$ que o tratamento controle $(37,39 \%)$.

Também, para consistência, dividiu-se o periodo total em 3 subperiodos: 2 a 10 (Figura 10), 11 a 20 (Figura 11) e 21 a 30 (Figura 12) dias. $\mathrm{Na}$ análise do primeiro subperiodo verificou-se diferença significativa entre tratamentos $(p<0,018)$. Dividindo-se as tabelas de contingência observou-se que os grupo alto e baixo não diferiram $(p<0,767)$, mas houve diferenças entre os tratamentos do grupo alto $(p<0,036)$, com o T4 apresentando $27,78 \%$ das notas classificadas como diarréicas. Dentro do grupo baixo, o T5 diferiu significativamente do T6 $(p<0,022)$ nesse primeiro subperiodo, apresentando incidência de $5,56 \%$ das notas do tratamento como diarréicas, contra $25 \%$ do T6.

$\mathrm{Na}$ análise do segundo subperiodo observaram-se diferenças entre tratamentos $(p<0,0001)$. Houve diferença entre os grupos alto e baixo $(p<0,002)$ e, dentro dos grupos alto $(p<0,056)$ e baixo $(p<0,001)$, os tratamentos também diferiram. Nesse subperiodo, observou-se maior frequência de diarréia nos animais do grupo baixo $(43,04 \%$ das notas) em relação ao grupo alto $(25,39 \%)$. Novamente, o que determinou a diferença foi a alta incidência de diarréia no T6 (61,54\%), pois o T5 apresentou frequência (25\%) próxima à verificada no grupo alto. No grupo alto, os tratamentos T1 e T3 apresentaram maior incidência de diarréia, com 30 e 33,75\% das notas, respectivamente.

No terceiro subperiodo, 21 a 30 dias, os tratamentos, também, diferiram $(p<0,0001)$. Dividindo-se a tabela de contingência verificou-se que os grupos alto e baixo não diferiram $(p<0,149)$, o mesmo ocorrendo para os tratamentos do grupo baixo, T5 e T6 $(p<0,228)$. Entre os tratamentos do grupo alto foram observadas diferenças significativas ( $p<0,0001$ ), com o T4 apresentando $41,25 \%$ de suas notas como fezes diarréicas. Nesse periodo, a menor incidência foi observada no T3, com apenas $12,5 \%$. 


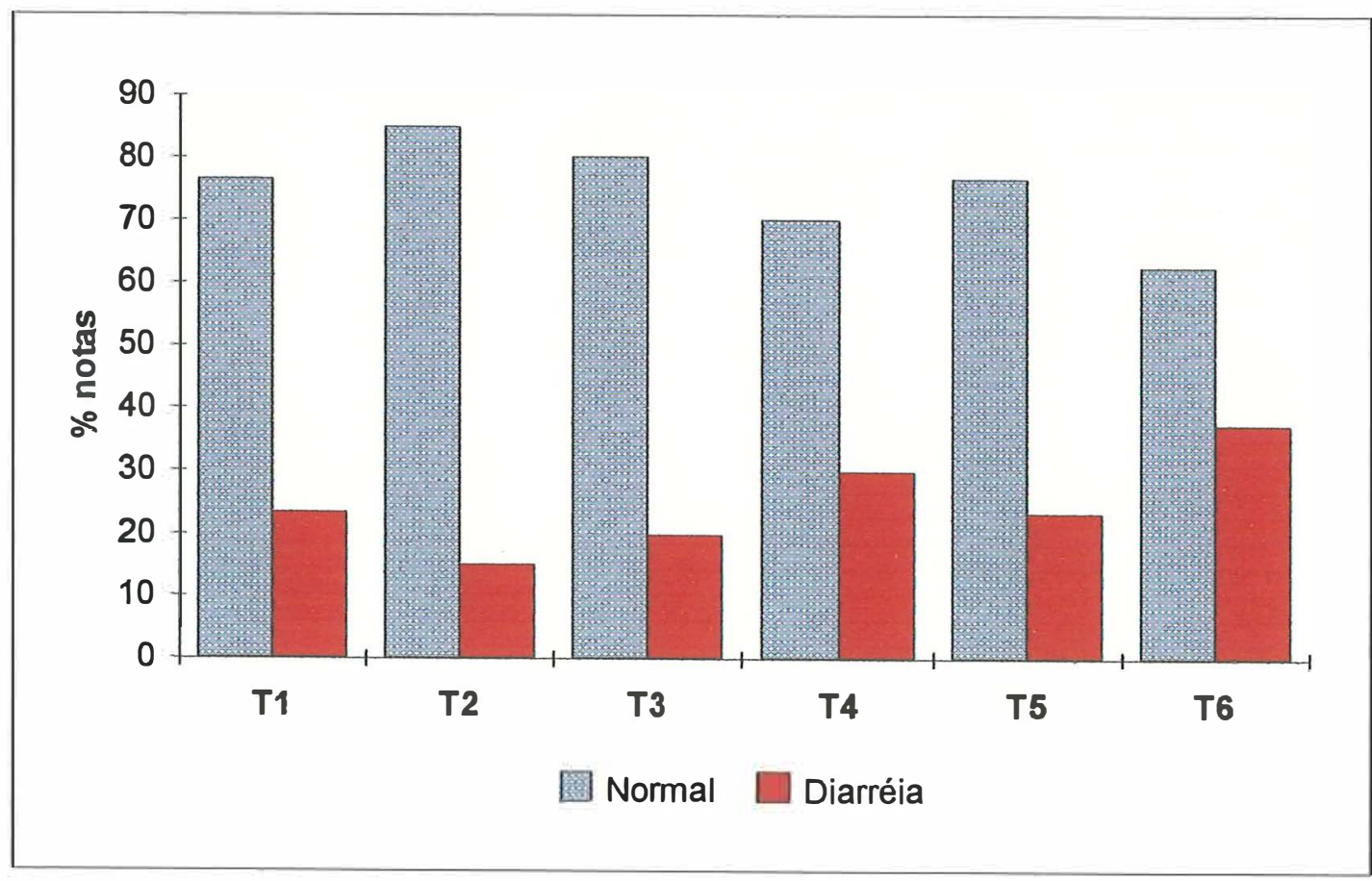

Figura 9. Frequência de notas de consistência de fezes no período de 2 a 30 dias nos tratamentos.

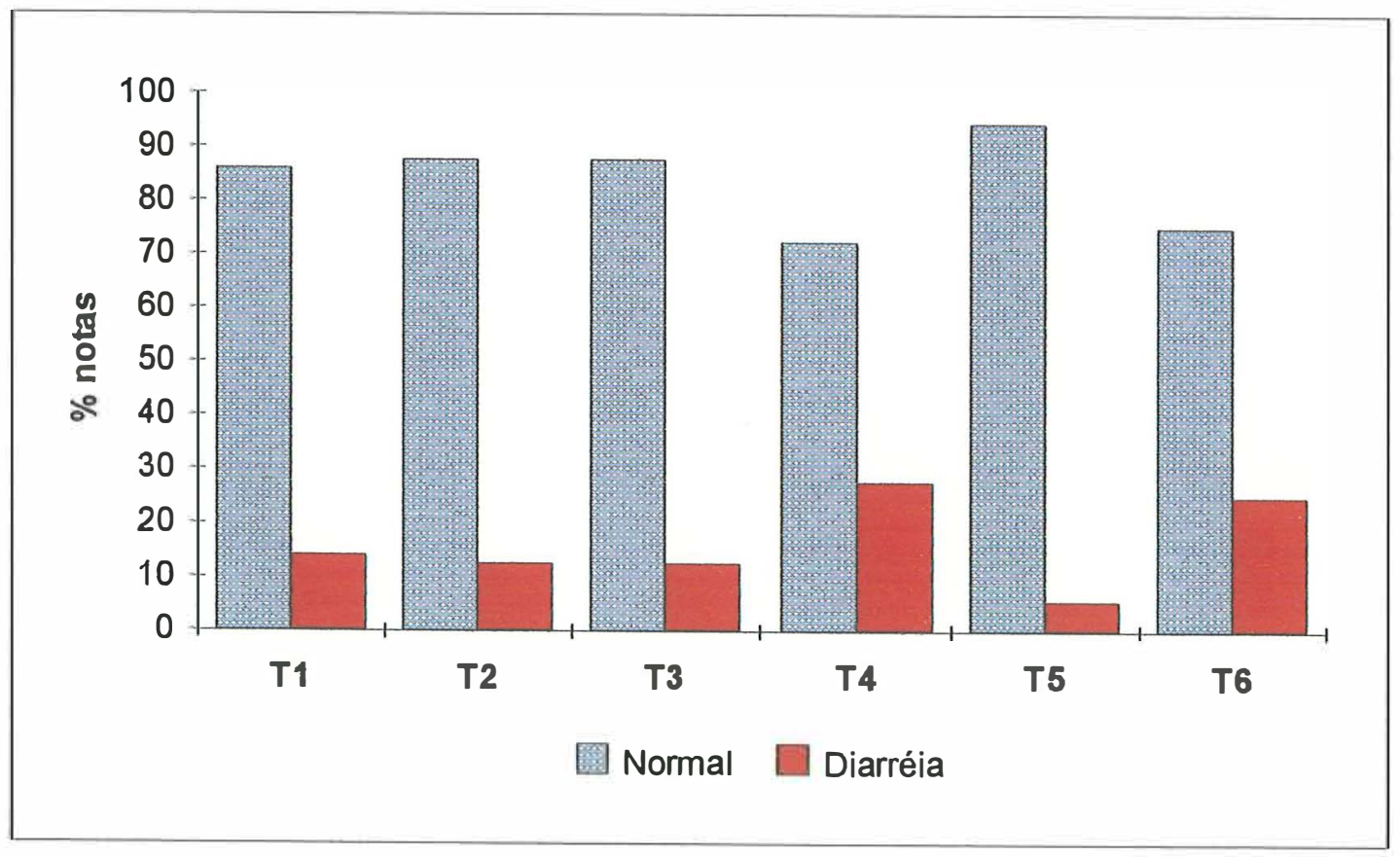

Figura 10. Frequência de notas de consistência de fezes no período de 2 a 10 dias nos tratamentos. 


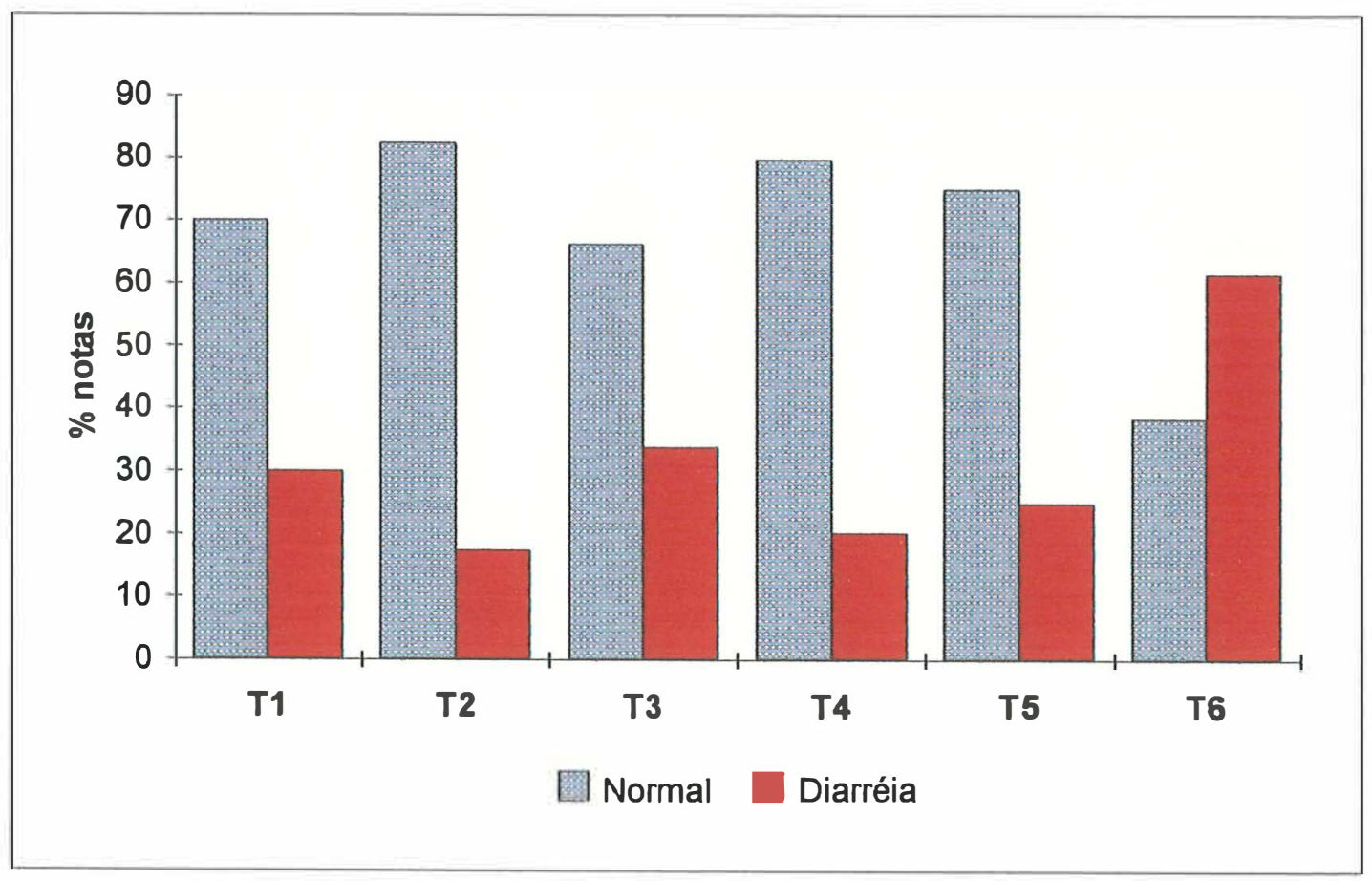

Figura 11. Frequência de notas de consistência de fezes no periodo de 11 a 20 dias nos tratamentos.

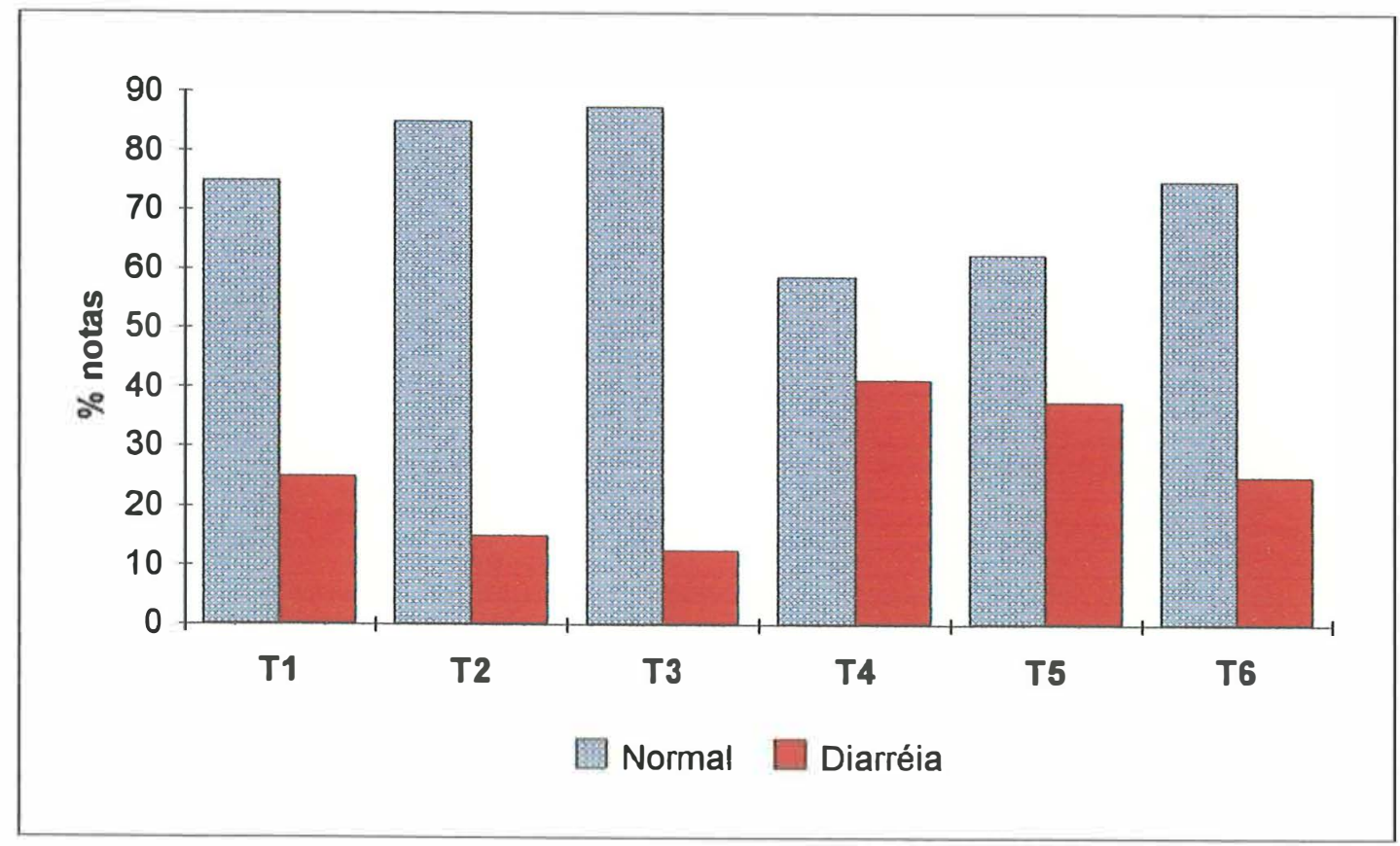

Figura 12. Frequência de notas de consistência de fezes no período de 21 a 30 dias nos tratamentos. 
Não houve efeito de tratamento sobre a variável inicio de diarréia para a variável consistência fecal, com médias de $9,12 \pm 7,51$ dias para $T 1 ; 8,37 \pm 5,95$ dias para $\mathrm{T} 2 ; 10,12 \pm 5,35$ dias para T3; 7,00 \pm 4,89 dias para $T 4 ; 10,00 \pm 2,16$ dias para T5 e 6,75 $\pm 3,09$ dias para T6. Quanto a duração de diarréia, no período total, 2 a 30 dias, os tratamentos não diferiram, mas no segundo subperíodo, T5 apresentou menor período de diarréia que o T6 ( $p<0,0358)$, com médias de 2,50 $\pm 1,00$ e 6,00 \pm 0,81 dias, respectivamente.

A variável consistência fecal mostrou-se mais sensivel, acusando a condição diarréia já no periodo de 2 a 10 dias nos tratamentos T4 e T6. Esse resultado indica o estabelecimento da condição diarréia mais precocemente nesses tratamentos. O T4 permaneceu com alta incidência de diarréia no terceiro subperiodo, fase na qual a incidência de diarréia diminuiu nos demais tratamentos, como já verificado para a variável cor fecal. Essa condição fez com que no resultado geral, no período de 2 a 30 dias, o T4 apresentasse desempenho inferior em relação aos outros tratamentos do grupo alto. O T6 permaneceu com maior frequência de notas de fezes diarréicas até os 20 dias de idade, determinando no resultado geral que os grupos alto e baixo diferissem entre si e, também, dentro do grupo baixo, que houvesse diferenças entre os tratamentos. Nos tratamentos do grupo de baixa imunidade passiva inicial, verifica-se uma plena concordância de comportamento da diarréia e da flutuação de lg. Em T5, a diarréia foi significativamente inferior à verificada em T6, enquanto os niveis de $\mathrm{lg}$ foram superiores a partir dos 25 dias de idade. Por outro lado, essa correspondência não foi verificada nos tratamentos do grupo alto.

No primeiro e terceiro subperíodos a incidência de diarréia foi semelhante entre os grupos alto e baixo, mas no segundo subperiodo, de 11 a 20 dias de idade, mesmo com a maior incidência de diarréia nos tratamentos T1 e T3, o grupo baixo apresentou a condição diarréia com maior frequência.

Foi realizada uma análise de $\chi^{2}$ englobando todos os tratamentos para se testar a hipótese $h_{0}$ de que a incidência de diarréia não diferiu nos 3 subperiodos estudados. Para a variável cor de fezes rejeitou-se $h_{0} \quad(p<0,0001)$, com o segundo subperíodo, 11 a 20 dias, apresentando maior incidência de diarréia $(40,70 \%$ das notas) em relação ao primeiro $(24,30 \%)$ e terceiro $(28,75 \%)$ subperiodos. Quanto à consistência fecal, a frequência de notas superiores à 1,5, também, estava associada 
aos subperiodos ( $p<0,0001)$. A incidência de diarréia foi menor $(5,10 \%$ das notas) de 2 a 10 dias de idade, enquanto os subperíodos de 11 a 20 e 21 a 30 dias apresentaram $28,89 \%$ e $25 \%$ das notas como fezes diarréicas, respectivamente. A maior incidência de diarréia nos bezerros após os 10 dias de idade pode estar relacionada ao agente causal desse distúrbio. De acordo com Saif \& Smith (1985), em animais entre 7 e 21 dias de idade a diarréia está frequentemente associada à infecções viróticas, justamente na fase em que se verifica redução da concentração sérica das Ig protetoras maternas.

\subsection{Desempenho}

Os dados referentes às pesagens dos animais estão apresentadas na Tabela 7, com os pesos médios observados nas idades de 1 a 60 dias separados por tratamentos. Os dados originais são apresentados nas tabelas 33 a 38 do Apêndice.

Peso inicial e o nível inicial de lg foram testados como covariáveis no modelo para análise da variância do peso final. Apenas peso inicial influenciou $(p<0,0001)$ o peso final dos animais, sendo utilizado como covariável para a análise dos dados. O peso final não diferiu entre os grupos alto e baixo e entre os tratamentos do grupo alto. Já no grupo baixo, houve uma tendência $(p<0,0604)$ do T5 ser superior ao T6, com médias ajustadas para peso inicial de 60,65 $\pm 5,94 \mathrm{~kg}$ para 0 T5 e 50,40 $\pm 10,75 \mathrm{~kg}$ para o T6. Verificou-se, também, que os animais do grupo baixo suplementados apresentaram maior ganho de peso total $(p<0,0533)$ que os animais controle. As médias foram $29,55 \pm 6,33 \mathrm{~kg}$ para o T5 e 17,43 $\pm 2,11 \mathrm{~kg}$ para o T6, que estão de acordo com os resultados obtidos por Daniele et al. (1994 b). O menor ganho de peso verificado nos animais do T6 pode ser justificado pela maior ocorrência de diarréia nesse tratamento. Segundo Daniele et al. (1994 b), uma menor severidade de diarréia garantiu um melhor desempenho em animais que receberam colostro por um periodo prolongado. 
Tabela 7. Peso médio $(\mathrm{kg})$ dos animais de cada tratamento, do nascimento aos 70 dias de idade.

\begin{tabular}{ccccccc}
\hline $\begin{array}{c}\text { Idade } \\
\text { (dias) }\end{array}$ & Média \pm DP & Média \pm DP & Média \pm DP & Média \pm DP & Média \pm DP & Média \pm DP \\
\hline 0 & $35,52 \pm 3,16$ & $37,17 \pm 3,60$ & $39,30 \pm 2,21$ & $40,75 \pm 3,37$ & $31,10 \pm 2,22$ & $32,97 \pm 4,99$ \\
5 & $34,43 \pm 3,06$ & $35,52 \pm 2,54$ & $38,21 \pm 2,54$ & $30,20 \pm 2,83$ & $32,40 \pm 1,71$ & $33,45 \pm 3,88$ \\
10 & $30,15 \pm 3,00$ & $39,21 \pm 3,24$ & $39,85 \pm 2,26$ & $30,90 \pm 2,76$ & $32,55 \pm 1,14$ & $33,85 \pm 3,60$ \\
15 & $38,12 \pm 2,56$ & $41,00 \pm 3,40$ & $40,08 \pm 2,76$ & $40,04 \pm 2,98$ & $34,00 \pm 1,10$ & $36,15 \pm 4,21$ \\
20 & $39,40 \pm 2,54$ & $39,85 \pm 3,01$ & $42,09 \pm 2,59$ & $39,66 \pm 3,08$ & $34,80 \pm 1,52$ & $35,55 \pm 4,72$ \\
25 & $40,65 \pm 3,17$ & $41,62 \pm 2,93$ & $42,20 \pm 2,68$ & $42,46 \pm 2,33$ & $36,80 \pm 2,60$ & $30,10 \pm 3,82$ \\
30 & $42,12 \pm 2,90$ & $44,12 \pm 2,53$ & $44,60 \pm 2,57$ & $43,31 \pm 2,64$ & $36,95 \pm 0,83$ & $39,05 \pm 3,86$ \\
35 & $44,02 \pm 3,03$ & $43,30 \pm 2,83$ & $46,80 \pm 2,19$ & $45,11 \pm 2,80$ & $44,45 \pm 1,98$ & $39,35 \pm 4,25$ \\
40 & $46,80 \pm 2,65$ & $45,29 \pm 2,46$ & $48,06 \pm 2,01$ & $46,86 \pm 2,60$ & $43,60 \pm 1,65$ & $41,95 \pm 4,92$ \\
45 & $49,00 \pm 3,82$ & $50,81 \pm 2,28$ & $50,06 \pm 2,28$ & $40,40 \pm 3,18$ & $46,55 \pm 1,79$ & $44,70 \pm 4,76$ \\
50 & $50,50 \pm 3,33$ & $51,30 \pm 2,69$ & $51,68 \pm 2,01$ & $52,09 \pm 2,80$ & $48,30 \pm 1,18$ & $45,90 \pm 3,40$ \\
70 & $58,58 \pm 4,26$ & $65,84 \pm 4,55$ & $63,18 \pm 3,36$ & $64,00 \pm 4,48$ & $60,65 \pm 2,97$ & $52,45 \pm 4,84$ \\
\hline
\end{tabular}

T1: Vitamina E + Selênio - nível alto de lg

T2: Controle - nivel alto de Ig

T3: Selênio - nível alto de Ig

T4: Vitamina $E$ - nível alto de lg

T5: Vitamina $E+$ Selênio - nível baixo de lg

T6: Controle - nível baixo de lg

DP: Desvio Padrão

\subsection{Resumo dos Resultados}

1. A concentração de proteína sérica total diferiu entre os grupos de alta e baixa imunidade passiva inicial, no periodo de 2 a 50 dias de idade. Entre os tratamentos do grupo alto não se verificou diferenças, enquanto, no grupo baixo, apenas aos 50 dias, o tratamento suplementado com vitamina $E$ e selênio apresentou concentração média superior à do tratamento controle.

2. A concentração de imunoglobulinas séricas foi siginificativamente superior nos animais do grupo alto, em relação ao baixo, no período de 2 a 50 dias. No grupo alto 
as concentrações médias não diferiram entre os 4 tratamento nas diferentes idades do periodo experimental. Já no grupo baixo, no periodo de 30 a 50 dias, os animais suplementados com vitamina $E$ e selênio apresentaram maior concentração de imunoglobulinas séricas.

3. Em relação a variável cor de fezes, no periodo de 11 a 20 dias de idade, os animais do T6 apresentaram maior frequência de fezes diarréicas que os animais do T5.

4. Para a variável consistência fecal o tratamento controle do grupo com baixa imunidade passiva inicial mostrou maior frequência de diarréia que os animais suplementados deste grupo, no período de 2 a 20 dias.

5. O período de maior incidência de diarréia nos bezerros avaliados foi de 11 a 20 dias de idade.

\subsection{Considerações finais}

A separação dos animais em dois grupos, de acordo com o nivel de imunoglobulinas séricas iniciais, promoveu maior uniformidade nos tratamentos permitindo uma melhor identificação dos efeitos dos tratamentos.

É importante ressaltar que os dados de variáveis fecais receberam um tratamento diferente, sob o ponto de vista estatístico, comparado ao que já foi feito em outros trabalhos deste grupo de pesquisa. A comparação da frequência das notas, agrupadas nas categorias fezes normais ou diarréicas, revela-se uma forma mais eficiente e clara de se expor os resultados. 


\section{CONCLUSŌES}

No manejo de bezerros recém-nascidos de raças leiteiras, a suplementação de vitamina $E$ e selênio tem potencial de se constituir em uma prática rotineira, pois mostrou-se efetiva no estabelecimento mais precoce da imunidade ativa em bezerros com baixa concentração de anticorpos maternos, bem como por proporcionar melhor higidez no periodo de maior incidência de diarréia.

As variáveis cor e consistência fecais, de acordo com a metodologia utilizada no presente trabalho, mostraram-se adequados para a avaliação da condição diarréica. 


\section{LITERATURA CITADA}

ABDELRAHMAN, M.M.; KINCAID, R.L. Effect of selenium supplementation of cows on maternal transfer of selenium to fetal and newborn calves. Journal of Dairy Science, v.78, n.3, p.625-630, mar. 1995.

ARNAUD, J.; FORTIS, I.; BLACHIER, S.; KIA, D.; FAVIER, A. Simultaneous determintaion of retinol, $\alpha$-tocopherol and $\beta$-carotene in serum by isocratic highperformance liquid chromatography. Journal of Chromatogaphy, v.572, p.103$116,1991$.

AVISSAR, N.; WHITIN, J.C.; ALLEN, P.Z.; WAGNER, D.D.; LIEGEV, P.; COHEN, H.J. Plasma selenium-dependent glutathione peroxidase. Journal of Biological Chemistry, v.264, n.27, p.15850-15855, set. 1989.

BARACAT, R.S. Efeito do fornecimento prolongado de colostro sobre a proteção e desempenho de bezerros recém-nascidos com diferentes nívesi de imunidade sérica passiva. Piracicaba, 1993. 160p. Dissertação (M.S.) - Escola Superior de Agricultura "Luiz de Queiroz", Universidade de São Paulo.

BEAUCHAMP, C.; FRIDOVICH, I. A mechanism for the production of ethylene from methional. The generation of the hydroxyl radical by xanthine oxidase. Journal of Biological Chemistry, v.245, n.18, p.4641-4646, set. 1970.

BECKETT, G.J.; BEDDOWS, S.E.; MORRICE, P.C.; NICOL, F.; ARTHUR, J.R. Inhibition of hepatic deiodination of thyroxine is caused by selenium deficiency in rats. Biochemistry Journal, v.248, n.2, p.443-447, dez. 1987.

BERRY, M.J.; BANU, L.; LARSEN, P.R. Type I iodothyronine deiodinaseis a selenocysteine-containing enzyme. Nature, v.349, n.6308, p.438-440, jan. 1991. 
BESSER, T.E.; GAY, C.C.; PRITCHETT, L. Comparison of three methods of feeding colostrum to dairy calves. Journal of the American Veterinary Medical Association, v.198, n.3, p.419-422, fev. 1991.

BESSER, T.E.; OSBORN, D. Effect of bovine serum albumin on passive transfer of immunoglobulin $G_{1}$ to newbom calves. Veterinary Immunology and Immunopathology, v.37, p.321-327, 1993.

BESSER, T.E.; SZENCI, O.; GAY, C.C. Decreased colostral immunoglobulin absorption in calves with postnatal respiratory acidosis. Journal of the American Veterinary Medical Association, v.196, n.8, p.1229-1234, abr. 1990.

BOWRY, V.W.; INGOLD, K.U.; STOCKER, R. Vitamin E in human low-density lipoprotein. When and how this antioxidant becomes a pro-oxidant. Biochemistry Journal, v.288, n.2, p.341-344, 1992.

BRAMBELL, J.W.R. The passive immunity of the young mammal. Biological Reviews, v.33, n.4, p.488-531, nov. 1958.

BREWER, J.M.; ASHWORTH, R.B. Disc electrophoresis. Journal of Chemical Education, v.46, p.41-45, 1969.

BRIGNOLE, T.J.; STOTT, G.H. Effect of suckling followed by bottle feeding colostrum on immunoglobulins absorption and calf survival. Journal of Dairy Science, v.63, n.3, p.451-456, mar. 1980.

BURTON, G.W. Vitamin E: molecular and biological function. Proceedings of the Nutrition Society, v.53, n.2, p.251-262, 1994.

BURTON, G.W. Vitamin E: molecular and biological function. Proceedings of Nutrition Society, v.53, n.2, p.251-262, jul. 1987.

BURTON, G.W.; JOYCE, A.; INGOLD, K.U. Is vitamin E the only lipid-soluble, chainbreaking antioxidant in human blood plasma and erythocyte membranes ? Archives of Biochemistry and Biophysics, v.221, n.1, p.281-290, fev. 1983.

BUSH, L.J.; AGUILERA, M.A.; ADAMS, G.D. Absorption of colostral immunoglobulins by newborn dairy calves. Journal of Dairy Science, v.54, n.10, p.1547-1549, out. 1971.

CALDWELL, K.A.; TAPPEL, A.L. Reactions of seleno- and sulfoamino acids with hydroperoxides. Biochemistry, v.3, n.11, p.1643-1647, nov. 1964. 
CALDWELL, K.A.; TAPPEL. A.L. Acceleration of sulfhydryl oxidations by selenocystine. Archives of Biochemistry and Biophysics, v.112, n.1, p.196-200, out. 1965.

CAMMACK, P.M.; ZWAHLEN, B.A.; CHRISTENSEN, M.J. Selenium deficiency alters thyroid hormone metabolism in guinea pigs. Journal of Nutrition, v.125, n.2, p.302-308, fev. 1995.

CAMPBELL, D.T.; MAAS, J.; WEBER, D.W.; HEDSTROM, O.R.; NORMAN, B.B. Safety and efficacy of two sustained-release intrareticular selenium suplements and the associated placental and colostral transfer of selenium in beef cattle. American Journal of Veterinary Research, v.51, n.5, p.813-817, mai. 1990.

CHAUDIERE, J.; WILHELMSEN, E.C.; TAPPEL, A.L. Mechanism of seleniumglutathione peroxidase and its inhibition by mercaptocarboxylic acids and other mercatans. Journal of Biological Chemistry, v.259, n.2, p. 1043-1050, jan. 1984.

CIPRIANO, J.E.; MORRIL, J.L.; ANDERSON, N.V. Effect of dietary vitamin $E$ on immune responses of calves. Journal of Dairy Science, v.65, n.12, p.2357-2365, dez.1982.

COHEN, G.; HOCHSTEIN, P. Glucose-6-phosphate dehydrogenase and detoxidation of hydrogen peroxide in human erythocytes. Science, v.134, n.3492, p.1756-1757, ago. 1961.

COMBS, Jr., G.F.; COMBS, S.B. The role of selenium in nutrition. Orlando: Academic Press, Inc., 1986. 532p.

CONRAD, H.R.; MOXON, A.L. Transfer of dietary selenium to milk. Journal of Dairy Science, v.62, n.3, p.404-411, mar.1979.

DANIELE, C.; MACHADO NETO, R.; BARACAT, R.S.; BESSI, R.; PACKER, I.U. Efeito de diferentes manejos no fornecimento prolongado de colostro sobre o comportamento imunológico e desempenho de bezerros leiteiros recém-nascidos. Revista da Sociedade Brasileira de Zootecnia, v.23, n.2, p.211-222, mar./abr. 1994 a.

DANIELE, C.; MACHADO NETO, R.; BARACAT, R.S.; BESSI, R.; PACKER, I.U. Efeito de diferentes manejos de fornecimento prolongado de colostro sobre os niveis de proteina e albumina séricas e desempenho de bezerras recém-nascidas. Scientia Agricola, v.5, n.2, p.381-388, maio/ago. 1994 b. 
DAVIES, E.T. Manual of Veterinary Investigation. London: Her Majesty's Stationery Office, Ministry of Agriculture, Fisheries and Food, 1984. v.2 196p.

De LEEUW, P.W.; ELLENS, D.J.; TALMON, F.P.; ZIMMER, G.N. Rotavirus infections in calves: efficacy of oral vacination in endemically infected herds. Research in Veterinary Science, v.29, p.142-147, 1980.

De TOLEDO, L.A.R.; PERRY, T.W. Distribuition of supplemental selenium in the serum, hair, colostrum and fetus of parturient dairy cows. Journal of Dairy Science, v.68, n.12, p.3249-3254, dez. 1985.

DEVERY, J.E.; DAVIS, C.L.; LARSON, B.L. Endogenous production of immunoglobulin $\lg _{1}$ in newborn calves. Journal of Dairy Science, v.62, n.11, p.1814-1818, nov. 1979.

DIPLOCK, A.T. The role of antioxidant nutrients in disease. Inform, v.3, n.11, p.12141217, nov. 1992.

DONOVAN, G.A.; BADINGA, L.; COOLIER, R.J.; WILCOX, C.J.; BRAUN, R.K. Factors influencing passive transfer in dairy calves. Journal of Dairy Science, v.69, p.754-759, 1986.

DROKE, E.A.; LOERCH, S.C. Effects of parenteral selenium and vitamin $E$ on performance, health and humoral immune response of steers new to the feedlot environment. Journal of Animal Science, v.67, p.1350-1359, 1989.

EDWARDS, S.A.; BROOM, D.M.; COLLIS, S.C. Factors affecting levels of passive immunity in dairy calves. British Veterinary Journal, v.138, n.3, p.233-240, mai./jun. 1982

EPP, O.; LADEINSTEIN, R.; WENDEL, Journal of Animal Science, v. The refined structure of the selenoenzyme glutathione peroxidase at 0,2 - $\mathrm{nm}$ resolution. European Journal of Biochemistry, v.133, n.1, p.51-69, jun. 1983.

EVANS, H.M.; BISHOP, K.S. On the existence of a hitherto unrecognized dietary factor essencial for reproduction. Science, v.56, n.1458, p.650-651, dez. 1922.

EVANS, H.M.; EMERSON, O.H.; EMERSON, G.A. The isolation from wheat germ oil of an alcohol, $\alpha$-tocopherol, having the properties of vitamin $E$. Journal of Biological Chemistry, v.113, n.1, p.319-332, fev. 1936.

FAGLIARI, J.J.; FERREIRA NETO, J.M.; LUCAS, A.; NETO, J.A. Proteina total e fracionamento eletroforético do soro de bezerros Guzerá passivamente imunizados 
contra paratifo. Arquivo Brasileiro de Medicina Veterinária e Zootecnia, v.35, n.3, p.317-332, jun. 1983.

FORSTROM, J.W.; ZAKOWSKI, J.J.; TAPPEL, A.L. Identification of the catalytic site fo rat liver glutathione peroxidase as selenocysteine. Biochemistry, v.17, n.13, p.2639-2644, jun. 1978.

FUKUZAWA, K.; GEBICKI, J.M. Oxidation of $\alpha$-tocopherol in micelles and liposomes by the hydroxyl, perhydroxyl, and superoxide free radicals. Archives of Biochemistry and Biophysics, v.226, n.1, p.242-251, out. 1983.

GAY, C.C.; ANDERSON, N.; FISHER, E.W.; McEWAN, A.D. Gammaglobulin levels and neonatal mortality in market calves. Veterinary Record, v.77, p.148-149, 1965.

GERSCHMAN, R.; GILBERT, D.L.; NYE, S.W.; DWYER, P.; FENN, W.O. Oxygen poisoning and X-irradiation: a mechanism in common. Science, v.119, n.3097, p.623-626, mai. 1954.

GOFF, J.P.; STABEL, J.R. Decreased plasma retinol, $\alpha$-tocopherol, and zinc concentrations during the periparturient period: effect of milk fever. Journal of Dairy Science, v.73, n.11, p.3195-3199, nov. 1990.

HALLIWELL, B. Free radicals and antioxidants: a personal view. Nutrition Reviews, v.52, n.8, p.253-265, ago. 1994.

HALLIWELL, B. Free radicals and metal ions in health and disease. Proceedings of Nutrition Society, v.46, n.1, p.13-26, fev. 1987.

HALLIWELL, B. Oxygen radicals: a commonsense look at their nature and medical importance. Medical Biology, v.62, p.71-77, 1984.

HALLIWELL, B.; CHIRICO, S. Lipid peroxidation: its mechanism, measurement, and significance. American Journal of Clinical Nutrition, v.57, n.5S, p.715S-725S, mai. 1993.

HALLIWELL, B.; GUTTERIDGE, J.M.C. Oxygen toxicity, oxygen radicals, transition metals and disease. Biochemical Journal, v.219, n.1, p.1-14, abr. 1984.

HAMILTON, J.W.; TAPPEL, A.L. Lipid antioxidant activity in tissues and proteins of selenium-fed animals. Journal of Nutrition, v.79, n.4, p.493-502, abr. 1963.

HIDIROGLOU, M. Mammary transfer of vitamin $E$ in dairy cows. Journal of Dainy Science, v.72, n.4, p.1067-1071, abr. 1989. 
HIDIROGLOU, M.; BATRA, T.R.; ROY, G.L. Chamges in plasma $\alpha$-tocopherol and selenium of gestating cows fed hay or silage. Journal of Dairy Science, v.77, n.1, p.190-195, jan. 1994.

HIDIROGLOU, M.; McALLISTER, WILLIAMS, C.J. Prepartum supplementation od selenium and vitamin $E$ to dairy cows: assessment of selenium status and reprodutive performance. Journal of Dairy Science, v.70, n.6, p.1281-1288, jun. 1987.

HILL, K.E.; LLOYD, R.S.; YANG, J.G.; READ, R.; BURK, R.F. The cDNA for rat selenoprotein $P$ contains 10 TGA codons in the open reading frame. Journal of Biological Chemistry, v.266, n.16, p.10050-10053, jun.1991.

HUSBAND, A.J.; BRANDON, M.R.; LASCELLES, A.K. Absorption and endogenous production of immunoglobulins in calves. Australian Journal of Experimental Biology and Medical Science, v.50, p.491-498, set. 1972.

HUSBAND, A.J.; LASCELLES, A.K. Antibody responses to neonatal immunization in calves. Research in Veterinary Science, v.18, p.201-207, 1975.

JAMES, R.E.; POLAN, C.E.; MCGILLIARD, M.L. Distributional uptake of $\gamma$-globulin in small intestine of neonatal calves. Journal of Dairy Science, v.62, n.9, p.14151419, set. 1979.

JEFFCOTT, L.B. Passive immunity and its transfer with special reference to the horse. Biological Reviews, v.47, n.4, p.439-464, nov. 1972.

JENKINS, K.J.; HIDIROGLOU, M.; WAUTHY, J.M.; PROULX, J.E. Prevention of nutritional muscular dystrophy in calves and lambs by selenium and vitamin $E$ additions to the maternal mineral supplement. Canadian Journal of Animal Science, v.54, n.1, p.49-60, mar. 1974.

KAGAN, V.E.; QUINN, P.J. The interaction of $\alpha$-tocopherol and homologues with shorter hydrocarbon chains with phospholipid bilayer dispersions. European Journal of Biochemistry, v.171, n.3, p.661-667, fev. 1988.

KIGOSHI, S.; ITO, R. High levels of free fatty acids in lymphoid cells, with special reference to their cytotoxicity. Experientia, v.29, p.1408-1410, nov. 1973.

KINCAID, R.L.; HODGSON, A.S. Relationship of selenium concentrations in blood of calves to blood selenium of the dam and sepplemental selenium. Journal of Dairy Science, v.72, n.1, p.259-263, jan. 1989. 
KINCAID, R.L.; MILLER, W.J.; NEATHERY, M.W.; GENTRY, R.P.; HAMPTON, D.L. Effect of added dietary selenium on metabolism and tissue distribution of radioactive and stable selenium in calves. Journal of Animal Science, v.44, n.1, p.147-151, jan. 1977.

KIREMIDJIAN-SCHUMACHER, L.; STOTZKY, G. Selenium and immune responses. Environmental Research, v.42, n.2, p.277-303, abr. 1987.

KIRK, J.H.; TERRA, R.L.; GADNER, I.A.; WRIGHT, J.C.; CASE, J.T.; MAAS, J. Comparison of maternal blood and fetal liver selenium concentrations in cattle in California. American Journal of Veterinary Research, v. 56, n.11, p.1460-1464, nov. 1995.

KLAUS, G.G.B.; BENNET, A.; JONES, E.W. A quantitative study of the transfer of colostral immunoglobulins to the newborn calf. Immunology, v.16, p.293-299, 1969.

KOLLER, L.D.; WHITBECK, G.A.; SOUTH, P.J. Transplacental transfer and colostral concentrations of selenium in beef cattle. American Journal of Veterinary Research, v.45, n.12, p.2507-2510, dez. 1984.

KRUSE, P.E. The importance of colostral immunoglobulin and their absorption from the intestine of the newborn animals. Annales de Recherches Veterinaires, v.14, n.4, p.349-353, 1983.

LADEINSTEIN, R.; BARTELS, K.; JONES, A.; HUBER, R.; WENDEL, Journal of Animal Science, v. Structure analysis and molecular model of the selenoenzyme glutathione peroxidase at $2.8 \mathrm{~A}$ resolution. Journal of Molecular Biology, v.134, n.2, p.199-218, out. 1979.

LECCE, J.D.; MORGAN, D.O. Effect of dietary regimen on cessation of intestinal absorption of Large molecules (closure) in the neonatal pig and lamb. Journal of Nutrition, v.78, n.3, p.263-268, nov. 1962.

LITTLE, W.; VAGG, M.J.; COLLIS, K.A.; SHAW, S.R.; GLEED, P.T. The effects of subcutaneous injections of sodium selenato on blood composition and milk yield in dairy cows. Research in Veterinary Science, v.26, p. 193-197, 1974.

LOGAN, E.F.; McBEATH, D.G.; LOWMAN, B.G. Quantitative studies of serum immunoglobulin levels in sucked calves from birth to five weeks. Veterinary Record, v.94, p.367-370, 1974. 
LOGAN, E.F.; McMURRAY, C.H.; O'NEILL, D.G.; McPARLAND, P.J.; McRORY, F.J. Absorption of colostral immunoglobulins by the neonatal calf. British Veterinary Journal, v.134, n.3, p.258-262, mai./jun. 1978.

LUCCI, C.S.; MOXON, A.L.; ZANETTI, M.A.; FRANZOLIN NETO, R.; MARCOMINI, D.G. Selênio em bovinos leiteiros do estado de São Paulo. II. Níveis de selênio nas forragens e concentrados. Revista da Faculdade de Medicina Veterinária e Zootecnia, v.21, n.1, p. 71-76, jan. 1984a.

LUCCI, C.S.; MOXON, A.L.; ZANETTI, M.A.L FUKUSHIMA, R.S.; SCHALCH, E.; PETTINATI, R. Selênio em bovinos leiteiros do estado de São Paulo. I. Níveis de selênio em soros snguíneos. Revista da Faculdade de Medicina Veterinária e Zootecnia, v.21, n.1, p.65-70, jan. 1984b.

LYNCH, G.L. Vitamin E structure and bioavailability. In: COELHO, M.B. ed. Vitamin $E$ in animal nutrition and management. New Jersey: BASF Corporation, 1991. cap.1, p. 1-10.

MACHADO NETO, R.; PACKER, I.U. Flutuação de imunoglobulina sérica em bezerros da raça holandesa submetidos a diferentes regimes de aleitamento. Revista da Sociedade Brasileira de Zootecnia, v.15, n.5, p.439-447, set./out. 1986.

MACHADO NETO, R.; PACKER, I.U.; SUSIN, I. Proteina total sérica em bezerros da raça holandesa submetidos a diferentes regimes de aleitamento. Anais da Escola Superior de Agricultira 'Luiz de Queiroz', v.43, n.1, p.265-283, 1986.

MAGUIRE, J.J.; WILSON, D.S.; PACKER, L. Mitocondrial electron transport-linked tocopheryl radical reduction. Journal of Biological Chemistry, v.264, n.36, p.21462-21465, dez. 1989.

MAUS, R.W.; MARTZ, F.A.; BELYEA, R.L.; WEISS, M.F. Relationship of dietary selenium to selenium in plasma and milk from dairy cows. Journal of Dairy Science, v.63, n.4, p.532-537, abr. 1980.

McCOY, G.C.; RENEAU, J.K.; HUNTER, A.G.;WILLIAMS, J.B. Effects of diet and time on blood serum proteins in the newborn calf. Journal of Dairy Science, v.53, n.3, p.358-362, mar. 1970. 
MCEVAN, A.D.; FISHER, E.W.; SELMAN, I.E.; PENHALE, W.J. A turbity test for the estimation of immunoglobulin levels in neonatal calf serum. Clinical Chemical Acta, v.27, p.155-163, 1970.

MICHANEK, P.; VENTORP, M.; WESTROM, B. Intestinal transmission of colostral antibodies in newborn dairy calves - initiation of closure by feeding colostrum. Swedish Journal of Agricultural Research, v.19, p.125-127, set. 1989.

MILLER, G.Y.; BARTLETT, P.C.; ERSKINE, R.J.L SMITH, K.L. Factors affecting serum selenium and vitamin $E$ concentrations in dairy cows. Journal of the American Veterinary Medical Association, v.206, n.9, p.1369-1373, mai. 1995.

MILLER, J.K.; BRZEZINSKA-SLEBODZINSKA, E.; MADSEN, F.C. Oxidative stress, antioxidants, and animal function. Journal of Dairy Science, v.76, n.9, p.28122823, set. 1993.

MILLS, G.C. Hemoglobin catabolism. II. The protection of hemoglobin from oxidative breakdown in the intact erythrocyte. Journal of Biological Chemistry, v.232, n.2, p.589-598, jun. 1958.

MILLS, G.C.; RANDALL, H.P. Hemoglobin catabolism. I. Glutathione peroxidase, an erythrocyte enzyme which protects hemoglobin from oxidative breakdown. Journal of Biological Chemistry, v.229, n.1, p.189-197, nov. 1957.

NATIONAL RESEARH COUNCIL. Nutrient requirements of dairy cattle nuttition. 6 ed. Washington, D.C.: National Academy Press, 1988. 157p.

NAYLOR, J.M.; KRONFELD, D.S.; BECH-NIELSEN, S..; BARTHOLOMEW, R.C. Plasma total protein measurement for prediction of disease and mortality in calves. Journal of the American Veterinary Medical Association, v.171, n.7, p.635-638, jul. 1977.

NEMEC, M.; HIDIROGLOU, M.; NIELSEN, K.; PROULX, J. Effect of vitamin E and selenium supplenetation on some immune parameters following vaccination against brucellosis in cattle. Journal of Animal Science, v.68, p.4303-4309, 1990.

NIKI, E.; KAWAKAMI, A.; SAITO, M.; YAMAMOTO, Y.; TSUCHIYA, J.; KAMIYA, Y. Effect of phytil side chain of vitamin $E$ on its antioxidant activity. Journal of Biological Chemistry, v.260, n.4, p.2191-2196,fev. 1985. 
NOCEK, J.E.; BRAUND, D.G.; WARNER, R.G. Influence of neonatal colostrum administration, immunoglobulin, and continued feeding of colostrum on calf gain. Journal of Dairy Science, v.67, n.2, p.319-333, fev. 1984.

OLCOTT, H.S.; BROWN, W.D.; VAN DER VEEN, J. Selenomethionine as a antioxidant. Nature, v.191, n.4794, p.1201-1202, set. 1961.

OLCOTT, H.S.; EMERSON, O.H. Antioxidants and autoxidation of fats. IX. The antioxidant properties of the tocopherols. Journal of Biological Chemistry, v.59, n.6, p. 1008-1009, jun. 1937.

OLCOTT, H.S.; MATTILL, H.A. The unsaponifiable lipids of lettuce. III. Antioxidant. Journal of Biological Chemistry, v.93, n.1, p.65-70, set. 1931.

PACKER, J.E.; SLATER, T.F.; WILLSON, R.L. Direst observation of a free radical interaction between vitamin $E$ and vitamin C. Nature, v.278, n.5706, p.737-738, abr. 1979.

PAGLIA, D.E.; VALENTINE, W.N. Studies on the quantitative and qualitative characterization of erythrocyte glutathione peroxidase. Journal of Laboratory and Clinical Medicine, v.70, n.1, p.158-169, jul. 1967.

PENHALE, W.J.; CHRISTIE, G.; McEWAN, A.D.; FISHER, E.W. Quantitative studies on bovine immunoglobulins. II. Plasma immunoglobulins levels in market calves and their relationship to neonatal infection. British Veterinary Journal, v.126, n.1, p.30-37, jan. 1970.

PERRY, T.W.; PETERSON, R.C.; BEESON, W.M. Selenium in milk from feeding small supplements. Journal of Dairy Science, v.60, n.11, p.1698-1770, nov. 1977. PERRY, T.W.; PETERSON, R.C.; GRIFFIN, D.D.; BEESON, W.M. Relationship of blood serum selenium levels of pregnant cows to low dietary intake, and effect on tissue selenium levels of their calves. Journal of Animal Science, v.46, n.2, p.562565, fev. 1978.

PORTER, P. Quantitatives changes in early lactation and by the neonatal calf. Immunology, v.23, p.225-238. 1972.

READ, R.; BELLEW, T.; YANG, J.G.; HILL, K.E.; PALMER, I.S.; BURK, R.F. Selenium and amino acid composition of selenoprotein $P$, the mayor selenoprotein in rat serum. Journal of Biological Chemistry, v.265, n.29, p.17899-17905, out. 1990. 
REDDY, P.G.; MORRIL, J.L.; FREY, R.A. Vitamin E requirements of dairy calves. Journal of Dairy Science, v.70, n.1, p.123-129, jan. 1987 a.

REDDY, P.G.; MORRIL, J.L.; FREY, R.A.; MORRIL, M.B.; MINOCHA, H.C.; GALITZER, S.J.; DAYTON, A.D. Effects of supplemental vitamin $E$ on the performance and metabolic profiles of dairy calves. Journal of Dairy Science, v.68, n.9, p.2258-2266, set. 1985.

REDDY, P.G.; MORRIL, J.L.; MINOCHA, H.C.; MORRIL, M.B.; DAYTON, A.D.; FREY,

R.A. Effect of supplemental vitamin $E$ on the immune system of calves. Journal of Dairy Science, v.69, n.1, p.164-171, jan. 1986.

REDDY, P.G.; MORRIL, J.L.; MINOCHA, H.C.; STEVENSON, J.S. Vitamin E is immunostimulatory in calves. Journal of Dairy Science, v.70, n.5, p.993-999, mai. 1987 b.

REFFETT, J.K.; SPEARS, J.W.; BROWN Jr., T.T. Effect of dietary selenium on the primary and secondary immune response in calves challenged with infectious bovine rhinotracheitis virus. Journal of Nutrition, v.118, n.2, p.229-235, fev. 1988.

REINHOLD, J.G. Total protein, albumin and globulin. In: REINER, M. Standard methods of clinical chemistry. New York: Academic Press, 1953. v.1, p.88.

RIBEIRO, M.F.B.; BELÉM, P.A.D.; PARARROYO, J.H.; De FARIA, J.E. Hipogamaglobulinemia em bezerros. Arquivo Brasileiro de Medicina Veterinária e Zootecnia, v.35, n.4, p.537-546, ago. 1983.

RICE, D.; KENNEDY, S. Vitamin E: function and effects of deficiency. British Veterinary Journal, v.144, n.5, p.482-496, set./out. 1988.

ROBISON, J.D.; STOTT, G.H.; DENIDE, S.K. Effects of passive immunity on the growth and survival in the dairy heifer. Journal of Dairy Science, v.71, n.5, p.1283-1287, mai. 1988.

ROTRUCK, J.T.; POPE, A.L.; GANTHER, H.E.; HOEKSTRA, W.G. Prevention of oxidative damage to rat erythrocytes by dietary selenium. Journal of Nutrition, v. 102, n.5, p.689-696, mai. 1972.

ROTRUCK, J.T.; POPE, A.L.; SWANSON, A.B.; HAFEMAN, D.G.; HOCKSTRA, W.G. Selenium: Biochemical role as a component of glutathione peroxidase. Science, v. 179, n.4072, p.588-590, fev. 1973. 
SAIF, L.J.; SMITH, L. Enteric viral infections of calves and immunity. Journal of Dairy Science, v.68, n.1, 206-228, jan. 1985.

SANTOS, G.T.; GRONGNET, J.F.; MAUBOIS, J.L.; LAREYNIE, J.; PIOT, M. Absorção pelo bezerro recém-nascido de imunoglobulinas extraídas do colostro bovino. Pesquisa Agropecuária Brasileira, v.24, n.1, p.75-83, jan. 1989.

SAS INSTITUTE SIA. SASISTAT: user's guide. Release 6.08 ed. Cary: SAS Institute Inc., 1989. 1028p.

SCHINGOETHE, D.J.; PARSONS, J.G.; LUDENS, F.C.; TUCKER, W.L.; SHAVE, H.J. Vitamin $E$ status of dairy cows fed stored feeds continuously or pastured during summer. Journal of Dairy Science, v.61, n.11, p.1582-1589, nov. 1978.

SCHWARZ, K.; FOLTZ, C.M. Selenium as a integral part of factor 3 against dietary necrotic liver degeneration. Journal of American Chemical Society, v.79, n.12, p.3292-3293, jun. 1957.

SELMAN, I.E.; DE LA FUENTE, G.H.; FISHER, E.W.; McEWAN, A.D. The serum immune globulin concentrations of newborn dairy heifer calves. A form survey. Veterinary Records, v.88, p.460-464, 1971

SHEFFY, B.E.; SCHULTZ, R.D. Influence of vitamin $E$ and selenium on immune response mechanisms. Federation Proceedings, v.38, n.7, p.2139-2143, jun. 1979.

SHIMAZU, F.; TAPPEL, A.L. Selenoamino acids: decrease of radiation damage to amino acids and proteins. Science, v.143, n.3604, p.369-371, jan. 1964.

SIDDONS, R.C.; MILLS, C.F. Glutathione peroxidase activity and erythrocyte stability in calves differing in selenium and vitamin $E$ status. British Journal of Nutrition, v.46, n.2, p.345-255, set. 1981.

SLATER, T.F. Free-radical mechanisms in tissue injury. Biochemistry Journal, v.222, n.1, p.1-15, ago. 1984.

SLATER, T.F.; CHEESEMAN, K.H.; DAVIES, M.J.; PROUDFOOT, K.; XIN, W. Free radical mechanisms in relation to tissue injury. Proceedings of Nutrition Society, v.46, n.1, p.1-12, fev. 1987.

SMITH, K.L.; HOGAN, J.S.; WEISS, B.P. Dietary vitamin E and selenium influence the resistance of cows to mastitis. In: COELHO, M.B. ed. Vitamin $E$ in animal 
nutrition and management. New Jersey: BASF Corporation, 1991. cap.17, p. $151-1157$.

STABEL, J.R.; SPEARS, J.W.; BROWN, T.T.; BRAKE, J. Selenium effects on glutathione peroxidase and the immune response of stressed calves challenged with Pasteurella hemolytica. Journal of Animal Science, v.67, n.2, p.557-564, fev. 1989.

STADTMAN, T.C. Biosynthesis and function of selenocysteine-containing enzymes. Journal of Biological Chemistry, v.266, n.25, p.16257-16260, set. 1991.

STOTT, G.H.; FELLAH, A. Colostral immunoglobulin absorption linearly related to concentration for calves. Journal of Dairy Science, v.66, n.6, p.1319-1328, jun. 1983.

STOTT, G.H.; MARX, D.B.; MENEFEE, B.E.; NIGHTENGALE, G.T. Colostral immunoglobulins transfer in calves. I. Period of absoption. Journal of Dairy Science, v.62, n.11, p.1632-1638, nov. 1979a.

STOTT, G.H.; MARX, D.B.; MENEFEE, B.E.; NIGHTENGALE, G.T. Colostral immunoglobulins transfer in calves. II. The rate of absoption. Journal of Dairy Science, v.62, n.11, p.1766-1773, nov. 1979b.

STOTT, G.H.; MARX, D.B.; MENEFEE, B.E.; NIGHTENGALE, G.T. Colostral immunoglobulins transfer in calves. III. Amount of absoption. Journal of Dairy Science, v.62, n.12, p.1902-1907, dez. 1979c.

STOTT, G.H.; MARX, D.B.; MENEFEE, B.E.; NIGHTENGALE, G.T. Colostral immunoglobulins transfer in calves. IV. Effect of suckling. Journal of Dairy Science, v.62, n.12, p.1908-1913, dez. 1979d.

STOWE, H.D.; THOMAS, J.W.; JOHNSON, T.; MARTENIUK, J.V.; MORROW, D.A.; ULLREY, D.E. Responses of dairy cattle to long-term and short-term supplementation with oral selenium and vitamin E. Journal of Dairy Science, v.71, n.7, p.1830-1839, jul. 1988.

STOYANOVSKY, D.A.; OSIPOV, A.N.; QUINN, P.J.; KAGAN, V.E. Ubiquinonedependent recycling of vitamin $E$ radicals by superoxide. Archives of Biochemistry and Biophysics, v.323, n.2, p.343-351, nov. 1995.

SURE, B. Dietary requirements for reproduction. II. The existence of a vitamin for reproduction. Journal of Biological Chemistry, v.58, n.3, p.693-709, jan. 1924. 
SWECKER, Jr., W.S.; EVERSOLE, D.E.; THATCHER, C.D.; BLODGETT, D.J.; SCHURIG, G.G.; MELDRUM, J.B. Influence of supplemental selenium on humoral immune responses in weaned beef calves. American Journal of Veterinary Research, v.50, n. 10, p.1760-1763, out. 1989.

SWECKER, Jr., W.S.; THATCHER, C.D.; EVERSOLE, D.E.; BLODGETT, D.J.; SCHURIG, G.G. Effect of selenium supplementation on colostral IgG concentration in cows grazing selenium-deficient pastures and on postsuckle serum lgG concentration in their calves. American Journal of Veterinary Research, v.56, $n$. 4, p.450-453, abr. 1995.

TENNANT, B.; HARROLD, D.; GUERRA, M.R.; LABEN, R.C. Neonatal alterations in serum gammaglobulin levels of Jersey and Holstein-Friesian calves. American Journal of Veterinary Research, v.30, n.2, p.345-354, fev. 1969.

THOMPSON, J.N.; SCOTT, M.L. Impaired lipid and vitamin E absorption related to atrophy of the pancreas in selenium-deficient chicks. Journal of Nutrition, v.100, n.7, p.797-809, jun. 1970.

THOMPSON, J.N.; SCOTT, M.L. Role of selenium in the nutrition of chick. Journal of Nutrition, v.97, n.3, p.335-342, mar. 1969.

THOMPSON, K.M., HAIBACH, H.; SUNDE, R.A. Growth and plasma triiodothyronine concentrations are modified bu selenium deficiency and repletion in secondgeneration selenium-deficient rats. Journal of Nutrition, v.125, n.4, p.864-873, abr. 1995.

TIZARD, I. Imunologia Veterinária. São Paulo: Livraria Roca Ltda., 1985. 329p.

TSUNEMITSU, H.; SHIMIZU, M.; HIRAI, T. Protection against bovine rotavirus in newborn calves by continuos feeding of immune colostrum. Japan Journal of Veterinary Science, v.51, n.2, p.300-308, fev. 1989.

ULLREY, D.E. Basis for regulation of selenium supplements in animal diets. Journal of Animal Science, v.70, n.12, p.3922-3927, dez. 1992.

URSINI, F.; MAIORINO, M.; GREGOLIN, C. The selenoenzyme phospholipid hydroperoxide glutathione peroxidase. Biochimica et biophysica Acta, v.839, p.62-70, 1985. 
VAN SAUN, R.J.; HEROT, T.H.; STOWE, H.D. Maternal and fetal selenium concentrations and their interrelationships in dairy cattle. Journal of Nutrition, v.119, n.8, p.1128-1137, ago. 1989.

WEISS, W.P.; COLENBRANDER, V.F.; CUNNINGHAM, D. Maternal transfer and retention of supplemental selenium in neonatal calves. Journal of Dairy Science, v.67, n.2, p.416-420, fev. 1984.

WEISS, W.P.; COLENBRANDER, V.F.; CUNNINGHAM, D.; CALLAHAN, C.I. Selenium / vitamin E: role in disease prevention and weight gain of neonatal calves. Journal of Dairy Science, v.66, n.5, p.1101-1107, mai. 1983.

WEISS, W.P.; TODHUNTER, D.A.; HOGAN, J.S.; SMITH, K.L. Effect of duration of supplementation of selenium and vitamin $E$ on periparturiente dairy cows. Journal of Dairy Science, v.73, n.11, p.3187-3194, nov. 1990. 
APÊNDICE 
Apêndice 1. Composição da ração fornecida aos bezerros.

$\begin{array}{cc}\text { Umidade (\%) } & 13,00 \\ \text { Proteina Bruta } & 16,00 \\ \text { Extrato Etéreo } & 2,00 \\ \text { Matéria Fibrosa } & 11,50 \\ \text { Matéria Mineral } & 11,00 \\ \text { Cálcio } & 2,50 \\ \text { Fósforo } & 0,40\end{array}$

Os ingredientes básicos da ração são: farelo de soja tostado, farelo de algodão, farelinho de trigo, milho moído, farinha de ossos, carbonato de cálcio, melaço, sal, suplemento vitamínico mineral. 
Apêndice 2. Classificação de consistência fecal.

\begin{tabular}{cl}
\hline Pontos & Descrição das caracteristicas \\
\hline 0 & Fezes firmes e formadas \\
1 & Fezes moles: perdem a forma sobre superficie plana \\
2 & Fezes semi-liquidas: fluem lentamente de um recipiente \\
3 & Fezes liquidas: fluem rapidamente \\
4 & Fezes aquosas \\
\hline
\end{tabular}

Obs.: Meio ponto foi empregado quando necessário.

Apêndice 3. Classificação de cor fecal.

\begin{tabular}{cl}
\hline Pontos & Cores \\
\hline 0 & Marrom / marrom esverdeado \\
0,5 & Amarelo / marrom \\
1,0 & Verde \\
1,5 & Cinza \\
2,0 & Bege ou amarelo \\
2,5 & Bege / creme ou amarelo / creme \\
3,0 & Creme ou branco \\
\hline
\end{tabular}


Apêndice 4. Classificação de presença de muco nas fezes.

\begin{tabular}{cl}
\hline Pontos & Descrição das características \\
\hline 0 & Ausência de muco \\
1 & Sinais de presença de muco \\
2 & Presença de pequena quantidade de muco \\
3 & Presença de grande quantidade de muco \\
\hline
\end{tabular}

Obs.: Meio ponto foi empregado quando necessário.

Apêndice 5. Classificação de presença de sangue nas fezes.

\begin{tabular}{cl}
\hline Pontos & Descrição das caracteristicas \\
\hline 0 & Ausência de sangue \\
1 & Sinais de presença de sangue \\
2 & Presença de pequena quantidade de sangue \\
3 & Presença de grande quantidade de sangue
\end{tabular}

Obs.: Meio ponto foi empregado quando necessário. 
Apêndice 6. Concentração de vitamina $E$ sérica $(\mu \mathrm{mol} / \mathrm{l})$ de bezerros aos 2 dias de idade, nos diferentes tratamentos.

\begin{tabular}{ccccccccc}
\hline $\begin{array}{c}\text { Animai } \\
\text { s }\end{array}$ & 1 & 2 & 3 & 4 & 5 & 6 & 7 & 8 \\
\hline T1 & 0,61 & 8,57 & 13,42 & 4,81 & 5,59 & 4,66 & 5,30 & 2,59 \\
T2 & 12,75 & 6,41 & 9,21 & 7,91 & 6,93 & 5,03 & 8,50 & 7,61 \\
T3 & 2,88 & 4,11 & 3,46 & 2,18 & 1,80 & 3,08 & 6,34 & 3,01 \\
T4 & 6,66 & 4,47 & 3,33 & 4,96 & 6,38 & 10,09 & 5,50 & 5,28 \\
T5 & 4,91 & 4,95 & 6,74 & 4,19 & & & & \\
T6 & 9,96 & 13,10 & 5,05 & 9,25 & & & & \\
\hline
\end{tabular}

Apêndice 7. Atividade de glutationa peroxidase (unidades/ml de eritrócitos) de bezerros aos 2 dias de idade, nos diferentes tratamentos.

\begin{tabular}{ccccccccc}
\hline $\begin{array}{c}\text { Animai } \\
\text { s }\end{array}$ & 1 & 2 & 3 & 4 & 5 & 6 & 7 & 8 \\
\hline T1 & 21,91 & 18,86 & 69,68 & 45,47 & 37,80 & 53,50 & 28,98 & 44,17 \\
T2 & 30,62 & 49,12 & 45,98 & 40,42 & 37,00 & 45,16 & 34,45 & 22,61 \\
T3 & 10,15 & 43,97 & 24,61 & 55,18 & 55,37 & 52,30 & 51,03 & 25,10 \\
T4 & 72,21 & 65,67 & 33,61 & 37,80 & 44,29 & 66,79 & 51,37 & 35,48 \\
T5 & 95,90 & 43,38 & 55,92 & 46,30 & & & & \\
T6 & 18,66 & 67,98 & 17,61 & 9,00 & & & & \\
\hline
\end{tabular}


Apêndice 8. Concentração de proteina total sérica $(g / 100 \mathrm{ml}$ ) nas 8 unidades experimentais do tratamento $\mathrm{T} 1$.

\begin{tabular}{ccccccccc}
\hline Idade & \multicolumn{7}{c}{ Animais } \\
\cline { 2 - 9 } (dias) & 1 & 2 & 3 & 4 & 5 & 6 & 7 & 8 \\
\hline 2 & 11,47 & 7,70 & 8,92 & 9,08 & 7,51 & 8,91 & 7,83 & 9,58 \\
5 & 10,26 & 6,74 & 8,92 & 8,61 & 7,13 & 10,07 & 7,33 & 8,85 \\
10 & 10,20 & 7,54 & 8,92 & 8,44 & 7,14 & 9,17 & 8,02 & 7,57 \\
15 & 9,30 & 7,65 & 8,47 & 8,44 & 7,70 & 8,40 & 7,85 & 7,57 \\
17 & 9,24 & 7,21 & 8,60 & 8,44 & 7,20 & 7,89 & 6,95 & 6,96 \\
20 & 8,40 & 6,77 & 7,72 & 8,38 & 7,57 & 7,95 & 7,52 & 6,23 \\
25 & 7,62 & 6,30 & 7,66 & 8,44 & 6,20 & 8,21 & 6,58 & 7,02 \\
30 & 7,44 & 5,89 & 7,84 & 8,90 & 6,20 & 7,50 & 7,33 & 6,65 \\
35 & 7,62 & 7,15 & 7,84 & 7,80 & 6,89 & 7,44 & 7,08 & 6,17 \\
40 & 7,68 & 7,04 & 7,05 & 8,61 & 7,95 & 7,63 & 6,83 & 6,29 \\
50 & 7,68 & 7,26 & 7,59 & 8,50 & 9,16 & 7,89 & 6,83 & 7,14 \\
70 & 8,88 & 7,59 & 8,47 & 6,93 & 8,82 & 8,34 & 6,89 & 7,02 \\
\hline
\end{tabular}

Apêndice 9. Concentração de proteína total sérica $(g / 100 \mathrm{ml}$ ) nas 8 unidades experimentais do T2.

\begin{tabular}{ccccccccc}
\hline Idade & \multicolumn{7}{c}{ Animais } \\
\cline { 2 - 9 } (dias) & 1 & 2 & 3 & 4 & 5 & 6 & 7 & 8 \\
\hline 2 & 9,28 & 9,84 & 9,58 & 8,52 & 8,51 & 9,04 & 8,70 & 9,94 \\
5 & 8,00 & 9,80 & 8,75 & 8,34 & 7,57 & 9,23 & 7,95 & 9,47 \\
10 & 8,25 & 9,27 & 8,88 & 8,16 & 8,57 & 8,53 & 7,70 & 8,68 \\
15 & 8,25 & 7,86 & 8,43 & 7,62 & 7,51 & 8,98 & 7,64 & 8,05 \\
17 & 8,25 & 8,32 & 5,68 & 7,74 & 8,13 & 8,53 & 7,52 & - \\
20 & 7,82 & 7,45 & 7,15 & 8,04 & 6,89 & 8,59 & 8,05 & 6,88 \\
25 & 7,64 & 7,92 & 4,79 & 6,90 & 7,32 & 7,70 & 7,72 & 6,88 \\
30 & 8,13 & 7,45 & 7,53 & 7,56 & 6,95 & 7,31 & 6,20 & 7,14 \\
35 & 7,76 & 7,57 & 8,81 & 7,26 & 6,70 & 6,93 & 6,02 & 6,68 \\
40 & 7,40 & 8,21 & 9,45 & 7,32 & 7,07 & 8,21 & 6,52 & 7,07 \\
50 & 7,52 & 8,50 & 9,07 & 7,02 & 7,51 & 7,70 & 6,52 & 7,07 \\
70 & 8,61 & 8,50 & 9,13 & 6,90 & 7,51 & 8,53 & 7,33 & 7,33 \\
\hline
\end{tabular}


Apêndice 10. Concentração de proteina total sérica $(g / 100 \mathrm{ml})$ nas 8 unidades experimentais do T3.

\begin{tabular}{ccccccccc}
\hline $\begin{array}{c}\text { Idade } \\
\text { (dias) }\end{array}$ & 1 & 2 & 3 & 4 & 5 & 6 & 7 & 8 \\
\hline 2 & 10,29 & 8,86 & 7,74 & 10,42 & 7,60 & 8,24 & 7,20 & 8,89 \\
5 & 9,57 & 8,25 & 7,68 & 9,69 & 7,38 & 7,38 & 7,08 & 7,92 \\
10 & 6,71 & 8,19 & 7,39 & 9,51 & 7,54 & 7,38 & 7,27 & 8,24 \\
15 & 8,31 & 7,82 & 6,81 & 8,18 & 6,88 & 7,20 & 5,95 & 7,07 \\
17 & 8,91 & 7,40 & 6,46 & 8,30 & 6,17 & 7,07 & 7,14 & 7,33 \\
20 & 8,14 & 6,67 & 6,58 & 7,88 & 7,15 & 7,32 & 6,70 & 6,68 \\
25 & 8,03 & 8,31 & 6,64 & 7,63 & 5,40 & 6,64 & 6,45 & 7,14 \\
30 & 7,81 & 7,28 & 6,87 & 7,33 & 6,60 & 6,83 & 6,20 & 8,05 \\
35 & 7,92 & 8,07 & 6,58 & 6,91 & 7,16 & 6,83 & 6,64 & 8,05 \\
40 & 8,15 & 7,76 & 7,16 & 8,06 & 7,27 & 7,38 & 6,27 & 7,33 \\
50 & 8,47 & 8,00 & 8,44 & 7,15 & 8,04 & 7,38 & 7,70 & 8,37 \\
70 & 8,91 & 8,43 & 7,86 & 7,33 & 8,20 & 8,85 & 7,52 & 8,57 \\
\hline
\end{tabular}

Apêndice 11. Concentração de proteina total sérica $(g / 100 \mathrm{ml})$ nas 8 unidades experimentais do $\mathrm{T} 4$.

\begin{tabular}{ccccccccc}
\hline Idade & \multicolumn{7}{c}{ Animais } \\
\cline { 2 - 9 } (dias) & 1 & 2 & 3 & 4 & 5 & 6 & 7 & 8 \\
\hline 2 & 7,98 & 7,50 & 10,18 & 7,33 & 8,78 & 10,29 & 10,64 & 9,60 \\
5 & 7,37 & 7,27 & 10,41 & 7,50 & 7,21 & 9,62 & 9,20 & 8,83 \\
10 & 7,37 & 7,96 & 8,67 & 7,33 & 7,03 & 9,25 & 9,10 & 7,46 \\
15 & 6,05 & 7,39 & 8,26 & 7,21 & 8,42 & 8,34 & 7,99 & 7,85 \\
17 & 3,75 & 7,08 & 8,67 & 7,62 & 7,95 & 8,46 & 8,76 & 7,98 \\
20 & 5,73 & 7,27 & 8,21 & 7,92 & 7,63 & 10,07 & 7,58 & 7,98 \\
25 & 5,89 & 7,08 & 8,15 & 6,50 & 7,57 & 8,02 & 7,07 & 7,01 \\
30 & 5,62 & 7,21 & 8,61 & 8,86 & 7,63 & 7,63 & 7,50 & 6,81 \\
35 & - & 7,21 & 8,38 & 5,50 & 7,88 & 8,46 & 7,50 & 7,01 \\
40 & - & 7,64 & 8,32 & 6,27 & 7,57 & 8,78 & 7,83 & 7,07 \\
50 & - & 7,39 & 8,22 & 6,56 & 7,63 & 9,04 & 7,81 & 7,46 \\
70 & - & 9,15 & 7,45 & 7,03 & 8,72 & 10,00 & 7,69 & 7,46 \\
\hline
\end{tabular}


Apêndice 12. Concentração de proteina total sérica $(g / 100 \mathrm{ml})$ nas 4 unidades experimentais do T5.

\begin{tabular}{ccccc}
\hline Idade & \multicolumn{4}{c}{ Animais } \\
\cline { 2 - 5 } (dias) & 1 & 2 & 3 & 4 \\
\hline 2 & 7,74 & 8,24 & 5,85 & 7,24 \\
5 & 5,76 & 8,66 & 5,60 & 6,58 \\
10 & 5,64 & 8,30 & 6,64 & 7,24 \\
15 & 6,18 & 7,63 & 6,09 & 6,52 \\
17 & 5,76 & 7,39 & 6,40 & 5,45 \\
20 & 6,18 & 7,45 & 6,64 & 5,75 \\
25 & 5,58 & 7,45 & 5,97 & 6,22 \\
30 & 5,70 & 7,09 & 6,64 & 6,64 \\
35 & 5,88 & 6,91 & 5,79 & 6,28 \\
40 & 6,48 & 9,39 & 6,83 & 6,15 \\
50 & 6,90 & 8,24 & 7,38 & 6,64 \\
70 & 7,80 & 8,54 & 8,18 & 7,00 \\
\hline
\end{tabular}

Apêndice 13. Concentração de proteina total sérica $(g / 100 \mathrm{ml})$ nas 4 unidades experimentais do T6.

\begin{tabular}{ccccc}
\hline Idade & \multicolumn{4}{c}{ Animais } \\
(dias) & 1 & 2 & 3 & 4 \\
\hline 2 & 7,38 & 6,05 & 7,24 & 7,00 \\
5 & 7,27 & 6,78 & 7,30 & 6,28 \\
10 & 6,72 & 6,78 & 6,82 & 6,70 \\
15 & 6,61 & 5,31 & 6,94 & 6,16 \\
17 & 6,55 & 5,98 & 7,24 & 5,75 \\
20 & 6,28 & 5,92 & 6,64 & 5,81 \\
25 & 6,72 & 5,38 & 6,34 & 5,87 \\
30 & 6,39 & 5,25 & 6,52 & 5,33 \\
35 & 6,44 & 5,01 & 6,40 & 5,57 \\
40 & 7,05 & 5,68 & 6,76 & 5,27 \\
50 & 6,66 & 5,38 & 6,88 & 5,51 \\
70 & 8,20 & 6,41 & 7,30 & 6,28 \\
\hline
\end{tabular}


Apêndice 14. Valores de ZST (absorbância x 100) observados nos bezerros às $24 \mathrm{~h}$ de vida, nos diferentes tratamentos.

\begin{tabular}{ccccccccc}
\hline $\begin{array}{c}\text { Animai } \\
\text { s }\end{array}$ & 1 & 2 & 3 & 4 & 5 & 6 & 7 & 8 \\
\hline T1 & 53,00 & 20,00 & 34,00 & 28,50 & 20,75 & 32,50 & 25,50 & 38,50 \\
T2 & 33,00 & 44,50 & 29,50 & 27,50 & 36,00 & 26,75 & 34,00 & 36,50 \\
T3 & 41,50 & 26,00 & 27,50 & 42,50 & 21,50 & 24,00 & 20,00 & 29,50 \\
T4 & 20,00 & 28,50 & 40,50 & 32,75 & 25,50 & 45,00 & 40,00 & 30,25 \\
T5 & 12,50 & 14,00 & 10,25 & 17,00 & & & & \\
T6 & 19,00 & 15,50 & 18,75 & 14,00 & & & & \\
\hline
\end{tabular}


Apêndice 15. Concentração de imunoglobulinas séricas $(\mathrm{g} / 100 \mathrm{ml})$ nas 8 unidades experimentais do T1.

\begin{tabular}{ccccccccc}
\hline Idade & \multicolumn{7}{c}{ Animais } \\
\cline { 2 - 9 } (dias) & 1 & 2 & 3 & 4 & 5 & 6 & 7 & 8 \\
\hline 2 & 6,517 & 1,821 & 3,790 & 3,709 & 2,330 & 3,851 & 2,786 & 4,482 \\
5 & 5,035 & 1,344 & 3,420 & 3,643 & 1,693 & 4,260 & 2,111 & 3,472 \\
10 & 5,234 & 1,290 & 2,978 & 3,131 & 1,698 & 3,432 & 2,298 & 2,890 \\
15 & 4,538 & 1,399 & 2,956 & 3,856 & 1,775 & 2,952 & 2,212 & 2,713 \\
17 & 4,281 & 1,129 & 2,523 & 3,176 & 1,904 & 2,770 & 1,972 & 2,367 \\
20 & 3,735 & 1,328 & 2,090 & 3,520 & 1,753 & 2,911 & 1,990 & 2,044 \\
25 & 2,807 & 1,242 & 2,076 & 2,772 & 1,349 & 2,511 & 1,547 & 2,679 \\
30 & 2,724 & 1,168 & 1,720 & 3,074 & 1,669 & 2,225 & 1,756 & 1,946 \\
35 & 2,419 & 1,236 & 2,106 & 2,427 & 2,136 & 2,268 & 1,626 & 1,705 \\
40 & 2,547 & 1,427 & 1,731 & 3,339 & 2,344 & 2,166 & 1,539 & 1,559 \\
50 & 2,523 & 1,497 & 2,024 & 3,168 & 3,326 & 2,332 & 1,381 & 1,967 \\
70 & 3,346 & 1,696 & 2,246 & 1,911 & 3,539 & 2,144 & 1,556 & 1,999 \\
\hline
\end{tabular}

Apêndice 16. Concentração de imunoglobulinas séricas $(\mathrm{g} / 100 \mathrm{ml})$ nas 8 unidades experimentais do $\mathrm{T} 2$.

\begin{tabular}{ccccccccc}
\hline Idade & \multicolumn{7}{c}{ Animais } \\
\cline { 2 - 9 } (dias) & 1 & 2 & 3 & 4 & 5 & 6 & 7 & 8 \\
\hline 2 & 3,963 & 5,285 & 4,185 & 3,976 & 3,653 & 3,918 & 3,743 & 5,088 \\
5 & 2,984 & 4,994 & 2,775 & 3,730 & 2,810 & 3,931 & 3,262 & 4,072 \\
10 & 3,091 & 4,168 & 3,297 & 3,608 & 3,197 & 3,425 & 2,754 & 3,421 \\
15 & 2,748 & 3,172 & 2,964 & 3,390 & 2,528 & 3,344 & 2,706 & 2,726 \\
17 & 2,913 & 3,137 & 1,929 & 3,278 & 2,434 & 3,794 & 2,571 & - \\
20 & 2,533 & 2,764 & 2,389 & 3,302 & 2,018 & 2,957 & 2,553 & 2,286 \\
25 & 2,386 & 2,448 & 1,477 & 2,595 & 2,176 & 3,172 & 2,297 & 1,667 \\
30 & 2,464 & 2,939 & 2,676 & 2,762 & 1,797 & 2,275 & 1,698 & 1,705 \\
35 & 2,278 & 2,585 & 2,782 & 2,419 & 1,843 & 2,057 & 1,643 & 1,570 \\
40 & 2,204 & 2,926 & 3,486 & 2,164 & 1,761 & 2,449 & 1,589 & 1,832 \\
50 & 2,625 & 3,433 & 3,425 & 2,465 & 1,925 & 2,069 & 1,764 & 1,433 \\
70 & 2,485 & 3,082 & 3,819 & 2,159 & 1,909 & 3,007 & 1,749 & 1,465 \\
\hline
\end{tabular}


Apêndice 17. Concentração de imunoglobulinas séricas $(g / 100 \mathrm{ml})$ nas 8 unidades experimentais do T3.

\begin{tabular}{ccccccccc}
\hline Idade & \multicolumn{7}{c}{ Animais } \\
\cline { 2 - 9 } (dias) & 1 & 2 & 3 & 4 & 5 & 6 & 7 & 8 \\
\hline 2 & 4,609 & 3,461 & 2,712 & 5,142 & 2,462 & 3,542 & 2,505 & 3,554 \\
5 & 3,721 & 2,609 & 2,505 & 4,409 & 2,032 & 2,721 & 2,263 & 2,725 \\
10 & 1,146 & 2,746 & 2,356 & 4,116 & 2,242 & 2,686 & 2,190 & 2,922 \\
15 & 2,845 & 2,553 & 2,059 & 3,166 & 2,045 & 2,529 & 1,487 & 2,180 \\
17 & 2,498 & 2,431 & 1,409 & 3,064 & 1,188 & 2,500 & 1,884 & 4,203 \\
20 & 2,233 & 1,824 & 1,696 & 2,543 & 1,902 & 2,262 & 1,676 & 1,781 \\
25 & 2,608 & 2,369 & 1,859 & 2,765 & 1,217 & 1,930 & 1,133 & 1,916 \\
30 & 2,568 & 1,924 & 1,796 & 2,361 & 1,715 & 1,999 & 1,287 & 2,456 \\
35 & 2,405 & 2,295 & 1,859 & 2,066 & 1,719 & 2,097 & 1,508 & 2,479 \\
40 & 2,707 & 2,479 & 2,099 & 2,025 & 1,764 & 2,089 & 1,525 & 2,342 \\
50 & 3,048 & 2,690 & 3,036 & 1,699 & 2,708 & 2,606 & 1,993 & 2,664 \\
70 & 3,480 & 3,133 & 2,401 & 1,858 & 2,841 & 3,229 & 1,752 & 2,832 \\
\hline
\end{tabular}

Apêndice 18. Concentração de imunoglobulinas séricas $(g / 100 \mathrm{ml})$ nas 8 unidades experimentais do T4.

\begin{tabular}{ccccccccc}
\hline Idade & \multicolumn{7}{c}{ Animais } \\
\cline { 2 - 8 } (dias) & 1 & 2 & 3 & 4 & 5 & 6 & 7 & 8 \\
\hline 2 & 2,231 & 2,381 & 5,176 & 3,321 & 3,193 & 5,500 & 5,649 & 3,555 \\
5 & 1,980 & 2,124 & 5,295 & 3,008 & 2,456 & 4,485 & 4,055 & 3,327 \\
10 & 1,640 & 2,437 & 3,443 & 3,090 & 2,436 & 4,134 & 3,682 & 2,544 \\
15 & 1,091 & 2,009 & 3,372 & 2,206 & 2,468 & 3,111 & 2,750 & 2,513 \\
17 & 0,699 & 2,066 & 3,159 & 2,530 & 2,235 & 3,326 & 2,926 & 2,411 \\
20 & 1,229 & 1,822 & 3,562 & 2,256 & 2,052 & 4,056 & 2,575 & 1,912 \\
25 & 1,231 & 1,703 & 2,809 & 2,032 & 1,897 & 2,732 & 1,948 & 1,865 \\
30 & 1,056 & 1,854 & 3,223 & 4,053 & 1,918 & 2,455 & 2,166 & 1,690 \\
35 & - & 1,777 & 3,702 & 1,078 & 2,236 & 2,955 & 2,102 & 1,890 \\
40 & - & 1,992 & 2,909 & 1,777 & 2,065 & 2,916 & 2,482 & 1,618 \\
50 & - & 2,308 & 2,683 & 1,617 & 1,910 & 3,197 & 2,197 & 1,624 \\
70 & - & 2,684 & 2,786 & 1,701 & 2,629 & 3,324 & 1,958 & 1,712 \\
\hline
\end{tabular}


Apêndice 19. Concentração de imunoglobulinas séricas $(\mathrm{g} / 100 \mathrm{ml})$ nas 4 unidades experimentais do T5.

\begin{tabular}{ccccc}
\hline Idade & \multicolumn{4}{c}{ Animais } \\
\cline { 2 - 5 } (dias) & 1 & 2 & 3 & 4 \\
\hline 2 & 2,192 & 2,776 & 1,059 & 1,874 \\
5 & 0,901 & 2,512 & 0,960 & 1,564 \\
10 & 1,279 & 3,139 & 1,639 & 2,295 \\
15 & 0,859 & 3,179 & 0,948 & 1,789 \\
17 & 1,362 & 2,115 & 1,005 & 1,258 \\
20 & 1,458 & 2,017 & 0,966 & 1,163 \\
25 & 1,087 & 2,975 & 0,933 & 1,349 \\
30 & 1,346 & 2,532 & 1,508 & 1,600 \\
35 & 1,347 & 2,071 & 1,366 & 2,304 \\
40 & 1,971 & 3,004 & 1,414 & 1,106 \\
50 & 1,755 & 2,404 & 1,980 & 1,246 \\
70 & 2,904 & 2,700 & 2,285 & 1,480 \\
\hline
\end{tabular}

Apêndice 20. Concentração de imunoglobulinas séricas $(\mathrm{g} / 100 \mathrm{ml})$ nas 4 unidades experimentais do T5.

\begin{tabular}{ccccc}
\hline Idade & \multicolumn{4}{c}{ Animais } \\
\cline { 2 - 5 } (dias) & 1 & 2 & 3 & 4,581 \\
\hline 2 & 1,959 & 2,058 & 2,605 & 1,58 \\
5 & 1,890 & 1,877 & 2,837 & 1,226 \\
10 & 1,265 & 2,015 & 1,837 & 1,501 \\
15 & 1,522 & 1,510 & 1,739 & 0,994 \\
17 & 1,557 & 1,541 & 1,801 & 1,157 \\
20 & 1,216 & 1,581 & 1,748 & 1,023 \\
25 & 1,069 & 1,577 & 1,492 & 0,909 \\
30 & 1,321 & 1,058 & 1,605 & 0,683 \\
35 & 1,049 & 1,350 & 1,721 & 0,798 \\
40 & 1,404 & 1,333 & 1,795 & 0,773 \\
50 & 1,374 & 1,123 & 1,644 & 0,626 \\
70 & 2,234 & 1,697 & 1,965 & 1,250 \\
\hline
\end{tabular}


Apêndice 21. Notas de consistência de fezes nas 8 unidades experimentais do T1.

\begin{tabular}{|c|c|c|c|c|c|c|c|c|}
\hline \multirow{2}{*}{$\begin{array}{l}\text { idade } \\
\text { (dias) }\end{array}$} & \multicolumn{8}{|c|}{ Animais } \\
\hline & 1 & 2 & 3 & 4 & 5 & 6 & 7 & 8 \\
\hline 2 & 0,0 & 0,0 & 0,5 & 1,0 & 3,0 & 0,5 & 0,0 & 0,5 \\
\hline 3 & 0,0 & 0,5 & 0,5 & 1,0 & 1,5 & . & 0,0 & 0,0 \\
\hline 4 & 0,5 & 2,5 & 0,0 & 0,5 & 0,0 & 0,5 & 0,0 & 0,5 \\
\hline 5 & 1,0 & 1,5 & 0,0 & 1,0 & 0,0 & 0,5 & 0,0 & 1,0 \\
\hline 6 & 0,5 & 3,0 & 0,0 & 0,0 & 0,5 & 0,0 & 0,0 & 2,0 \\
\hline 7 & 1,0 & 1,0 & 0,0 & 0,0 & 0,5 & 0,5 & 0,0 & 2,0 \\
\hline 8 & 0,5 & 0,5 & 0,0 & 0,0 & 1,0 & 0,5 & 0,0 & 3,0 \\
\hline 9 & 1,0 & 1,0 & 0,5 & 0,5 & 0,0 & 1,0 & 0,5 & 3,0 \\
\hline 10 & 1,0 & 1,0 & 0,0 & 0,0 & 0,5 & 0,0 & 0,0 & 1,5 \\
\hline 11 & 1,0 & 0,0 & 0,0 & 0,0 & 1,0 & 0,5 & 4,0 & 0,0 \\
\hline 12 & 2,0 & 0,5 & 0,0 & 0,0 & 0,5 & 0,0 & 3,5 & 0,0 \\
\hline 13 & 3,0 & 1,5 & 0,0 & 0,0 & 0,5 & 1,0 & 1,5 & 0,0 \\
\hline 14 & 3,0 & 2,0 & 0,0 & 0,0 & 0,5 & 0,0 & 3,0 & 0,0 \\
\hline 15 & 2,5 & 1,5 & 0,5 & 0,0 & 1,5 & 0,0 & 2,0 & 0,5 \\
\hline 16 & 0,0 & 1,0 & 0,0 & 0,0 & 0,0 & 2,0 & 3,0 & 0,0 \\
\hline 17 & 1,5 & 2,0 & 0,0 & 0,0 & 0,5 & 0,0 & 1,5 & 0,5 \\
\hline 18 & 3,0 & 1,5 & 0,0 & 0,0 & 1,0 & 0,0 & 4,0 & 1,0 \\
\hline 19 & 2,5 & 2,0 & 0,5 & 0,0 & 0,5 & 0,0 & 1,0 & 0,0 \\
\hline 20 & 3,0 & 0,5 & 0,5 & 0,0 & 0,5 & 0,0 & 1,0 & 0,5 \\
\hline 21 & 2,5 & 0,0 & 0,0 & 0,0 & 0,0 & 0,0 & 2,0 & 0,0 \\
\hline 22 & 2,5 & 0,5 & 1,5 & 0,0 & 0,5 & 0,0 & 1,0 & 0,0 \\
\hline 23 & 1,0 & 1,5 & 0,0 & 0,0 & 2,5 & 0,0 & 2,5 & 0,0 \\
\hline 24 & 4,0 & 1,0 & 0,0 & 0,0 & 1,0 & 1,0 & 0,0 & 0,5 \\
\hline 25 & 3,5 & 1,0 & 1,0 & 0,0 & 0,5 & 0,0 & 1,5 & 0,5 \\
\hline 26 & 3,0 & 0,5 & 0,0 & 0,5 & 2,0 & 0,0 & 1,0 & 3,5 \\
\hline 27 & 3,0 & 0,5 & 1,0 & 1,0 & 1,5 & 0,0 & 0,5 & 1,0 \\
\hline 28 & 0,5 & 2,0 & 0,5 & 0,0 & 2,0 & 0,0 & 0,0 & 1,0 \\
\hline 29 & 0,0 & 1,0 & 0,0 & 0,0 & 2,0 & 0,0 & 0,0 & 2,0 \\
\hline 30 & 0,0 & 0,0 & 0,0 & 0,0 & 0,5 & 0,0 & 0,0 & 2,0 \\
\hline
\end{tabular}


Apêndice 22. Notas de consistência de fezes nas 8 unidades experimentais do T2.

\begin{tabular}{|c|c|c|c|c|c|c|c|c|}
\hline \multirow{2}{*}{$\begin{array}{l}\text { idade } \\
\text { (dias) }\end{array}$} & \multicolumn{8}{|c|}{ Animais } \\
\hline & 1 & 2 & 3 & 4 & 5 & 6 & 7 & 8 \\
\hline 2 & 1,0 & 0,5 & 0,0 & 0,0 & 0,0 & 0,5 & 0,5 & 0,0 \\
\hline 3 & 1,5 & 1,0 & 1,0 & 0,5 & 0,5 & 0,0 & 1,0 & 0,0 \\
\hline 4 & 1,5 & 0,5 & 0,0 & 0,0 & 0,5 & 2,0 & 0,0 & 0,0 \\
\hline 5 & 0,5 & 0,0 & 0,0 & 1,0 & 0,0 & 0,5 & 1,0 & 0,0 \\
\hline 6 & 1,0 & 0,0 & 0,0 & 1,0 & 0,5 & 0,5 & 0,0 & 0,5 \\
\hline 7 & 2,5 & 0,0 & 0,0 & 0,0 & 1,0 & 1,0 & 0,0 & 1,5 \\
\hline 8 & 1,5 & 0,0 & 0,0 & 1,0 & 1,0 & 0,0 & 0,0 & 0,5 \\
\hline 9 & 1,0 & 0,0 & 0,0 & 0,5 & 2,0 & 0,0 & 0,0 & 0,0 \\
\hline 10 & 1,0 & 0,0 & 0,5 & 1,0 & 2,0 & 0,0 & 0,0 & 3,0 \\
\hline 11 & 0,0 & 0,0 & 0,5 & 0,0 & 4,0 & 0,0 & 1,0 & 3,0 \\
\hline 12 & 0,0 & 0,0 & 0,0 & 0,5 & 2,0 & 0,0 & 1,0 & 0,5 \\
\hline 13 & 0,0 & 0,0 & 0,0 & 1,5 & 0,5 & 0,0 & 0,0 & 0,5 \\
\hline 14 & 1,0 & 1,5 & 0,0 & 0,0 & 3,0 & 0,0 & 1,0 & 4,0 \\
\hline 15 & 0,0 & 0,0 & 0,0 & 0,5 & 0,0 & 1,5 & 0,0 & 4,0 \\
\hline 16 & 0,0 & 1,0 & 0,0 & 0,0 & 0,5 & 0,0 & 0,0 & 2,5 \\
\hline 17 & 0,0 & 3,0 & 0,0 & 1,5 & 0,0 & 1,0 & 1,5 & 0,5 \\
\hline 18 & 0,0 & 0,0 & 0,0 & 0,0 & 0,0 & 1,5 & 1,0 & 0,5 \\
\hline 19 & 0,0 & 0,5 & 0,0 & 0,0 & 0,0 & 1,0 & 1,0 & 0,5 \\
\hline 20 & 0,0 & 0,5 & 0,5 & 0,0 & 0,5 & 0,0 & 1,0 & 0,0 \\
\hline 21 & 0,0 & 0,0 & 0,0 & 0,0 & 3,5 & 0,0 & 3,0 & 0,0 \\
\hline 22 & 0,0 & 0,0 & 0,0 & 0,0 & 1,5 & 0,5 & 2,5 & 0,0 \\
\hline 23 & 0,0 & 0,0 & 0,0 & 1,5 & 0,0 & 0,5 & 3,0 & 0,5 \\
\hline 24 & 0,0 & 0,0 & 0,0 & 0,0 & 0,5 & 0,0 & 1,5 & 0,0 \\
\hline 25 & 2,0 & 0,0 & 0,5 & 0,0 & 0,0 & 0,0 & 0,0 & 0,0 \\
\hline 26 & 0,5 & 0,0 & 0,5 & 1,0 & 0,5 & 0,0 & 0,5 & 0,5 \\
\hline 27 & 0,0 & 0,0 & 0,0 & 0,5 & 2,0 & 0,0 & 0,0 & 1,5 \\
\hline 28 & 1,0 & 0,0 & 0,5 & 1,5 & 0,0 & 0,0 & 0,0 & 0,0 \\
\hline 29 & 0,0 & 0,0 & 0,0 & 1,0 & 1,5 & 0,0 & 1,0 & 0,5 \\
\hline 30 & 0,0 & 0,0 & 0,0 & 0,0 & 0,0 & 0,0 & 0,5 & 1,0 \\
\hline
\end{tabular}


Apêndice 23. Notas de consistência de fezes nas 8 unidades experimentais do T3.

\begin{tabular}{|c|c|c|c|c|c|c|c|c|}
\hline \multirow{2}{*}{$\begin{array}{l}\text { Idade } \\
\text { (dias) }\end{array}$} & \multicolumn{8}{|c|}{ Animais } \\
\hline & 1 & 2 & 3 & $\overline{4}$ & 5 & 6 & 7 & 8 \\
\hline 2 & $\overline{0,0}$ & 0,5 & 1,5 & 0,0 & 0,0 & 1,0 & 0,5 & 0 \\
\hline 3 & 0,0 & 0,5 & 2,0 & 0,0 & 0,0 & 0,5 & 0,5 & 0,5 \\
\hline 4 & 1,0 & 0,0 & 1,0 & 0,0 & 1,0 & 0,0 & 1,0 & 0,5 \\
\hline 5 & 1,0 & 0,0 & 0,5 & 0,5 & 0,5 & 1,5 & 0,5 & 1,0 \\
\hline 6 & 1,0 & 0,5 & 1,0 & 0,5 & 0,0 & 1,5 & 0,0 & 0,0 \\
\hline 7 & 0,5 & 0,0 & 1,0 & 0,5 & 0,0 & 0,5 & 0,5 & 0,0 \\
\hline 8 & 0,0 & 0,0 & 0,5 & 0,5 & 0,0 & 1,5 & 0,0 & 0,0 \\
\hline 9 & 3,0 & 0,5 & 0,5 & 0,0 & 0,0 & 1,5 & 0,0 & 0,0 \\
\hline 10 & 1,0 & 0,5 & 0,5 & 0,0 & 3,0 & 1,0 & 0,0 & 1,5 \\
\hline 11 & 0,0 & 3,0 & 1,0 & 0,5 & 1,0 & 3,0 & 0,0 & 2,0 \\
\hline 12 & 0,5 & 2,5 & 1,0 & 3,5 & 3,0 & 3,0 & 0,0 & 3,0 \\
\hline 13 & 0,0 & 2,0 & 3,0 & 0,0 & 4,0 & 1,0 & 0,0 & 1,5 \\
\hline 14 & 0,5 & 0,0 & 3,0 & 0,5 & 2,0 & 0,0 & 0,0 & 1,0 \\
\hline 15 & 3,0 & 0,0 & 1,0 & 0,5 & 1,5 & 0,0 & 1,0 & 0,5 \\
\hline 16 & 1,0 & 0,0 & 2,0 & 0,0 & 1,5 & 0,0 & 0,0 & 0,0 \\
\hline 17 & 1,0 & 0,0 & 1,0 & 1,5 & 3,0 & 0,5 & 0,0 & 0,5 \\
\hline 18 & 0,5 & 2,0 & 0,5 & 0,0 & 1,5 & 2,5 & 0,0 & 1,5 \\
\hline 19 & 1,0 & 1,0 & 0,0 & 0,5 & 4,0 & 1,5 & 0,0 & 2,0 \\
\hline 20 & 1,0 & 0,0 & 0,0 & 0,5 & 1,0 & 0,0 & 0,0 & 0,5 \\
\hline 21 & 0,0 & 0,0 & 0,0 & 0,0 & 0,5 & 0,0 & 2,5 & 1,0 \\
\hline 22 & 0,5 & 0,0 & 0,0 & 1,0 & 1,0 & 0,0 & 0,0 & 2,5 \\
\hline 23 & 1,0 & 0,0 & 0,5 & 1,0 & 0,5 & 0,0 & 1,0 & 1,5 \\
\hline 24 & 0,5 & 0,0 & 0,0 & 0,0 & 1,0 & 0,0 & 0,0 & 1,0 \\
\hline 25 & 1,0 & 0,0 & 0,0 & 1,5 & 0,0 & 0,0 & 0,0 & 0,0 \\
\hline 26 & 1,0 & 0,0 & 0,0 & 3,0 & 0,0 & 0,0 & 0,5 & 0,5 \\
\hline 27 & 0,0 & 0,0 & 0,0 & 1,0 & 0,0 & 0,0 & 0,0 & 1,0 \\
\hline 28 & 0,5 & 0,0 & 0,0 & 1,5 & 1,5 & 0,5 & 3,0 & 3,5 \\
\hline 29 & 0,5 & 0,0 & 0,0 & 0,0 & 0,0 & 2,0 & 0,0 & 0,0 \\
\hline 30 & 1,0 & 0,0 & 0,0 & 0,0 & 0,0 & 0,0 & 0,0 & 1,0 \\
\hline
\end{tabular}


Apêndice 24. Notas de consistência de fezes nas 8 unidades experimentais do T4.

\begin{tabular}{|c|c|c|c|c|c|c|c|c|}
\hline \multirow{2}{*}{$\begin{array}{l}\text { Idade } \\
\text { (dias) }\end{array}$} & \multicolumn{8}{|c|}{ Animais } \\
\hline & 1 & 2 & 3 & 4 & 5 & 6 & 7 & 8 \\
\hline 2 & $\overline{0,0}$ & 0,0 & 1,0 & 1,0 & 0,0 & 0,0 & 1,0 & 0,0 \\
\hline 3 & 2,0 & 0,0 & 3,5 & 0,0 & 0,0 & 0,0 & 0,5 & 0,0 \\
\hline 4 & 1,0 & 2,5 & 0,0 & 0,0 & 0,0 & 0,0 & 0,0 & 0,5 \\
\hline 5 & 1,0 & 0,5 & 2,0 & 0,0 & 3,0 & 0,5 & 1,0 & 0,0 \\
\hline 6 & 1,0 & 0,0 & 0,0 & 0,0 & 1,0 & 0,0 & 0,5 & 0,5 \\
\hline 7 & 4,0 & 0,0 & 0,0 & 1,0 & 0,5 & 0,0 & 0,5 & 3,0 \\
\hline 8 & 4,0 & 0,0 & 0,5 & 0,0 & 2,0 & 2,0 & 1,5 & 0,5 \\
\hline 9 & 0,0 & 2,0 & 2,0 & 1,0 & 1,5 & 2,0 & 1,0 & 2,0 \\
\hline 10 & 0,5 & 1,5 & 0,0 & 0,0 & 1,5 & 2,0 & 1,0 & 3,0 \\
\hline 11 & 1,5 & 1,5 & 1,0 & 0,0 & 0,5 & 3,0 & 0,0 & 0,5 \\
\hline 12 & 0,5 & 0,5 & 0,0 & 0,0 & 1,0 & 1,0 & 0,5 & 1,5 \\
\hline 13 & 3,5 & 1,0 & 0,0 & 1,0 & - & 3,0 & 2,0 & 0,0 \\
\hline 14 & 1,5 & 2,0 & 1,0 & 0,0 & 0,0 & 1,0 & 0,0 & 0,0 \\
\hline 15 & 1,0 & 3,0 & 0,0 & 0,0 & 0,5 & 0,0 & 3,5 & 0,0 \\
\hline 16 & 0,0 & 2,5 & 0,0 & 0,0 & 1,0 & 0,5 & 1,0 & 0,0 \\
\hline 17 & 1,0 & 0,0 & 0,0 & 0,0 & 0,0 & 1,5 & 1,0 & 0,0 \\
\hline 18 & 0,5 & 1,0 & 0,0 & 1,5 & 0,0 & 0,0 & 0,5 & 0,0 \\
\hline 19 & 0,0 & 0,0 & 0,0 & 0,5 & 0,0 & 0,5 & 0,0 & 0,0 \\
\hline 20 & 0,5 & 0,0 & 0,0 & 2,0 & 0,5 & 3,0 & 0,5 & 0,5 \\
\hline 21 & 0,0 & 0,5 & 0,5 & 1,5 & 1,0 & 0,0 & 0,5 & 0,0 \\
\hline 22 & 1,0 & 2,5 & 0,0 & 1,5 & 1,0 & 0,0 & 0,0 & 0,0 \\
\hline 23 & 0,0 & 2,0 & 0,5 & 1,0 & 3,0 & 0,0 & 0,5 & 0,5 \\
\hline 24 & 0,0 & 3,0 & 0,0 & 3,5 & 1,0 & 0,0 & 1,5 & 0,0 \\
\hline 25 & 0,0 & 4,0 & 2,0 & 4,0 & 1,5 & 0,0 & 1,5 & 1,0 \\
\hline 26 & 0,0 & 3,0 & 0,0 & 4,0 & 0,5 & 0,0 & 1,5 & 3,0 \\
\hline 27 & 1,5 & 1,5 & 1,0 & 3,0 & 0,5 & 1,0 & 1,0 & 1,0 \\
\hline 28 & 1,0 & 1,0 & 0,5 & 3,0 & 0,5 & 0,5 & 2,0 & 2,5 \\
\hline 29 & 2,0 & 2,0 & 0,0 & 3,5 & 0,5 & 0,5 & 3,0 & 0,0 \\
\hline 30 & 3,0 & 2,0 & 0,0 & 3,0 & 2,0 & 0,5 & 2,0 & 2,5 \\
\hline
\end{tabular}


Apêndice 25. Notas de consistência de fezes nas 4 unidades experimentais do T5.

\begin{tabular}{|c|c|c|c|c|}
\hline \multirow{2}{*}{$\begin{array}{l}\text { Idade } \\
\text { (dias) }\end{array}$} & \multicolumn{4}{|c|}{ Animais } \\
\hline & 1 & 2 & 3 & 4 \\
\hline 2 & 1,0 & 0,5 & 0,0 & 1,0 \\
\hline 3 & 1,0 & 0,0 & 0,0 & 0,5 \\
\hline 4 & 0,0 & 0,0 & 0,5 & 1,0 \\
\hline 5 & 0,0 & 0,0 & 1,0 & 0,0 \\
\hline 6 & 0,0 & 0,0 & 0,5 & 0,0 \\
\hline 7 & 0,5 & 1,5 & 0,0 & 0,0 \\
\hline 8 & 0,0 & 1,0 & 1,0 & 1,0 \\
\hline 9 & 1,0 & 1,0 & 0,0 & 0,5 \\
\hline 10 & 0,5 & 0,5 & 1,0 & 3,5 \\
\hline 11 & 0,5 & 1,0 & 1,5 & 4,0 \\
\hline 12 & 2,5 & 0,5 & 1,0 & 2,0 \\
\hline 13 & 1,0 & 0,0 & 1,0 & 3,5 \\
\hline 14 & 1,5 & 0,5 & 1,5 & 0,0 \\
\hline 15 & 0,0 & 2,5 & 0,5 & 1,5 \\
\hline 16 & 0,5 & 0,5 & 0,0 & 0,0 \\
\hline 17 & 0,5 & 0,0 & 0,0 & 0,5 \\
\hline 18 & 0,0 & 1,0 & 0,0 & 0,5 \\
\hline 19 & 0,0 & 0,0 & 1,0 & 0,0 \\
\hline 20 & 0,0 & 2,0 & 0,5 & 0,5 \\
\hline 21 & 0,0 & 1,5 & 0,0 & 1,0 \\
\hline 22 & 2,0 & 1,0 & 1,0 & 1,0 \\
\hline 23 & 1,0 & 0,5 & 0,0 & 2,0 \\
\hline 24 & 1,5 & 1,5 & 0,0 & 3,0 \\
\hline 25 & 1,0 & 0,0 & 0,0 & 3,0 \\
\hline 26 & 3,5 & 0,0 & 0,0 & 3,5 \\
\hline 27 & 1,5 & 1,0 & 1,0 & 1,0 \\
\hline 28 & 1,0 & 0,0 & 0,0 & 3,5 \\
\hline 29 & 0,0 & 0,5 & 0,0 & 3,0 \\
\hline 30 & 1,5 & 1,5 & 0,0 & 2,0 \\
\hline
\end{tabular}


Apêndice 26. Notas de consistência de fezes nas 4 unidades experimentais do T6.

\begin{tabular}{|c|c|c|c|c|}
\hline \multirow{2}{*}{$\begin{array}{l}\text { Idade } \\
\text { (dias) }\end{array}$} & \multicolumn{4}{|c|}{ Animais } \\
\hline & 1 & 2 & 3 & 4 \\
\hline 2 & $\overline{0,0}$ & 0,0 & 0,5 & 0,0 \\
\hline 3 & 1,0 & 0,5 & 1,0 & 0,0 \\
\hline 4 & 0,0 & 1,5 & 0,5 & 0,5 \\
\hline 5 & 2,0 & 0,0 & 0,0 & 0,0 \\
\hline 6 & 0,5 & 0,0 & 1,0 & 0,0 \\
\hline 7 & 0,0 & 0,0 & 1,5 & 0,0 \\
\hline 8 & 4,0 & 0,0 & 3,5 & 1,0 \\
\hline 9 & 1,0 & 1,5 & 1,0 & 0,5 \\
\hline 10 & 3,5 & 3,0 & 1,5 & 0,0 \\
\hline 11 & 3,0 & 2,0 & 2,5 & 1,5 \\
\hline 12 & 1,5 & 0,0 & 2,5 & 3,5 \\
\hline 13 & 1,5 & 0,5 & 2,0 & 2,0 \\
\hline 14 & 1,5 & 3,0 & 2,0 & 1,5 \\
\hline 15 & 1,0 & 3,0 & 0,0 & - \\
\hline 16 & 0,0 & 0,5 & 1,0 & 2,5 \\
\hline 17 & 0,5 & 0,0 & 1,5 & 0,0 \\
\hline 18 & 3,0 & 3,5 & 2,0 & 0,0 \\
\hline 19 & 2,0 & 2,5 & 1,5 & 0,0 \\
\hline 20 & 0,0 & 1,5 & 1,0 & 0,0 \\
\hline 21 & 1,0 & 0,0 & 0,5 & 0,0 \\
\hline 22 & 1,0 & 0,0 & 1,0 & 0,5 \\
\hline 23 & 0,5 & 0,0 & 0,5 & 0,0 \\
\hline 24 & 1,0 & 0,0 & 1,5 & 0,0 \\
\hline 25 & 0,0 & 0,5 & 1,5 & 1,0 \\
\hline 26 & 0,5 & 0,0 & 1,0 & 2,5 \\
\hline 27 & 0,5 & 1,5 & 0,5 & 0,0 \\
\hline 28 & 0,0 & 1,5 & 3,0 & 2,0 \\
\hline 29 & 0,0 & 2,5 & 3,0 & 0,0 \\
\hline 30 & 0,0 & 0,5 & 3,0 & 0,5 \\
\hline
\end{tabular}


Apêndice 27. Notas de cor de fezes nas 8 unidades experimentais do T1.

\begin{tabular}{|c|c|c|c|c|c|c|c|c|}
\hline \multirow{2}{*}{$\begin{array}{l}\text { Idade } \\
\text { (dias) }\end{array}$} & \multicolumn{8}{|c|}{ Animais } \\
\hline & 1 & 2 & 3 & 4 & 5 & 6 & 7 & 8 \\
\hline 2 & 0,5 & 0,0 & 0,5 & 0,5 & 2,5 & 0,5 & 0,5 & 0,5 \\
\hline 3 & 0,5 & 0,0 & 0,5 & 0,5 & 2,0 & 0,5 & 0,5 & 0,5 \\
\hline 4 & 0,5 & 2,0 & 0,5 & 0,0 & 0,5 & 0,0 & 0,5 & 0,5 \\
\hline 5 & 0,0 & 2,0 & 0,5 & 0,0 & 0,5 & 0,0 & 0,0 & 0,5 \\
\hline 6 & 0,0 & 2,5 & 0,5 & 0,0 & 0,5 & 0,5 & 0,0 & 2,0 \\
\hline 7 & 0,0 & 3,0 & 0,5 & 0,0 & 0,5 & 0,5 & 0,0 & 2,0 \\
\hline 8 & 0,0 & 2,0 & 0,5 & 0,0 & 0,5 & 0,0 & 0,0 & 2,5 \\
\hline 9 & 0,0 & 2,0 & 0,5 & 0,0 & 2,0 & 0,5 & 0,0 & 2,5 \\
\hline 10 & 0,0 & 2,0 & 0,0 & 0,0 & 0,0 & 0,0 & 2,0 & 2,0 \\
\hline 11 & 2,0 & 0,0 & 0,5 & 0,0 & 0,0 & 2,0 & 2,5 & 2,0 \\
\hline 12 & 1,5 & 0,0 & 2,0 & 0,0 & 0,0 & 0,0 & 2,5 & 2,0 \\
\hline 13 & 2,5 & 2,0 & 2,0 & 0,0 & 0,0 & 0,0 & 2,0 & 3,0 \\
\hline 14 & 2,5 & 2,0 & 1,5 & 0,0 & 0,0 & 0,0 & 2,0 & 2,0 \\
\hline 15 & 1,5 & 2,0 & 0,0 & 0,0 & 0,0 & 0,0 & 2,0 & 2,0 \\
\hline 16 & 1,5 & 2,0 & 2,0 & 0,0 & 0,0 & 2,0 & 2,0 & 2,0 \\
\hline 17 & 3,0 & 0,0 & 0,0 & 0,0 & 0,0 & 0,0 & 0,5 & 2,0 \\
\hline 18 & 2,5 & 0,0 & 0,0 & 0,0 & 0,0 & 0,0 & 2,0 & 2,0 \\
\hline 19 & 2,5 & 0,0 & 0,0 & 0,0 & 0,0 & 0,0 & 2,0 & 0,0 \\
\hline 20 & 2,0 & 0,0 & 0,0 & 0,0 & 0,0 & 0,5 & 0,0 & 0,0 \\
\hline 21 & 2,0 & 0,0 & 0,0 & 0,0 & 0,0 & 0,0 & 0,0 & 0,0 \\
\hline 22 & 2,0 & 0,0 & 2,0 & 0,0 & 0,0 & 0,0 & 0,0 & 0,0 \\
\hline 23 & 1,5 & 0,0 & 0,0 & 0,0 & 2,0 & 0,0 & 0,0 & 0,0 \\
\hline 24 & 3,0 & 0,0 & 0,0 & 0,0 & 2,0 & 2,0 & 0,0 & 2,0 \\
\hline 25 & 2,5 & 0,0 & 0,0 & 0,0 & 0,0 & 0,0 & 2,0 & 2,0 \\
\hline 26 & 2,0 & 0,0 & 0,0 & 2,0 & 0,0 & 2,0 & 0,0 & 2,0 \\
\hline 27 & 2,5 & 0,0 & 0,0 & 0,0 & 2,0 & 0,0 & 0,0 & 0,0 \\
\hline 28 & 1,5 & 0,0 & 0,0 & 0,0 & 2,0 & 0,0 & 0,0 & 2,0 \\
\hline 29 & 1,5 & 0,0 & 0,0 & 0,0 & 0,0 & 0,0 & 0,0 & 2,0 \\
\hline 30 & 0,0 & 0,0 & 0,0 & 0,0 & 0,0 & 2,0 & 0,0 & 0,0 \\
\hline
\end{tabular}


Apêndice 28. Notas de cor de fezes nas 8 unidades experimentais do T2.

\begin{tabular}{|c|c|c|c|c|c|c|c|c|}
\hline \multirow{2}{*}{$\begin{array}{l}\text { Idade } \\
\text { (dias) }\end{array}$} & \multicolumn{8}{|c|}{ Animais } \\
\hline & 1 & 2 & 3 & 4 & 5 & 6 & 7 & 8 \\
\hline 2 & $\overline{0,5}$ & 0,5 & 0,5 & 0,5 & 0,5 & & 0,5 & 0,5 \\
\hline 3 & 2,0 & 0,5 & 0,5 & 0,5 & 0,5 & 0,5 & 0,5 & 0,5 \\
\hline 4 & 2,0 & 0,5 & 0,0 & 0,0 & 0,5 & 0,5 & 0,0 & 0,5 \\
\hline 5 & 2,0 & 0,0 & 0,0 & 2,0 & 2,0 & 0,5 & 0,0 & 0,5 \\
\hline 6 & 2,0 & 0,0 & 0,0 & 2,0 & 0,0 & 0,5 & 0,5 & 0,5 \\
\hline 7 & 2,0 & 0,0 & 0,0 & 0,0 & 0,0 & 0,0 & 0,0 & 0,0 \\
\hline 8 & 2,0 & 0,0 & 0,0 & 2,0 & 0,0 & 0,0 & 0,0 & 0,0 \\
\hline 9 & 2,0 & 0,0 & 0,0 & 2,0 & 2,0 & 0,0 & 0,0 & 0,0 \\
\hline 10 & 2,0 & 0,0 & 0,0 & 2,0 & 3,0 & 0,0 & 0,0 & 2,5 \\
\hline 11 & 2,5 & 0,0 & 0,0 & 0,0 & 2,5 & 0,0 & 0,0 & 3,0 \\
\hline 12 & 2,0 & 0,0 & 2,0 & 0,0 & 0,0 & 0,0 & 0,0 & 0,0 \\
\hline 13 & 2,0 & 0,0 & 0,0 & 0,0 & 2,0 & 1,5 & 0,0 & 0,0 \\
\hline 14 & 2,0 & 2,0 & 0,0 & 0,0 & 2,0 & 0,0 & 0,0 & 3,0 \\
\hline 15 & 0,0 & 0,0 & 0,0 & 0,0 & 0,0 & 0,0 & 0,0 & 3,0 \\
\hline 16 & 2,0 & 2,0 & 0,0 & 0,0 & 0,0 & 0,0 & 0,0 & 0,0 \\
\hline 17 & 0,0 & 2,0 & 0,0 & 2,0 & 0,0 & 0,0 & 2,0 & 0,0 \\
\hline 18 & 0,0 & 0,0 & 0,0 & 0,0 & 0,0 & 2,0 & 0,0 & 0,0 \\
\hline 19 & 0,0 & 0,0 & 0,0 & 0,0 & 0,0 & 2,0 & 2,0 & 0,0 \\
\hline 20 & 0,0 & 1,5 & 2,0 & 0,0 & 2,0 & 2,0 & 2,0 & 0,0 \\
\hline 21 & 0,0 & 2,0 & 2,0 & 0,0 & 2,0 & 0,0 & 2,0 & 0,0 \\
\hline 22 & 0,0 & 0,0 & 0,0 & 0,0 & 2,0 & 0,0 & 2,0 & 0,0 \\
\hline 23 & 0,0 & 0,0 & 0,0 & 0,0 & 0,0 & 0,0 & 2,0 & 0,0 \\
\hline 24 & 0,0 & 0,0 & 0,0 & 0,0 & 0,0 & 2,0 & 0,0 & 0,0 \\
\hline 25 & 0,0 & 0,0 & 0,0 & 0,0 & 0,0 & 0,0 & 0,0 & 0,0 \\
\hline 26 & 0,0 & 0,0 & 0,0 & 0,0 & 0,0 & 2,0 & 0,0 & 2,0 \\
\hline 27 & 0,0 & 0,0 & 0,0 & 0,0 & 0,0 & 0,0 & 0,0 & 0,0 \\
\hline 28 & 1,5 & 0,0 & 0,0 & 2,0 & 0,0 & 0,0 & 0,0 & 0,0 \\
\hline 29 & 0,0 & 0,0 & 0,0 & 0,0 & 2,0 & 0,0 & 0,0 & 0,0 \\
\hline 30 & 0,0 & 0,0 & 0,0 & 0,0 & 0,0 & 0,0 & 0,0 & 0,0 \\
\hline
\end{tabular}


Apêndice 29. Notas de cor de fezes nas 8 unidades experimentais do T3.

\begin{tabular}{ccccccccc}
\hline Idade & \multicolumn{7}{c}{ Animais } \\
\cline { 2 - 8 } (dias) & 1 & 2 & 3 & 4 & 5 & 6 & 7 & 8 \\
\hline 2 & 0,0 & 0,5 & 0,5 & 0,5 & 0,5 & 0,5 & 0,5 & 0,5 \\
3 & 0,0 & 0,0 & 0,5 & 0,5 & 0,5 & 0,5 & 0,5 & 0,5 \\
4 & 0,0 & 0,0 & 2,0 & 2,0 & 2,5 & 0,0 & 0,0 & 0,5 \\
5 & 1,5 & 0,0 & 0,5 & 0,0 & 2,0 & 0,0 & 0,0 & 0,5 \\
6 & 2,0 & 0,0 & 2,0 & 0,0 & 2,0 & 0,5 & 0,0 & 0,5 \\
7 & 2,0 & 0,0 & 0,0 & 2,0 & 2,0 & 0,0 & 1,0 & 0,5 \\
8 & 2,5 & 0,0 & 0,0 & 0,0 & 0,0 & 0,0 & 0,0 & 0,0 \\
9 & 2,5 & 0,0 & 0,0 & 0,0 & 0,0 & 0,0 & 0,0 & 0,0 \\
10 & 0,0 & 2,0 & 0,0 & 0,0 & 2,0 & 0,0 & 0,0 & 2,5 \\
11 & 0,0 & 2,5 & 2,0 & 0,0 & 2,0 & 2,0 & 0,0 & 2,0 \\
12 & 0,0 & 2,5 & 2,0 & 2,0 & 2,0 & 2,5 & 0,0 & 0,0 \\
13 & 0,0 & 2,5 & 2,0 & 0,0 & 2,5 & 2,0 & 0,0 & 0,0 \\
14 & 0,0 & 2,5 & 2,0 & 0,0 & 1,5 & 0,0 & 0,0 & 2,0 \\
15 & 2,5 & 2,0 & 0,0 & 0,0 & 1,5 & 0,0 & 0,0 & 2,0 \\
16 & 2,0 & 0,0 & 0,0 & 0,0 & 2,0 & 0,0 & 0,0 & 0,0 \\
17 & 2,0 & 2,0 & 0,0 & 2,0 & 2,0 & 0,0 & 0,0 & 2,0 \\
18 & 2,0 & 1,5 & 1,5 & 0,0 & 1,5 & 2,0 & 0,0 & 0,0 \\
19 & 2,0 & 1,0 & 0,0 & 0,0 & 2,0 & 0,0 & 0,0 & 0,0 \\
20 & 0,0 & 2,0 & 0,0 & 0,0 & 2,0 & 0,0 & 0,0 & 0,0 \\
21 & 0,0 & 2,0 & 0,0 & 0,0 & 0,0 & 0,0 & 2,0 & 0,0 \\
22 & 1,5 & 2,0 & 0,0 & 0,0 & 0,0 & 0,0 & 0,0 & 2,0 \\
23 & 0,0 & 0,0 & 0,0 & 2,0 & 0,0 & 0,0 & 2,0 & 0,0 \\
24 & 0,0 & 0,0 & 0,0 & 2,0 & 0,0 & 0,0 & 0,0 & 0,0 \\
25 & 0,0 & 0,0 & 0,0 & 0,0 & 0,0 & 0,0 & 2,0 & 0,0 \\
26 & 1,5 & 0,0 & 0,0 & 2,0 & 0,0 & 0,0 & 2,0 & 0,0 \\
27 & 0,0 & 0,0 & 0,0 & 2,0 & 0,0 & 0,0 & 0,0 & 2,0 \\
28 & 0,0 & 0,0 & 0,0 & 1,0 & 0,0 & 0,0 & 2,0 & 2,0 \\
29 & 0,0 & 0,0 & 0,0 & 0,0 & 0,0 & 0,0 & 2,0 & 2,0 \\
30 & 2,0 & 0,0 & 0,0 & 0,0 & 0,0 & 0,0 & 0,0 & 0,0 \\
\hline
\end{tabular}


Apêndice 30. Notas de cor de fezes nas 8 unidades experimentais do T4.

\begin{tabular}{|c|c|c|c|c|c|c|c|c|}
\hline \multirow{2}{*}{$\begin{array}{l}\text { Idade } \\
\text { (dias) }\end{array}$} & \multicolumn{8}{|c|}{ Animais } \\
\hline & 1 & 2 & 3 & 4 & 5 & 6 & 7 & 8 \\
\hline 2 & 0,5 & 0,5 & 0,5 & 0,5 & 0,5 & 0,5 & 0,5 & 0,5 \\
\hline 3 & 0,0 & 0,5 & 2,0 & 0,5 & 0,5 & 0,5 & 0,0 & 0,5 \\
\hline 4 & 2,0 & 2,0 & 0,5 & 0,5 & 0,5 & 0,5 & 0,5 & 0,5 \\
\hline 5 & 2,0 & 0,0 & 2,0 & 0,0 & 2,5 & 0,0 & 0,0 & 0,0 \\
\hline 6 & 2,0 & 0,0 & 0,0 & 0,0 & - & 0,0 & 0,0 & 0,0 \\
\hline 7 & 2,5 & 0,0 & 0,0 & 0,0 & 2,0 & 0,0 & 2,0 & 2,0 \\
\hline 8 & 2,5 & 0,0 & 0,0 & 0,0 & 2,0 & 0,5 & 0,5 & 2,0 \\
\hline 9 & 2,5 & 2,0 & 0,0 & 0,0 & 2,0 & 1,5 & 0,0 & 2,5 \\
\hline 10 & 2,0 & 2,0 & 0,0 & 0,0 & 0,0 & 2,0 & 0,0 & 2,5 \\
\hline 11 & 2,0 & 2,0 & 0,5 & 0,0 & 2,0 & 2,0 & 0,0 & 0,0 \\
\hline 12 & 2,0 & 2,0 & 0,0 & 0,0 & 2,0 & 1,0 & 2,0 & 0,0 \\
\hline 13 & 2,0 & 2,0 & 0,0 & 0,0 & 0,0 & 2,0 & 2,0 & 0,0 \\
\hline 14 & 2,0 & 2,0 & 2,0 & 0,0 & 0,0 & 0,0 & 0,0 & 0,0 \\
\hline 15 & 2,0 & 2,0 & 2,0 & 0,0 & 0,0 & 2,0 & 2,0 & 0,0 \\
\hline 16 & 0,5 & 2,0 & 2,0 & 0,0 & 0,0 & 2,0 & 0,0 & 0,0 \\
\hline 17 & 2,0 & 0,0 & 2,0 & 0,0 & 0,0 & 2,0 & 0,0 & 0,0 \\
\hline 18 & 0,5 & 0,0 & 0,0 & 0,0 & 0,0 & 0,0 & 0,0 & 0,0 \\
\hline 19 & 2,5 & 1,5 & 0,0 & 0,0 & 0,0 & 2,0 & 2,0 & 0,0 \\
\hline 20 & 2,0 & 0,0 & 0,0 & 0,0 & 0,0 & 2,0 & 2,0 & 0,0 \\
\hline 21 & 2,0 & 2,0 & 0,0 & 0,0 & 0,0 & 0,0 & 2,0 & 0,0 \\
\hline 22 & 2,0 & 2,0 & 0,0 & 0,0 & 2,0 & 2,0 & 0,0 & 0,0 \\
\hline 23 & 2,0 & 2,0 & 0,0 & 0,0 & 2,0 & 0,0 & 2,0 & 0,0 \\
\hline 24 & 2,0 & 2,0 & 0,0 & 0,0 & 2,0 & 2,0 & 2,0 & 0,0 \\
\hline 25 & 2,0 & 2,5 & 1,5 & 0,0 & 2,0 & 0,0 & 2,0 & 2,0 \\
\hline 26 & 0,0 & 2,0 & 2,0 & 0,0 & 1,5 & 0,0 & 2,0 & 2,0 \\
\hline 27 & 2,0 & 2,0 & 2,0 & 0,0 & 0,0 & 2,0 & 2,0 & 0,0 \\
\hline 28 & 2,0 & 2,0 & 0,0 & 0,0 & 0,0 & 2,0 & 2,0 & 2,0 \\
\hline 29 & 0,0 & 0,0 & 0,0 & 0,0 & 0,0 & 2,0 & 0,0 & 0,0 \\
\hline 30 & 2,0 & 0,0 & 0,0 & 0,0 & 2,0 & 2,0 & 0,0 & 2,0 \\
\hline
\end{tabular}


Apêndice 31. Notas de cor de fezes nas 4 unidades experimentais do T5.

\begin{tabular}{|c|c|c|c|c|}
\hline \multirow{2}{*}{$\begin{array}{l}\text { Idade } \\
\text { (dias) }\end{array}$} & \multicolumn{4}{|c|}{ Animais } \\
\hline & 1 & 2 & 3 & 4 \\
\hline 2 & 0,5 & 0,5 & 0,5 & 0,5 \\
\hline 3 & 0,5 & 0,5 & 0,5 & 0,0 \\
\hline 4 & 2,0 & 0,5 & 0,0 & 0,0 \\
\hline 5 & 2,0 & 0,5 & 0,0 & 0,0 \\
\hline 6 & 0,0 & 0,5 & 0,0 & 0,0 \\
\hline 7 & 0,0 & 2,0 & 0,0 & 0,0 \\
\hline 8 & 2,0 & 2,0 & 0,0 & 0,0 \\
\hline 9 & 0,0 & 0,0 & 0,0 & 0,0 \\
\hline 10 & 0,0 & 0,0 & 2,0 & 2,0 \\
\hline 11 & 0,0 & 0,0 & 0,5 & 2,0 \\
\hline 12 & 2,0 & 0,0 & 2,0 & 2,0 \\
\hline 13 & 0,0 & 0,0 & 0,0 & 2,0 \\
\hline 14 & 0,0 & 0,0 & 2,0 & 3,0 \\
\hline 15 & 0,0 & 2,0 & 2,0 & 0,0 \\
\hline 16 & 0,0 & 0,0 & 2,5 & 0,0 \\
\hline 17 & 0,0 & 0,0 & - & 0,0 \\
\hline 18 & 0,0 & 0,0 & 2,0 & 0,0 \\
\hline 19 & 0,0 & 0,0 & 2,0 & 0,0 \\
\hline 20 & 0,0 & 2,0 & 2,0 & 0,0 \\
\hline 21 & 0,0 & 2,0 & 2,0 & 2,0 \\
\hline 22 & 0,0 & 1,5 & 2,0 & 0,0 \\
\hline 23 & 0,0 & 0,0 & 2,0 & 0,0 \\
\hline 24 & 2,0 & 2,0 & 0,0 & 0,0 \\
\hline 25 & 0,0 & 0,0 & 0,0 & 0,0 \\
\hline 26 & 0,0 & 2,0 & 0,0 & 0,0 \\
\hline 27 & 2,0 & 2,0 & 0,0 & 0,0 \\
\hline 28 & 2,0 & 2,0 & 0,0 & 0,0 \\
\hline 29 & 0,0 & 2,0 & 0,0 & 0,0 \\
\hline 30 & 2,0 & 2,0 & 0,0 & 0,0 \\
\hline
\end{tabular}


Apêndice 32. Notas de cor de fezes nas 4 unidades experimentais do T6.

\begin{tabular}{|c|c|c|c|c|}
\hline \multirow{2}{*}{$\begin{array}{l}\text { Idade } \\
\text { (dias) }\end{array}$} & \multicolumn{4}{|c|}{ Animais } \\
\hline & 1 & 2 & 3 & 4 \\
\hline 2 & 0,5 & $\overline{0,5}$ & 0,5 & 0,0 \\
\hline 3 & 2,0 & 0,5 & 0,5 & 0,5 \\
\hline 4 & 0,5 & 0,0 & 0,5 & 0,0 \\
\hline 5 & 2,0 & 0,0 & 0,0 & 0,0 \\
\hline 6 & 0,0 & 0,0 & 0,0 & 0,0 \\
\hline 7 & 2,0 & 0,0 & 0,5 & 0,0 \\
\hline 8 & 3,0 & 0,0 & 2,5 & 0,0 \\
\hline 9 & 2,0 & 1,5 & 2,5 & 0,0 \\
\hline 10 & 2,5 & 2,5 & 2,0 & 0,5 \\
\hline 11 & 2,5 & 2,0 & 2,0 & 2,0 \\
\hline 12 & 2,5 & 2,0 & 2,0 & 2,5 \\
\hline 13 & 2,0 & 2,0 & 2,0 & 2,0 \\
\hline 14 & 2,5 & 2,0 & 0,0 & 2,0 \\
\hline 15 & 0,0 & 2,0 & 0,0 & - \\
\hline 16 & 0,0 & 0,0 & 0,0 & 2,0 \\
\hline 17 & 2,0 & 0,0 & 0,0 & 2,0 \\
\hline 18 & 2,5 & 2,0 & 2,0 & 2,0 \\
\hline 19 & 2,5 & 0,0 & 2,0 & 2,0 \\
\hline 20 & 1,5 & 0,0 & 2,0 & 0,0 \\
\hline 21 & 1,5 & 0,0 & 2,0 & 0,0 \\
\hline 22 & 1,5 & 0,0 & 2,0 & 0,0 \\
\hline 23 & 0,0 & 0,0 & 2,0 & 0,0 \\
\hline 24 & 0,0 & 0,0 & 2,0 & 0,0 \\
\hline 25 & 0,0 & 0,0 & 2,0 & 0,0 \\
\hline 26 & 0,0 & 0,0 & 2,0 & 0,0 \\
\hline 27 & 0,0 & 0,0 & 2,0 & 0,0 \\
\hline 28 & 0,0 & 0,0 & 0,0 & 2,0 \\
\hline 29 & 0,0 & 0,0 & 2,0 & 2,0 \\
\hline 30 & 0,0 & 0,0 & 0,0 & 0,0 \\
\hline
\end{tabular}


Apêndice 33. Pesos $(\mathrm{kg})$ das 8 unidades experimentais do T1.

\begin{tabular}{ccccccccc}
\hline Idade & \multicolumn{7}{c}{ Animais } \\
\cline { 2 - 8 } (dias) & 1 & 2 & 3 & 4 & 5 & 6 & 7 & 8 \\
\hline 0 & 37,50 & 40,00 & 21,00 & 45,00 & 23,00 & 42,80 & 34,60 & 40,30 \\
5 & 36,50 & 40,20 & 22,50 & - & 24,40 & 43,20 & 33,80 & 40,40 \\
10 & 40,70 & 40,60 & 24,70 & 47,00 & 24,00 & 43,20 & 35,80 & 41,20 \\
15 & 40,00 & 39,60 & 28,80 & 46,80 & 27,00 & 43,60 & 35,00 & 44,20 \\
20 & 39,60 & 38,80 & 31,00 & 50,00 & 28,80 & 44,20 & 37,20 & 45,60 \\
25 & 42,20 & 40,40 & 28,00 & 50,00 & 26,20 & 45,40 & 44,00 & 49,00 \\
30 & 43,60 & 42,40 & 32,60 & 51,80 & 27,20 & 46,00 & 45,60 & 47,80 \\
35 & 45,00 & 46,20 & 34,40 & 52,80 & 27,60 & 48,00 & 48,60 & 49,60 \\
40 & 49,20 & 49,00 & 38,40 & 55,40 & 32,40 & 50,00 & 50,00 & 50,00 \\
45 & 49,40 & 58,40 & 38,40 & - & 32,40 & 50,00 & 56,40 & 58,00 \\
50 & 49,00 & 50,00 & 41,60 & 62,80 & 34,00 & 50,40 & 59,20 & 57,00 \\
70 & 50,00 & 60,00 & 48,00 & 79,40 & 44,20 & 61,60 & 71,20 & 54,20 \\
\hline
\end{tabular}

Apêndice 34. Pesos $(\mathrm{kg})$ das 8 unidades experimentais do T2.

\begin{tabular}{ccccccccc}
\hline Idade & \multicolumn{10}{c}{ Animais } \\
\cline { 2 - 8 } (dias) & 1 & 2 & 3 & 4 & 5 & 6 & 7 & 8 \\
\hline 0 & 47,00 & - & 49,00 & 33,00 & 26,00 & 40,00 & 40,20 & 25,00 \\
5 & 44,80 & 26,40 & 46,20 & 35,00 & 26,20 & 40,20 & 39,80 & 25,60 \\
10 & 44,60 & 30,70 & 50,60 & 36,60 & 26,00 & 43,80 & 42,20 & - \\
15 & 48,80 & 32,00 & 50,00 & 42,40 & 25,60 & 45,80 & 42,40 & - \\
20 & 49,80 & 31,40 & 48,00 & 41,80 & 29,00 & 45,00 & 44,20 & 29,60 \\
25 & 49,40 & 36,00 & 53,00 & 43,80 & 29,80 & 46,00 & 43,00 & 32,00 \\
30 & 53,00 & 36,80 & 50,00 & 46,20 & 31,60 & 46,40 & 48,00 & 41,00 \\
35 & - & 39,60 & 51,60 & 50,00 & 33,60 & 43,80 & 50,00 & 35,00 \\
40 & 50,00 & 44,00 & - & 50,00 & 35,00 & 48,60 & 51,40 & 38,00 \\
45 & 52,00 & 43,50 & 60,80 & 51,20 & - & 50,00 & 54,40 & 43,80 \\
50 & 55,60 & 42,40 & 60,40 & 54,80 & 40,20 & 55,00 & 57,20 & 44,80 \\
70 & 64,50 & - & 76,60 & 78,60 & 50,00 & 66,00 & 75,20 & 50,00 \\
\hline
\end{tabular}


Apêndice 35. Pesos $(\mathrm{kg})$ das 8 unidades experimentais do T3.

\begin{tabular}{ccccccccc}
\hline Idade & \multicolumn{7}{c}{ Animais } \\
\cline { 2 - 9 } (dias) & 1 & 2 & 3 & 4 & 5 & 6 & 7 & 8 \\
\hline 0 & 40,00 & 37,00 & 40,40 & 28,00 & 41,20 & 48,30 & 45,00 & 34,50 \\
5 & 40,70 & 35,20 & 40,00 & 23,40 & 40,40 & 48,00 & 42,40 & 35,60 \\
10 & 39,40 & 36,40 & 40,00 & 27,60 & 41,00 & 50,00 & 44,40 & 40,00 \\
15 & 43,00 & 35,40 & 41,60 & 24,40 & 40,40 & 49,40 & 47,80 & 38,60 \\
20 & 42,90 & 37,20 & 46,20 & 27,00 & 44,20 & 50,00 & 48,20 & 41,00 \\
25 & 47,00 & 50,00 & 47,40 & 26,60 & 45,00 & 51,00 & 38,00 & 42,60 \\
30 & 50,00 & 38,60 & 49,40 & 30,40 & 46,80 & 52,00 & 48,00 & 41,60 \\
35 & 50,60 & 42,60 & 50,00 & 35,60 & 50,00 & 53,00 & 51,40 & 41,20 \\
40 & 50,00 & 44,20 & 50,00 & 38,20 & 48,50 & 56,60 & 52,60 & 44,40 \\
45 & 51,00 & 46,40 & 50,00 & 42,00 & 50,00 & 61,80 & - & 49,20 \\
50 & 50,20 & 48,60 & 50,40 & 42,40 & 53,00 & 58,00 & 60,80 & 50,00 \\
70 & 62,60 & 50,40 & 63,00 & 55,60 & 57,00 & 76,60 & 77,00 & 63,20 \\
\hline
\end{tabular}

Apêndice 36. Pesos $(\mathrm{kg})$ das 8 unidades experimentais do T4.

\begin{tabular}{ccccccccc}
\hline Idade & \multicolumn{7}{c}{ Animais } \\
\cline { 2 - 8 } (dias) & 1 & 2 & 3 & 4 & 5 & 6 & 7 & 8 \\
\hline 0 & 43,00 & 47,50 & - & 38,50 & 49,80 & 39,10 & 26,60 & - \\
5 & 39,40 & 44,20 & 24,80 & 38,40 & 46,60 & 40,80 & 25,40 & 38,00 \\
10 & 40,20 & 46,40 & 29,20 & 43,40 & - & 39,80 & 26,60 & 40,20 \\
15 & 42,00 & 44,60 & 29,40 & - & 45,80 & 45,80 & 29,60 & 48,00 \\
20 & 41,20 & 44,00 & 28,00 & 50,00 & - & 41,60 & 29,00 & 43,80 \\
25 & 41,00 & 46,20 & 35,50 & 50,00 & 48,40 & 42,80 & 30,60 & 45,20 \\
30 & 41,70 & 46,20 & 33,60 & 50,00 & 51,80 & 46,60 & 31,00 & 45,60 \\
35 & - & 49,80 & 34,00 & 50,40 & 50,00 & 50,00 & 34,80 & 46,80 \\
40 & - & 51,80 & 37,00 & 52,00 & 51,00 & 50,00 & 36,20 & 50,00 \\
45 & - & 50,00 & 38,60 & 55,40 & 53,80 & 50,00 & 37,00 & - \\
50 & - & 52,60 & 44,60 & 61,00 & 60,80 & 54,60 & 41,00 & 50,00 \\
70 & - & 67,00 & 55,20 & 79,40 & 70,00 & 67,80 & 48,80 & - \\
\hline
\end{tabular}


Apêndice 37. Pesos $(\mathrm{kg})$ das 4 unidades experimentais do T5.

\begin{tabular}{ccccc}
\hline Idade & \multicolumn{4}{c}{ Animais } \\
\cline { 2 - 5 } (dias) & 1 & 2 & 3 & 4 \\
\hline 0 & 24,50 & 33,10 & 32,60 & 34,20 \\
5 & 28,40 & 34,00 & 36,20 & 31,00 \\
10 & 29,40 & 33,40 & 34,80 & 32,60 \\
15 & - & 36,20 & 33,00 & 32,80 \\
20 & 32,20 & 39,00 & 33,00 & 35,00 \\
25 & 32,40 & 41,40 & 36,60 & - \\
30 & 35,80 & 37,20 & 39,20 & 35,60 \\
35 & 41,00 & 50,00 & 42,40 & 44,40 \\
40 & 39,00 & 46,00 & 43,40 & 46,00 \\
45 & 44,20 & 49,20 & 42,80 & 50,00 \\
50 & 48,20 & 50,00 & 45,00 & 50,00 \\
70 & 58,20 & 69,20 & 55,60 & 59,60 \\
\hline
\end{tabular}

Apêndice 38. Pesos $(\mathrm{kg})$ das 4 unidades experimentais do T6.

\begin{tabular}{ccccc}
\hline $\begin{array}{c}\text { Idade } \\
\text { (dias) }\end{array}$ & \multicolumn{4}{c}{ Animais } \\
\cline { 2 - 5 } & 1 & 2 & 3 & 4 \\
\hline 0 & - & 23,00 & 37,40 & 38,50 \\
5 & 34,40 & 22,20 & 39,00 & 38,20 \\
10 & 35,60 & 23,40 & 35,80 & 40,60 \\
15 & 38,00 & 23,80 & 40,40 & 42,40 \\
20 & 40,40 & 21,40 & 39,60 & 40,80 \\
25 & 41,00 & 25,80 & 39,20 & 42,40 \\
30 & 41,80 & 27,80 & 41,20 & 45,40 \\
35 & 44,60 & 26,80 & 41,40 & 44,60 \\
40 & 45,40 & 27,60 & 44,80 & 50,00 \\
45 & 47,00 & 31,00 & 47,80 & 53,00 \\
50 & 48,00 & 35,60 & 50,00 & 50,00 \\
70 & 58,60 & 38,00 & 56,20 & 57,00 \\
\hline
\end{tabular}

